\title{
On skin microvascular reactivity in patients with lower limb ischaemia
}

Citation for published version (APA):

Ubbink, D. T. (1992). On skin microvascular reactivity in patients with lower limb ischaemia. [Doctoral Thesis, Maastricht University]. Rijksuniversiteit Limburg. https://doi.org/10.26481/dis.19920624du

Document status and date:

Published: 01/01/1992

DOI:

10.26481/dis.19920624du

Document Version:

Publisher's PDF, also known as Version of record

\section{Please check the document version of this publication:}

- A submitted manuscript is the version of the article upon submission and before peer-review. There can be important differences between the submitted version and the official published version of record.

People interested in the research are advised to contact the author for the final version of the publication, or visit the DOI to the publisher's website.

- The final author version and the galley proof are versions of the publication after peer review.

- The final published version features the final layout of the paper including the volume, issue and page numbers.

Link to publication

\footnotetext{
General rights rights.

- You may freely distribute the URL identifying the publication in the public portal. please follow below link for the End User Agreement:

www.umlib.nl/taverne-license

Take down policy

If you believe that this document breaches copyright please contact us at:

repository@maastrichtuniversity.nl

providing details and we will investigate your claim.
}

Copyright and moral rights for the publications made accessible in the public portal are retained by the authors and/or other copyright owners and it is a condition of accessing publications that users recognise and abide by the legal requirements associated with these

- Users may download and print one copy of any publication from the public portal for the purpose of private study or research.

- You may not further distribute the material or use it for any profit-making activity or commercial gain

If the publication is distributed under the terms of Article $25 \mathrm{fa}$ of the Dutch Copyright Act, indicated by the "Taverne" license above, 
ON SKIN MICROVASCULAR REACTIVITTY IN PATIENTS WITH LOWER LIMB ISCHAEMIA 


\section{Promotores:}

Prof. Dr. R.S. Reneman

Prof. Dr. P.J.E.H.M. Kitslaar

\section{Co-promotores:}

Dr. M.J.H.M. Jacobs

Dr. G.W.J.M. Tangelder

\section{Beoordelingscommissie:}

Prof. Dr. H.A.J. Struijker Boudier (voarzitter)

Prof. Dr. A. Bollinger (Universitätsspital Zürich, Zwilserland)

Prof. Dr. F. ten Hoor

Prof. Dr. P.W. de Leeuw

Prof. Dr. H.J.J. Wellens 


\section{On skin microvascular reactivity in patients with lower limb ischaemia}

\section{PROEFSCHRIFT}

ter verkrijging van de graad van doctor aan de Rijksuniversiteit Limburg te Maastricht, op gezag van de Rector Magnificus, Prof. Mr. M.J. Cohen, volgens het besluit van het College van Dekanen, in het openbaar te verdedigen op woensdag 24 juni 1992 om 14.00 uur

door

Dirk Theodoor Ubbink 
CHYDAJA ROYAL LIBHAARY, THE HAGUE

Ubtrink, Dirk Theodoor

On skin microvascular reactivity in patients with lower

limb ischamia / Dirk "Theodoor Ubbink. - [S.1. : s.n.]

(maastricht: : Datawyse), - Ill.

Thesis Mastricht, - With ref. - With summary in Dutch. ISBN y0m $9095152 x$

NUCI $742 / 743$

Subjed headings: skin microcirculation / microvascular constutction / yschaemia.

Cover design: H. C. Labega, Amsterdam

Production: Datawyse, Maastricht

(c) D. Th. Ubbink, Maastricht, 1992. All rights reserved.

Financial support by the Netherlands Heart Foundation for the publication of this thesis is gratefully acknowledged. Furthermore, this edition is supported by Medtronic BV, Schering AG, Radiometer Nederland and Gambro BV. 
To Thêrèse, my wother and all patients

That our dealings may be of more significance than this man's tail coat is to his promotion. Yet, not a little of that we describe as our achievement is, in fact, no more than a garnment in which, on special occasions, we seek to hide our nakedness. 


\section{Contents}

Chapter 1 General introduction

1.1 Microcirculation of the skin $\ldots \ldots \ldots \ldots \ldots \ldots .9$

1.2 Techniques to measure skin microcirculation ....... 12

1.3 Aims of the thesis . . . . . . . . . . . . . . . 15

Chapter 2 Techniques and methods applied to investigate macro and microcirculation

2.1 Macrocirculatory investigative techniques ......... 17

2.2 Capillary microscopy $\ldots \ldots \ldots \ldots \ldots \ldots \ldots \ldots, 18$

2.3 Transcutaneous oximetry $\ldots \ldots \ldots \ldots \ldots \ldots \ldots, 24$

2.4 Laser Doppler fluxmetry . . . . . . . . . . . . . . . 27

2.5 Statistical analyses $\ldots \ldots \ldots \ldots \ldots \ldots \ldots \ldots . \ldots \ldots$

Chapter 3 Capillary recruitment and pain relief on dependency in patients with severe lower limb ischaemia

3.1 Introduction $\ldots \ldots \ldots \ldots \ldots \ldots \ldots \ldots \ldots \ldots \ldots \ldots$

3.2 Patients and methods $\ldots \ldots \ldots \ldots \ldots \ldots \ldots \ldots, 32$

3.3 Results $\ldots \ldots \ldots \ldots \ldots \ldots \ldots \ldots \ldots \ldots \ldots, \ldots \ldots$

3.4 Discussion $\ldots \ldots \ldots \ldots \ldots \ldots \ldots \ldots \ldots \ldots \ldots, 40$

Chapter 4 Posturally induced microvascular constriction in patients with different stages of leg ischaemia: effect of local skin heating

4.1 Introduction . . . . . . . . . . . . . . . . . 43

4.2 Patients and methods ................... 44

4.3 Results $\ldots \ldots \ldots \ldots \ldots \ldots \ldots \ldots \ldots \ldots \ldots \ldots$. . . . 47

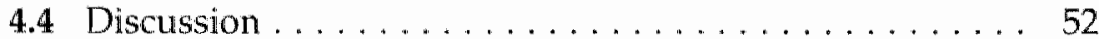

Chapter 5 Microvascular reactivity differences between the two legs of patients with unilateral lower limb ischaemia

5.1 Introduction . . . . . . . . . . . . . . . 55

5.2 Patients and methods $\ldots \ldots \ldots \ldots \ldots \ldots \ldots \ldots, 56$ 
5.3 Results $\ldots \ldots \ldots \ldots \ldots \ldots \ldots \ldots \ldots \ldots \ldots \ldots \ldots \ldots$

5.4 Discussion . . . . . . . . . . . . . . . . . . 61

Chapter 6 The relevance of posturally induced microvascular constriction after revascularisation in patients with chronic leg ischaemia

6.1 Introduction $\ldots \ldots \ldots \ldots \ldots \ldots \ldots \ldots \ldots \ldots \ldots \ldots . \ldots \ldots$

6.2 Patients . . . . . . . . . . . . . . . . . . 68

6.3 Methods . . . . . . . . . . . . . . . . . . . . . 69

6.4 Results ... . . . . . . . . . . . . . . . . . . 70

6.5 Discussion . . . . . . . . . . . . . . . 75

Chapter 7 The usefulness of capillary microscopy, laser Doppler fluxmetry and transcutaneous oximetry in the assessment of the severity of lower limb ischaemia

7.1 Introduction $\ldots \ldots \ldots \ldots \ldots \ldots \ldots \ldots \ldots \ldots \ldots$

7.2 Patients . . . . . . . . . . . . . . . . . 80

7.3 Methods . . . . . . . . . . . . . . . . . . 81

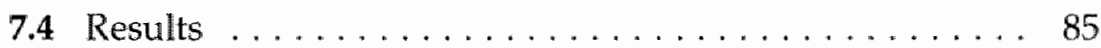

7.5 Discussion ........................ 96

Chapter 8 General discussion .................. 101

8.1 Conclusions . . . . . . . . . . . . . . 106

Chapter 9 Summary ..................... 109

Chapter 10 Samenvatting ................... 115

References .............................. 121

In appreciation $\ldots \ldots \ldots \ldots \ldots \ldots \ldots \ldots \ldots \ldots \ldots \ldots \ldots$

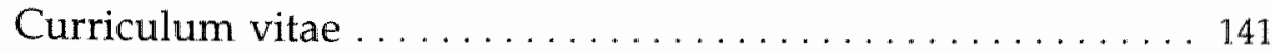





\section{Chapter 1}

\section{General introduction}

Usually, lower limb ischaemia is caused by atherosclerosis. This is a generalized disease of the major arteries, characterized by narrowing of these vessels, resulting in disturbed peripheral blood flow. The severity of ischaemic leg disease is normally classified according to the clinical stages of Fontaine $^{57}$, as described in table 1.1.

Table 1.1 Clinical stages according to Fontaine

Stage 1: asymptomatic subjects (but having subclinical atherosclerosis)

Stage 2: patients with intermittent claudication

Stage 3: patients with pain at rest

Stage 4: patients with rest pain and / or ulceration or gangrene

In patients suffering from lower limb ischaemia, blood flow in the larger blood vessels, the so-called macrocirculation, is disturbed. Subsequently, this may lead to disturbances in the skin microcirculation. This is defined as the blood circulation in capillaries, together with their supplying arterioles and draining venules. The lymph vessels originating in the skin are also considered to be part of the microcirculatory system.

An intriguing phenomenon of this disease is that some of these patients with ischaemic rest pain experience relief of pain when they lower the leg. This is surprising, because healthy subjects show a restricted blood flow on dependency due to posturally induced microvascular vasoconstriction ${ }^{78}$, 151

To objectify and quantify the severity of lower limb ischaemia, several diagnostic techniques are available. Angiography is, albeit an invasive 
technique, the method of choice to visualize anatomical pathology in the course of the major blood vessels towards and in the legs ${ }^{162}$. Doppler ultrasonography $35,59,141$ is widely used to measure peripheral ${ }^{187,} 188$ or segmen$\mathrm{tal}^{189}$ blood pressures and to analyse arterial signals ${ }^{107,} 171,172$. Various plethysmographic techniques, such as pulse volume or impedance plethysmography, have become established methods to estimate arterial limb circulation ${ }^{8}$. Photoplethysmography can be applied to assess toe systolic blood pressures $^{28,58,140}$. The ankle blood pressure is the most commonly used parameter to evaluate the severity of leg ischaemia. However, atherosclerosis is characterized by vessel wall sclerosis and thus, lesser vessel compressibility. This may lead to overestimation of the ankle pressure, particularly in patients suffering from diabetes mellitus ${ }^{42,67}$. Toe pressures appear to correlate better with the severity of ischaemia, because the digital arteries themselves are less frequently afflicted by the atherosclerotic disease $^{20,} 145,183$. Furthermore, a variety of sophisticated ultrasound techniques have been developed to assess the presence and localisation of atherosclerotic lesions. Duplex scanning has won ground in the field of haemodynamic analysis of aorto-iliac and peripheral arteries ${ }^{101,102,108}$. This technique combines B-mode ultrasonic imaging with single-gate pulsed Doppler examination, thus enabling the localisation of haemodynamically important stenoses, i.e. stenoses causing a more than $50 \%$ diameter reduction, even in central and more deeply situated vessels. Multigate pulsed Doppler systems $^{87,149}$, in combination with a $2-\mathrm{D}$-echo image ${ }^{\mathrm{750}}$, can detect even minor, but relevant lesions by investigating vessel wall movement in addition to local blood flow disturbances ${ }^{124,125}$.

In this thesis, however, mainly microcirculatory techniques have been utilized, because these techniques are of great interest to study patients with lower limb ischaemia. The reason for this is the fact that the standard diagnostic techniques merely apprise us of macrocirculatory abnormalities, whereas nutritional microcirculatory disturbances appear to be the ultimate cause for the skin lesions as found in severely ischaemic patients. Moreover, clinically severe ischaemia can exist without corresponding macrocirculatory disturbances, and vice versa ${ }^{86,129,160}$. In addition, techniques investigating the macrocirculation cannot explain the pathophysiological mechanism of a typical clinical symptom, such as the relief of ischaemic pain when they lower the leg. 


\subsection{MICROCIRCULATION OF THE SKIN}

In the human skin, the microcirculatory vessels form an ingenious vascular system, which is organized in two functional subdivisions. One part consists of the superficial capillaries in the dermal papillae, supplying nutrition to the skin dermal tissue and the basal cells layers of the epidermis. The second element are the sub-papillary arteriolar and venular plexus, interconnected by arteriolo-venular (AV) anastomoses (see figure 1.1). These are mainly involved in the regulation of body temperature (thermoregulation) ${ }^{126},{ }^{184}$. They have relatively thick muscular walls, which are richly innervated by the sympathetic nerve system. AV anastomoses are predominantly found in the digital pulps, but not in the dorsal sides of the extremities $^{69}$.

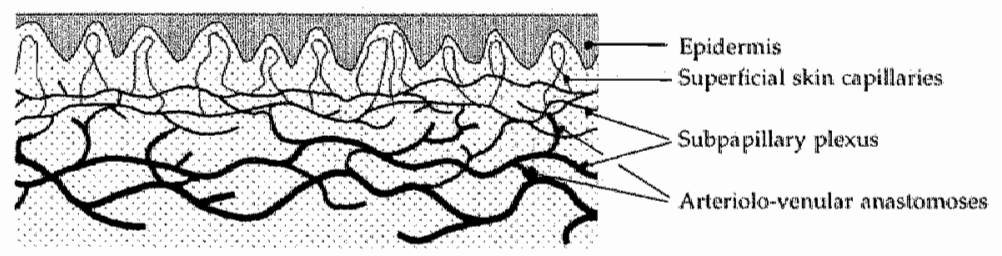

Figure 1.1 Anatomy of skin microcirculation (modificd after Spalteholz, 1893).

The regulatory mechanisms in this vascular system are complex, as they warrant optimum reactivity upon changes not only in local metabolic demands, but also in posture, temperature and blood pressure. In this thesis, the regulation of blood flow through this system is referred to as microvascular reactivity. This reactivity is governed by both local and central mechanisms. Local mechanisms to control skin perfusion comprise a myogenic vasoconstriction response. This is a contraction of smooth muscle cells in the arteriolar wall upon an increase in transmural pressure, i.e. the pressure difference between inside and outside the vessel ${ }^{3,56,83}$. Similarly, dilatation takes place upon lowering transmural pressure ${ }^{151}$. Secondly, a veno-arteriolar axon reflex ${ }^{66}$, also called veno-vasomotor reflex ${ }^{156}$, is known, 
which leads to arteriolar constriction when venous pressure is elevated. Thirdly, locally released vasodilatating substances, such as certain metabolites or endothelium-derived relaxing factor ${ }^{71}$, play a role. In addition, skin perfusion is influenced by vasomotion. This represents the tonic, spontaneous changes in arteriolar diameter causing simultaneous variations in skin blood flow, or flowmotion. This was discovered in as early as the nineteenth century in animals ${ }^{73,104,158}$ and later in $\operatorname{man}^{76}$. Central mechanisms are sympathetic nerve impulses, originating prevalently from the baroreceptors in the carotid bulb ${ }^{154,157}$, and humoral control systems ${ }^{85,138}$.

\subsection{TECHNIQUES TO MEASURE SKIN MICROCIRCULATION}

In this thesis, three non-invasive techniques have been employed to evaluate skin microcirculation:

1) capillary microscopy, which enables investigation of the nutritional. part of skin perfusion exclusively

2) transcutaneous oximetry, quantifying skin oxygenation

3) laser Doppler fluxmetry, measuring total skin perfusion

\section{Capillary microscopy}

Capillary (video-)microscopy or intravital capillaroscopy directly visualizes superficial skin capillaries (se figure 1.2). The diagnostic importance of the morphology and pathological anatomy of human capillaries has been acknowledged already in the beginning of this century ${ }^{118,128}$. Subsequently, this method was used as a diagnostic tool to assess a variety of diseases ${ }^{33}$, 123 and in particular the severity of lower limb ischaemia ${ }^{50}$. Later, when red blood cell velocity could be measured ${ }^{10}$, capillary haemodynamics were assessed in various clinical conditions ${ }^{12}$. Since that time, capillary microscopy has proven to be preeminently useful to assess disturbances in nutritional skin perfusion in both feet ${ }^{50,31}$ and hands ${ }^{94,96}$, and to evaluate drug
treatment ${ }^{4,46,98}$.

In the evaluation of lower limb ischaemia, this technique has thus far been applied only while the patient is sitting. In this position, there is good blood filling and thus, good visibility of the microvessels. However, it might 
well be that investigation of patients in the supine position discloses differences in capillary morphology or dynamics, useful in the assessment of the severity of lower limb ischaemia. Furthermore, the investigation of patients in both the sitting and the supine position yields information about postural vasoconstriction at the nutritional level of skin microcirculation. This can broaden our knowledge of microvascular reactivity in patients with severe lower limb ischaemia. Such knowledge has so far been obtained only by using techniques that measure perfusion in all layers of the skin, such as transcutaneous oximetry ${ }^{41,127}$ and laser Doppler fluxmetry ${ }^{6,77}$.
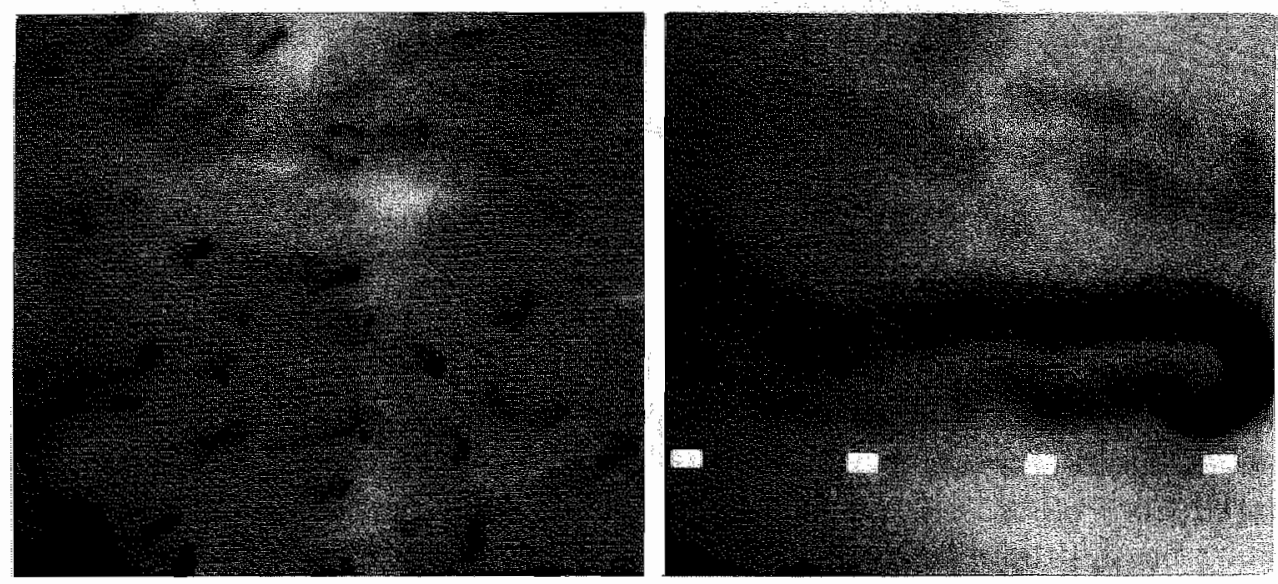

Figure 1.2 Images of skin capillaries in the nailfold of the big toe, as obtained by capillary microscopy. Left panel: general view; right panel: detail, including flying spots.

\section{Transcutaneous oximetry}

Transcutaneous oximetry measures the oxygen tension in superficial skin tissue (see figure 1.3). The technique has been applied in various clinical settings, such as the monitoring of neonates ${ }^{93}$, the early detection of shock $^{177}$, the assessment of the optimum amputation level ${ }^{18,106}$ and the appraisal of wound healing ${ }^{112,147}$ in patients with critical ischaemia. This oxygenation parameter is influenced both by the arterial oxygen pressure and by the skin blood flow ${ }^{92}$. Therefore, this method can also be used to study skin microcirculation. 


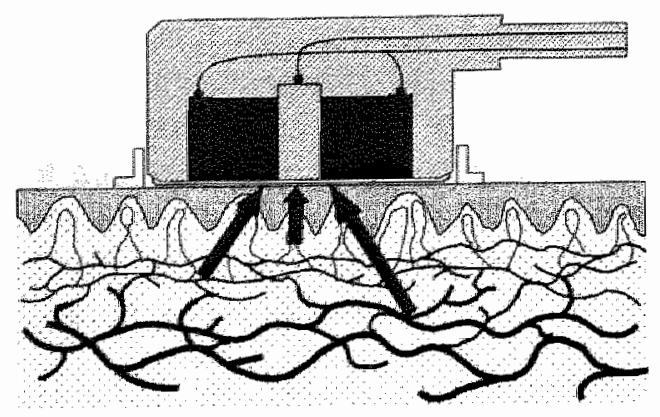

Figure 1.3 Schematic drawing of transcutaneous oximetry

\section{Laser Doppler fluxmetry}

Laser Doppler fluxmetry is a relatively new, but increasingly popular techinique in the assessment of skin perfusion in both healthy and diseased subjects. The method is based on the Doppler shift of laser light backscattered from blood cells moving in skin vessels (see figure 1.4). The principle of 'coherent light scattering' or 'light beating spectroscopy' was firstly employed in 1972 to measure blood flow in retinal arteries ${ }^{153}$. In 1975 and 1977, application of the technique to measure skin microcirculation was reported $^{89,168,169}$. However, an instrument for clinical practice was not developed until $1980^{133}$. Nowadays, it is widely used, not only in surgery, to assess skin perfusion in ischaemic disease ${ }^{11}$, but also in, for example, plastic surgery to monitor wound healing of transplants ${ }^{90,103}$, in perinatal care ch? $^{167}$ and in basic sciences to measure organ perfusion ${ }^{163}$ and drug effects ${ }^{34,186}$. The instrument provides a measure of total skin perfusion, since it measures not only at the nutritional, capillary level, but mainly at the deeper, thermoregulatory level of skin microcirculation ${ }^{134}$. 


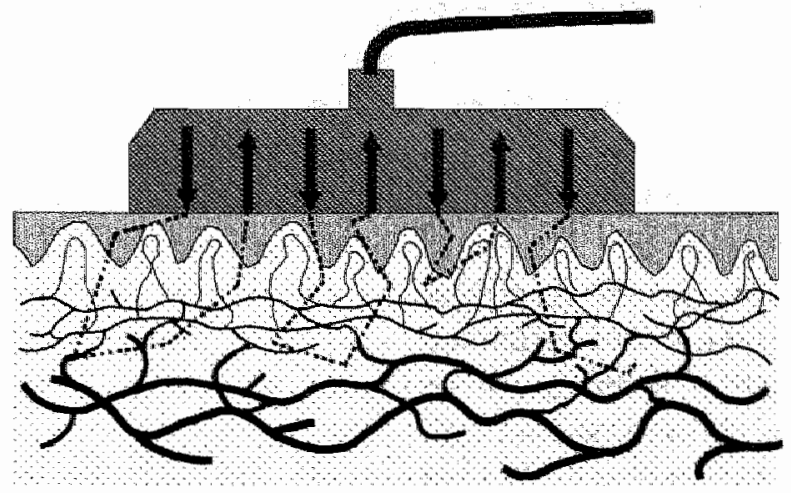

Figure 1.4 Schewatic drawing of the emission and scattering of laser light through the skin

\subsection{AIMS OF THE THESIS}

Although the above-mentioned techniques are widely used in the evaluation of lower limb ischaemia, few studies have focused on the relation between the total skin perfusion, as obtained by transcutaneous oximetry and laser Doppler fluxmetry on the one hand, and capillary, nutritional skin perfusion on the other. Also, the postural microvascular constriction mechanisms have never been investigated in both levels of the microcirculation in patients with ischaemic disease. Therefore, the major objectives of this thesis were:

1) the assessment of the microcirculatory disturbances in different stages of chronic lower limb ischaemia

2) the investigation of pathophysiological mechanisms in skin microvascular reactivity, in particular the microvascular response upon a change in posture, and the role of local and central mechanisms

3) the assessment of the putative merits of microcirculatory investigation in addition to the macrocirculatory diagnostic techniques to discriminate different degrees of severity in patients with chronic leg ischaemia. 
In chapter 2 the different techniques and methods to investigate the macro and microcirculation are described. In chapter 3 the microcirculatory disturbances and compensatory mechanisms at the nutritional level of skin microcirculation are discussed that may account for the relief of pain on leg dependency, as experienced by patients with severe leg ischaemia. In chapter 4 the disturbances at a deeper level of skin microvascular perfusion and the constriction responses upon changes in posture and local skin temperature in asymptomatic and ischaemic subjects is addressed. This posturally induced constriction is further investigated in chapter 5 , in an attempt to unravel the local pathophysiological processes that take place in skin microcirculation due to ischaemia. In chapter 6 the reversibility of this disturbed reactivity after arterial reconstructive therapy is reported. Chapter 7 deals with the value of the three microcirculatory techniques in the assessment of the severity of arterial obstructive disease. Chapter 8 is a general discussion in which concluding remarks are made. Summaries and appendices conclude this thesis. 


\section{Chapter 2}

\section{Techniques and methods applied to investigate macro and microcirculation}

Both macrocirculatory and microcirculatory measurements were performed after the patient had acclimatized for a period of 15 minutes in a room with an ambient temperature kept constant between 22 and $23^{\circ} \mathrm{C}$. Posturally induced microvascular constriction responses were tested at the nutritional and thermoregulatory level of skin microcirculation. For this purpose, the patients were investigated in both the supine and the sitting position.

\subsection{MACROCIRCULATORY INVESTIGATIVE TECHNIQUES}

In order to classify the patients according to their macrocirculatory disturbances, we measured systolic blood pressure at the ankle and upper arm in the supine position, by means of a cuff and an 8-MHz Doppler probe. The ratio of these two values yields the ankle-to-brachial pressure index (ABI). This parameter was used as a standard of reference to assess the severity of the ischaemic disease and, together with the Fontaine stages, to judge the value of microcirculatory techniques. Brachial blood pressure was also measured by means of the Riva Rocci and Korotkoff (1905) method. Mean arterial pressure was calculated using the formula $2 / 3 \times$ diastolic pressure + $1 / 3 \times$ systolic pressure. Toe systolic blood pressures were assessed using a photoplethysmograph and a toe cuff with an appropriate cuff width ${ }^{21,62}$. Finally, systolic ankle blood pressure was also measured in the sitting position to calculate the orthostatic pressure increase after the change in posture. 
In addition to the $\mathrm{ABI}$, we employed Doppler ultrasonography for the detection of arterial pathology in the major vessels of the leg under investigation. Patients were defined as having a normal arterial system when their ABI was higher than $95 \%$ and the Doppler tracings of their major leg arteries were normal. The criteria to consider Doppler signals to be pathologic are shown in table 2.1.

Table 2.1 Doppler criteria for vascular pathology

1 Absence of backflow, indicating vascular rigidity

2 Decrease of the systolic signal and an increased diastolic level, i.e. diminished pulsatility. This occurs when arterial perfusion pressure is diminished, resulting in reduced peripheral vascular resistance

3 Prolonged rise-time to peak velocity

Reduced backflow or a slightly reduced signal amplitude was considered not to be pathologic.

\section{Validation and reproducibility}

The reproducibility of ankle blood pressure measurements has been investigated by other investigators ${ }^{144}$. They found a coefficient of variation ( $\mathrm{CV}$; see subsection 2.5) of less than $10 \%$. Investigating the reproducibility of toe pressure measurements ${ }^{117}$ yielded a CV ranging from $24 \%$ in asymptomatic controls to $55 \%$ in patients with rest pain and/or ulceration. In diabetic patients this CV varied between 37 and $79 \%$.

\subsection{CAPILLARY MICROSCOPY}

In most areas of the human skin, the capillary loops are located in a $90^{\circ}$ angle to the skin surface. Thus, only the apex of the loops can be visualized. In the nailfold area (eponychium) of hands and feet, however, these loops run successively more parallel to the skin surface and in the last rows of capillaries, they can be visualized properly in their full length (see figure 
1.2). Therefore, these areas are the most valuable to investigate both capillary morphology and their perfusion.

\section{Equipment}

Capillaries were visualized using a modified Leitz Orthoplan microscope in combination with a television circuitry (figure 2.1). Capillary density was measured using a Leitz $4 x$ objective (numerical aperture (NA) 0.14). A Leitz $10 x$ objective (NA 0.30 ) was used for diameter and velocity measurements. Magnification at the front plane of the television camera (Philips Newvicon XQ $1275,2 / 3$ inch tube), which was positioned at the intermediate

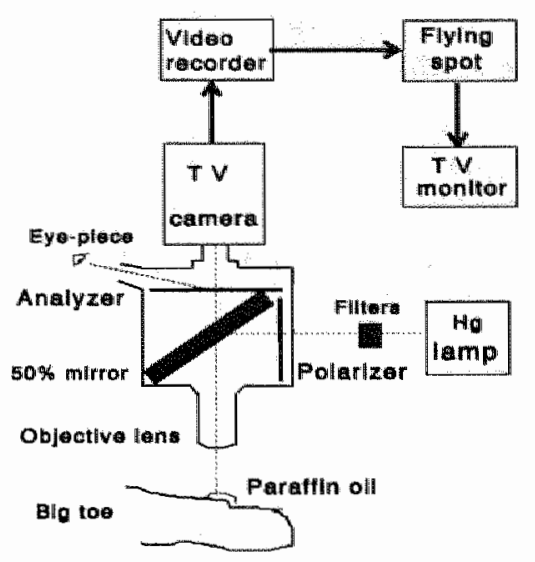

Figure 2.1 Schematic drawing of the capillary microscopy set-tip image plane, was $5 x$ and $12.5 x$, respectively. The camera was rotated to orientate the capillaries parallel to the video lines. An image was produced on a monitor screen (Philips LDH 2122; 12 inch) with a final magnification of $165 x$ and $410 x$, respectively. The images were stored on tape for off-line analysis, using a video cassette recorder (Sony Betamax SL-C9 ES). The whole system was electrically grounded to warrant the patient's safety.

Incident illumination was achieved using a Leitz Ploemopak 2.1 system, equipped with a Leitz POL (polarizer)-cube. The light from a $100 \mathrm{~W}$ mercury arc was projected directly through the POL-cube and the objective lens onto the nailfold. The POL-cube consists of a $50 \%$ transmission /50\% reflection mirror in a $45^{\circ}$ position with respect to the optical axis of the microscope. The POL-cube contains a polarizer in the illumination pathway and a crossed analyzer in the image forming pathway to cancel the light reflected from lenses and skin surface ${ }^{14,165}$. The mercury light is preeminently useful, because its spectrum contains intensity peaks at wavelengths of approximately 400 and $430 \mathrm{~mm}$. At these wavelengths, most of the light is absorbed by haemoglobin. This enhances the contrast between red blood cells and the surrounding tissues. Neutral density filters were used to adjust the light intensity at the camera. A heat absorption / reflection filter was 
used to protect the skin against a local temperature increase caused by the incident light.

Capillary red blood cell velocity (RBCV) was measured using a flying spot device $\mathrm{e}^{16,178}$. This instrument generates dots that move over the monitor screen (see figure 2.2) at a known, adjustable speed. RBCV is assessed by synchronizing the moving dots with the blood cells and plasma gaps in the arteriolar branch of the capillary. This technique was used because very low velocities, as can be expected in the patients studied, can be

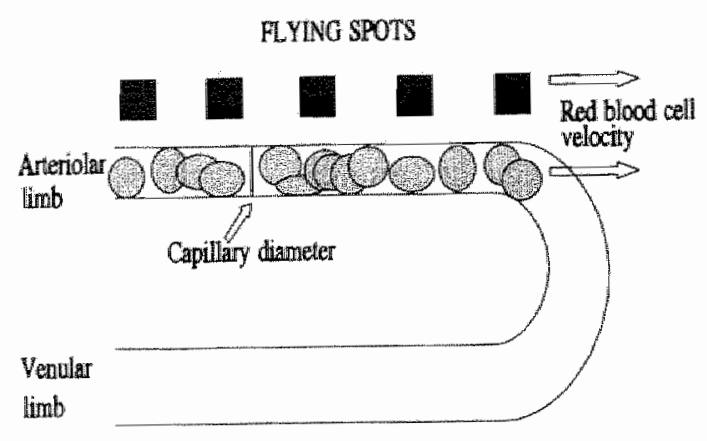

Figure 2.2

Schematic drawing of the flying spot techniaue to measure capillary diameter and red blood cell velocity assessed in a reproducible and more accurate manner than with other techniques currently in $u^{15} \mathrm{e}^{15}$.

\section{Investigatory protocol}

Capillary microscopy was performed firstly with the patient in the sitting position. The patient's foot was placed on the stage of the microscope and was gently immobilized in a mass of clay. Capillary microscopy was performed in the nailfold of the great toe. Only in exceptional cases, in which the hallux had been amputated, the second toe was used for investigation. The nailfold to be investigated was covered with a drop of paraffin oil to reduce skin reflections and improve skin transparency. We did not employ peeling of the skin or immobilisation of the digit by means of a fixation bracket, in an attempt to improve capillary visibility. These interventions were regarded as factors that possibly disturb capillary perfusion.

The measurements in the sitting position were followed by a ten minute interval in which the set-up was readjusted and the patient could adapt to the supine position before repeating the measurements. In this position, capillary microscopy was performed after tilting the microscope and stage about $45^{\circ}$. The patient was positioned on a bench, with the knee slightly (approximately $30^{\circ}$ ) flexed, so that the foot could be placed on the 
stage of the microscope and inflation of the cuff could not cause movement artifacts.

Measurements and data analyses were performed by a single investigator, thus avoiding inter-observer variability. Capillary morphology and dynamics were measured in usually four, but at least three capillaries. These were chosen randomly from the capillaries with good visibility. In severely diseased patients, sometimes only three capillaries could sufficiently be investigated. In either position, the same capillaries could usually be measured, because identification is easy due to the fact that every capillary has an almost unique morphology.

\section{Parameters measured}

With this technique, the following parameters could be assessed:

* Capillary density, defined as the number of erythrocyte-perfused capillaries per square millimetre of nailfold skin. Capillaries were counted at rest in one video screen, which has an effective surface area of 1.86 $\mathrm{mm}^{2}$. An area was chosen of about $1.6 \mathrm{~mm}$ proximal to the terminal row of capillaries. This distance was the width of one screen. This area gives a more accurate estimation of the true skin capillary density, because here, capillaries run perpendicular to the skin surface. Taking the terminal row, where capillaries run parallel to the skin, would result in an underestimation of the actual capillary density.

* Capillary diameter (in $\mu \mathrm{m}$ ), represented by the RBC column width ${ }^{121}$ in the arteriolar limbs of the capillary loops. The diameter was measured halfway between the visible base and the crest of the loop. For this purpose, we used the flying spot device (see figure 2.2): one of the spots was positioned over the capillary loop. The spot width was then adjusted until it exactly overlapped the capillary width. The distance between the measuring site and the capillary crest ranged from about 50 to 250 microns. Within this distance, the diameter did not vary substantially.

* Rest RBCV (in $\mu \mathrm{m} / \mathrm{s}$ ): capillary red blood cell velocity at rest.

* Peak $R B C V$ (in $\mu \mathrm{m} / \mathrm{s}$ ): red blood cell velocity at the peak of reactive hyperaemic response, following the release of a one minute occlusion. Arterial occlusion was induced by inflating a sufficiently wide sphyg- 
momanometer cuff around the ankle. The response was studied in each capillary investigated in both positions. Peak $\mathrm{RBCV}$ was measured as follows: from the release of the cuff on, the hyperemic response was observed and the velocity of the moving dots was continuously synchronized with the moving blood cells until the speed did not increase anymore. At that moment, RBCV was read from the display and was recorded as peak $R B C V$. The purpose of measuring also during reactive hyperaemia is to assess the residing functional reserve and to reduce measurement variability. The one-minute occlusion duration was chosen, because severely diseased patients usually could no longer tolerate the inflated cuff without moving their foot under the microscope. It is noteworthy that after one minute of ischaemia, hyperaemia is caused mainly by arteriolar smooth muscle relaxation and possibly capillary dilatation rather than an accumulation of vasoactive metabolites ${ }^{52}$. To ensure that the previous hyperaemic response had subsided, the measurements in the different capillaries were performed with an interval of at least three minutes. This interval was longer than the duration of the reactive hyperaemia, which in our patients was less than two minutes.

* Time to peak $R B C V$ (Ttpv in s): the time needed to reach peak velocity after release of the occlusion.

The patient's readings were derived from the average values of the capillary diameters and the different dynamic parameters, as measured in each capillary at rest as well as during reactive hyperaemia and in both positions.

Parameters calculated from the above mentioned parameters were:

* Hyperaemic increase in RBCV (HIV in $\mu \mathrm{m} / \mathrm{s}$ ), calculated as Peak RBCV minus Rest RBCV. This parameter was used as a measure of nutritional reserve flow.

* Transport capacity index (TCD), defined as $\pi \times$ (average capillary radius) $^{2}$ $x$ density. This index is a measure of the anatomical blood transport capacity.

* Capillary volume flow (Volflow, in $\mu \mathrm{m}^{3} / \mathrm{s} / \mu \mathrm{m}^{2}$ ) at rest, calculated as average RBCV $\times$ TCI. 
* Vasoconstriction indices: the supine to silting velocity ratios, obtained by dividing Rest or Peak RBCV in both positions in each patient. This ratio was used to obtain better insight into the individual changes in perfusion due to changes in posture. It serves as an index for the effectiveness of the postural vasoconstrictive mechanisms: the lower the index, the more the vasoconstriction response is disturbed. This approach was taken because the median of the ratios in a group may be different from the ratio calculated from the group median values of the respective velocities. When $\mathrm{RBCV}$ was zero in both the supine and the sitting position, the vasoconstriction index was also regarded as zero, insinuating disturbed postural vasoconstriction. This disturbance is conceivable, as it concerns severely diseased patients, in whom RBCV is already nil in the supine position, while RBCV approaches zero in the sitting position.

\section{Validation and reproducibility}

To check whether illumination could increase local skin temperature, and thus, capillary perfusion ${ }^{48}$, a nailfold was illuminated during 10 minutes with a light intensity $130 \%$ higher than that used in this study. Local skin temperature increased by only $0.3^{\circ} \mathrm{C}$.

To test the accuracy of the flying spot technique to measure red blood cell velocity, we processed previously stored recordings of 26 patients whose severity of vascular disease (as judged from their $\mathrm{ABI}$ ) was similar to that in the present study. These recordings were independently judged by one experienced and one beginning investigator. The coefficients of variation ( $C V$ 's, see subsection 2.5) for Rest RBCV and Peak RBCV were fairly similar between the beginning and experienced investigator (Rest RBCV: $68 \%$ and $86 \%$; Peak RBCV: $54 \%$ and $66 \%$, respectively). The slightly higher $\mathrm{CV}^{\prime} \mathrm{s}$ were scored by the experienced investigator. This may imply that experience enables the measurement of a wider range of RBCV's. The RBCV's and derived parameters measured by the experienced and beginning investigator showed correlations with a coefficient exceeding 0.90 ( $\mathrm{p}<0.005$ ). Hence, this technique was considered reliable in the investigation of these patients.

We also tested the reproducibility of the assessment of capillary diameter, density and RBCV parameters by repeating these measurements in 
three healthy sitting volunteers, two times daily for a period of five days. Healthy subjects were chosen, because their perfusion is not restricted by occlusive vascular disease. Hence, they may show the greatest variation in their microcirculatory perfusion parameters. In each session, the same three capillaries (both well and poorly visible ones) were investigated. The CV's calculated from the data obtained in healthy subjects was $9 \%$ for the capillary density and diameter. Rest RBCV showed a CV of 59\%, Peak RBCV of $25 \%$ and Ttpv of $19 \%$. A CV for the Peak RBCV of about $30 \%$ is comparable to the $\mathrm{CV}^{\prime} \mathrm{s}$ for macrocirculatory parameters ${ }^{117}$ and for rest and peak parameters as measured by means of transcutaneous oximetry ${ }^{39}, 120$ and laser Doppler fluxmetry ${ }^{120}, 173,175$. The $\mathrm{CV}$ for Rest RBCV, however, was evidently higher. This is supposedly due to the greater physiologic variation in capillary perfusion, in part caused by the presence of flowmotion in the capillaries of these healthy persons. Flowmotion results from rhythmic, spontaneous changes in the diameter of the feeding arterioles. The large variability in Rest RBCV measurements illustrates the usefulness of postocclusive reactive hyperemia parameters, in which case variation is reduced.

\subsection{TRANSCUTANEOUS OXIMETRY}

This technique measures at the skin surface the tissue pressure of oxygen. that diffuses from skin blood vessels. This transcutaneously measured tissue $\mathrm{pO}_{2}\left(\mathrm{tcpO}_{2}\right)$ is calculated from the electrical potential changes caused by a redox reaction between a platinum cathode and silver anode. This reaction takes place inside the electrode in the presence of oxygen. The resulting current is a measure of the amount of oxygen present.

The electrode also contains a heating element to increase local skin temperature, which was usually approximately $29^{\circ} \mathrm{C}$. Measurements can be performed only at an electrode temperature set between $37^{\circ}$ and $45^{\circ} \mathrm{C}$, because $t \mathrm{COO}_{2}$ values of non-hyperaemic adult skin are nil or close to zero. This temperature increase causes dilatation of the superficial arterioles, and a shift of the oxygen dissociation curve to the right ${ }^{92}$. This leads to release of oxygen from oxyhaemoglobin and thus, a higher blood $\mathrm{pO}_{2}$ for the same total oxygen content. The increase in blood $\mathrm{pO}_{2}$ is estimated to be about $6 \%$ 
per ${ }^{\circ} \mathrm{C}$. Subsequently, oxygen diffuses from the skin vessels in the vicinity of the epidermal basement membrane towards the surrounding tissues. Depending on the rate of blood flow, the $\mathrm{pO}_{2}$ decrease due to this transit is approximately $30 \mathrm{~mm} \mathrm{Hg}$, while the average mid-capillary $\mathrm{pO}_{2}$ amounts to about $125 \mathrm{~mm} \mathrm{Hg}$. However, the $\mathrm{pO}_{2}$ drops in the passage from the superficial vessels to the surface of the skin, because the oxygen has to pass metabolically highly active cells in the epidermis and the keratin layers of the outer epidermis. Furthermore, a small portion of the remaining oxygen is consumed by the electrode itself. In normal skin, the tcpO $\mathrm{O}_{2}$ on the heated surface has been found to be $33 \mathrm{~mm} \mathrm{Hg}$ lower than the mid-capillary $\mathrm{pO}_{2}$.

\section{Equipment}

A Radiometer TCM2 transcutaneous oximeter (Copenhagen) was used, incorporating a membrane-covered, Clark-type electrode ${ }^{25}$. Recordings were made with a Radiometer TCM200 recorder, the speed of which was set at $0.5 \mathrm{~cm} /$ minute.

\section{Investigatory protocol}

$\mathrm{TcpO}_{2}$ and laser Doppler flux measurements (see subsection 2.4) were performed simultaneously. The dorsum of the foot was scoured with alcohol to remove any barriers on the skin that would interfere with oxygen diffusion. The instrument was calibrated against atmospheric oxygen ten$\operatorname{sion}^{92}$. Subsequently, the tcpO $\mathrm{O}_{2}$ measuring electrode was attached to an intact part of the skin in the first intermetatarsal space by an adhesive fixation ring containing contact liquid. Measurements were performed with an electrode temperature of $37^{\circ} \mathrm{C}$. In this situation, the arterioles are dilated, albeit modestly, and the tc $\mathrm{O}_{2}$ recorded depends on arteriolar flow rather than arteriolar $\mathrm{pO}_{2}$. Measurements were repeated after heating of the electrode to $44^{\circ} \mathrm{C}$, in order to overrule local vasoconstrictive mechanisms. At this temperature, the tcpO $\mathrm{C}_{2}$ recorded in healthy subjects reflects predominantly the arteriolar $\mathrm{pO}_{2}^{68}$ and is almost flow-independent ${ }^{32,92,119}$. The instrument needed 10-15 minutes to reach a stable value. The same protocol was repeated after changing the patient's position from the sitting to the supine position or vice versa, without moving the electrode. 

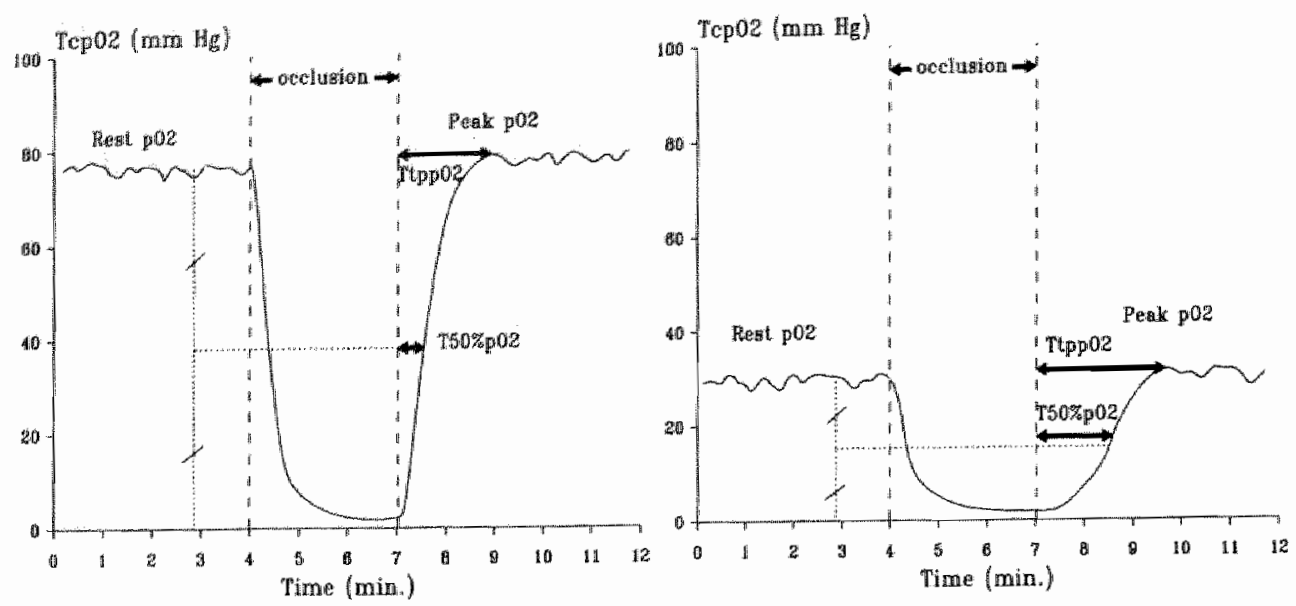

Figure $2.1 \quad \mathrm{TCPO}_{2}$ recording of an asymptomatic subject (left panel) and an ischaemic patient (right panel)

\section{Parameters measured}

Figure 2.1 shows examples of a tcpO $\mathrm{O}_{2}$ recording, performed at $44^{\circ} \mathrm{C}$, of an asymptomatic subject (left panel) and a patient with an $\mathrm{ABI}<40 \%$ (right panely, both in the sitting position. Note that at this temperature a peak after release of an occlusion is almost absent, as opposed to measurements at $37^{\circ} \mathrm{C}$.

The parameters obtained using this technique were:

* Rest $\mathrm{pO}_{2}$ (in $\mathrm{mm} \mathrm{Hg}$ ). The word 'rest' refers to the tcpO $\mathrm{O}_{2}$ before arterial occlusion, but not to the skin microcirculation under resting conditions, since measuring at $37^{\circ}$ or $44^{\circ} \mathrm{C}$ causes significant changes in skin perfusion.

* Peak- $\mathrm{pO}_{2}$ (in $\mathrm{mm} \mathrm{Hg}$ ). This was the maximum tcpO $\mathrm{O}_{2}$ reached during reactive hyperaemia after release of a three-minute arterial occlusion. The reasons for choosing this period of time are mentioned in chapter 2.4 .

* Time to $50 \%$ of rest $\mathrm{pO}_{2}\left(\mathrm{Tt} 50 \% \mathrm{pO}_{2}\right.$, in s) after release of the occlusion.

* Time to peak-pO $\mathrm{O}_{2}$ (TtppO $\mathrm{O}_{2}$ in s) after release of the occlusion. 
* Vasoconstriction indices were calculated as the quotient of supine and sitting Rest and Peak- $\mathrm{pO}_{2}$ values, respectively (see corresponding section in chapter 2.2).

* Hyperaemic increase in ${ }^{\mathrm{c}} \mathrm{cpO} \mathrm{O}_{2}$ (HIT in $\mathrm{mm} \mathrm{Hg}$ ), being Peak- $\mathrm{pO}_{2}$ minus Rest-pO $\mathrm{O}_{2}$.

\section{Validation and reproducibility}

The value and reproducibility of this technique have been investigated in extenso by others ${ }^{2}, 24,27,30,32,39,44,53,72,113,120$. Consequently, this was not done as a part of the present thesis.

\subsection{LASER DOPPLER FLUXMETRY}

A laser Doppler instrument generates monochromatic light with a wavelength of $632.8 \mathrm{~nm}$. The laser light passes through a flexible fibreoptic wire towards the measuring probe. The emitted light penetrates the skin to a depth of about 1-2 mm. Subsequently, the light is backscattered by the tissue and moving blood cells in superficial skin vessels. The measuring volume is approximately a few $\mathrm{mm}^{3}{ }^{133}$. Hence, not only the flow in superficial capillaries contributes to the signal, but particularly the thermoregulatory skin blood flow in deeper skin vessels ${ }^{11,47,176}$, such as the venous plexus and AV anastomoses. It has been estimated that more than $95 \%$ of the signal is derived from the thermoregulatory flow ${ }^{49}$. The laser Doppler flux (LDF) signal is derived from the Doppler shift of the reflected laser light, which is caused by the moving blood corpuscles (see figure 1.2). The instrument displays this signal in arbitrary units ('perfusion units"). This value is directly proportional to microvascular blood flux, i.e. the product of the number and mean velocity of the moving blood cells, and is not equal to blood flow. Since this technique promptly traces changes in skin perfusion, it is applicable to measure vasomotion. The repercussions of vasomotion on microvascular blood flow ${ }^{64,}{ }^{132}$, especially in peripheral arterial occlusive disease ${ }^{9,88,161}$, have been investigated elaborately. Hence, investigation of this phenomenon was not included in this thesis. The instrument 
was calibrated on 250 perfusion units (equal to 2.5 Volts), using the Periflux Motility Standard.

\section{Equipnent}

A Periflux PB3 laser Doppler instrument (Perimed, Sweden) was applied, containing a low power $2 \mathrm{~mW}$ Helium-Neon laser source. The laser Doppler probe holder contains a temperature measuring device and a heater. Temperature can be measured continuously and the heater can be set at any level between $26^{\circ} \mathrm{C}$ to $44{ }^{\circ} \mathrm{C}$, or can be switched off. During the measurements, the built-in low band pass filter was used to reduce movement artifacts. The time constant was set at 2 seconds to evade heart beat oscillations. The $0.07-12 \mathrm{kHz}$ 'wide' band was used, unless perfusion was so low that switching to the $0.07-4 \mathrm{kHz}$ band, and, hence, improving the signal-to-noise ratio, was required. The output was fed into a pen recorder. The recording speed was $3 \mathrm{~cm} / \mathrm{s}$.

\section{Investigatory protocol}

The laser Doppler probe holder was attached to the plantar side of the great toe with double-sided adhesive tape. The probe itself was secured to the holder with adhesive tape to avoid flux variations due to rotation of the probe. The cables were suspended to avoid pressure or traction on the skin area under investigation. The pulp of the great toe was chosen, because in this area, AV anastomoses involved in thermoregulation are numerous, so that insight could be obtained into thermoregulatory flow in addition to the nutritional blood flow (capillary microscopy; section 2.2).

At first, LDF recordings were performed at unheated skin temperature in order to assess the integrity of microvascular constriction mechanisms under basal conditions. Hereafter, LDF was performed at $36^{\circ} \mathrm{C}$ to study the degree of microvascular constriction after limited impairment of local vasoconstricting mechanisms. Recordings started after the laser Doppler fluxmeter had reached a stable value, which took at least ten minutes. Measurements were repeated in the other position after a ten minute adaptation period, during which the parameters reached a steady state again. The laser Doppler probe was kept in place while changing position. 


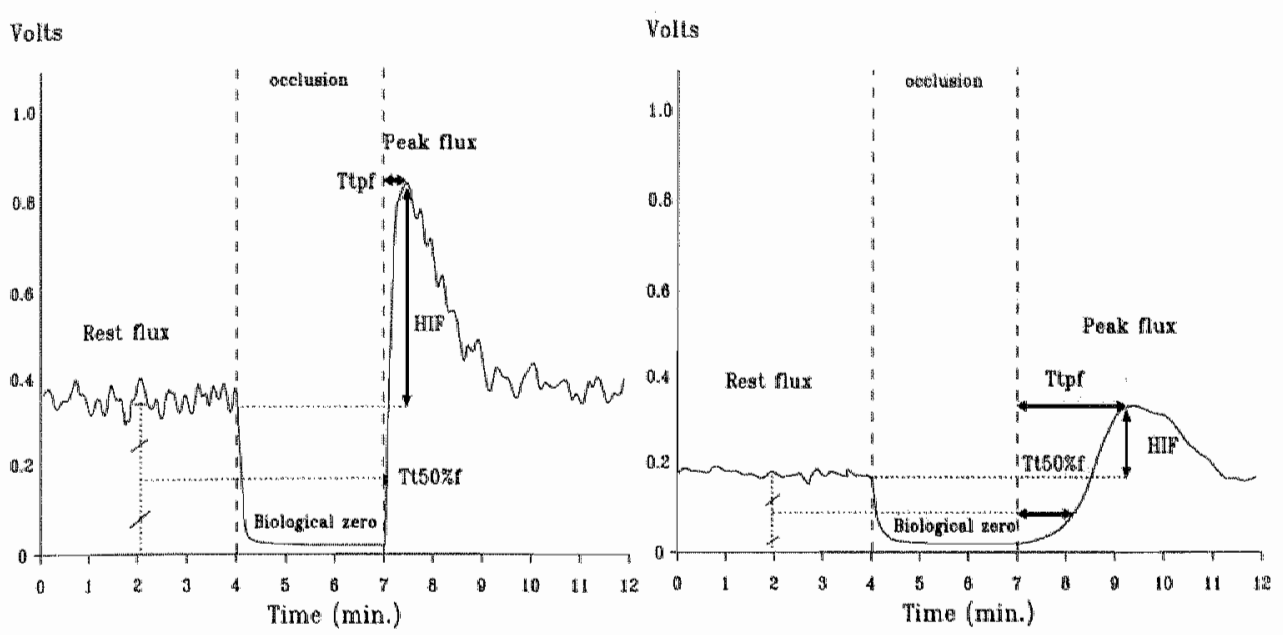

Figure 2.2 Laser Doppler flux recording in an asymptonatic subject (left panel) and in an ischaemic patient (right panel)

\section{Parameters measured}

Figure 2.2 shows examples of a LDF recording, performed at $36^{\circ} \mathrm{C}$, of an asymptomatic subject (figure $2.2 \mathrm{a}$ ) and a patient with an $\mathrm{ABI}<40 \%$ (figure $2.2 b$ ), both in the sitting position.

The following parameters were assessed using laser Doppler fluxmetry:

* Rest flux (Volts). Biological zero flux ${ }^{22}$ was subtracted from the rest and peak flux values measured (vide infra).

* Peak flux (Volts): maximum flux during reactive hyperaemia, following the release of a three minute arterial occlusion. This occlusion duration gives rise to vasodilatation not only because of arteriolar relaxation due to myogenic mechanisms, but also due to the accumulation of vasoactive metabolites ${ }^{52}$. The induction of reactive hyperaemia in the foot in this standard manner was applied not only to reduce measurement variability at rest ${ }^{146}$, but also to assess whether the larger vessels between ankle and skin had any additional effect on microvascular reactivity upon dependency. 
* The time to reach half of the rest flux (T50\%flux, in s) after release of the occlusion.

* The time to peak flux (in s) after release of the occlusion (Ttpflux).

From these data, the following additional parameters were derived:

* The vasoconstriction index: individual supine to sitting flux ratios, both at rest and during reactive hyperaemia, as an index for the effectiveness of the postural vasoconstrictive mechanisms. The lower this index is, the more these mechanisms are impaired. If the rest flux was zero in both the supine and the sitting position, the ratio was regarded to be zero (see subsection 2.2).

* Hyperaemic increase in LDF (HIF, in Volts), defined as peak minus rest flux values. The HIF was used as a measure of thermoregulatory reserve capacity.

\section{Validation and reproducibility}

The significance and reproducibility of this technique has been documented earlier ${ }^{2}, 120,173,175$, and hence, was not repeated here.

\subsection{STATISTICAL ANALYSES}

* The coefficient of variation $(\mathrm{CV})$ was calculated as the standard deviation divided by the mean value for each parameter, expressed as a percentage.

* Patients were grouped according to their ABI. Of each patient group, the median values are presented, because the results of all parameters obtained in each ABI-group were not symmetrically distributed.

* The non-parametric, two-sided Wilcoxon matched-pairs signed-ranks test was used for statistical analysis of the differences between the results obtained in the two positions or at the various local temperatures within the same patient group.

* The non-parametric, two-sided Mann-Whitney $U$ and Kruskal-Wallis test were used to evaluate differences between two and all patient groups, respectively, for statistical significance. 


\section{Chapter 3}

\section{Capillary recruitment and pain relief on dependency in patients with severe lower limb ischaemia*}

\subsection{INTRODUCTION}

Patients with severe lower limb ischaemia may experience relief of nocturnal or rest pain on leg dependency. As yet, this phenomenon has not been explained satisfactorily. Under physiological conditions, arteriolar vasoconstrictive mechanisms lead to reduced lower limb perfusion when changing from the supine to the sitting position ${ }^{2,78,152}$. The mechanism involved can be of central sympathetic ${ }^{40,77}$ and / or local origin. In the latter case, a myogenic response or a veno-arteriolar axon reflex have been considered ${ }^{81,84}$. There are indications that these mechanisms are disturbed in patients experiencing relief of pain on leg dependency, resulting in enhanced rather than decreased perfusion upon dependency $5,6,29,31,32,65,82,182$. In these studies, skin perfusion was measured with the use of the ${ }^{133} \mathrm{Xe}$ washout method, transcutaneous oximetry or laser Doppler fluxmetry. Techniques measuring total skin microcirculatory blood flow do not allow the distinction between capillary and thermoregulatory flow. Moreover, the measured increases in flow were often limited.

It was the aim of the present study to investigate the microcirculatory changes induced by leg dependency in patients with different stages of lower limb ischaemia. To this end, in these patients skin nutritive flow was determined in both the supine and the sitting position using intravital video

The study described in this chapter has been published in Circulation: 1992: 85:

223-229 
microscopy of the toe nailfold. Beside dynamic, also morphological parameters were assessed, because improvement on dependency might not only result from enhanced flow, but also by an increase in erythrocyte-perfused capillary density, leading to an enlarged surface area for exchange.

\subsection{PATIENTS AND METHODS}

\section{Patients}

Twelve subjects with an asymptomatic leg and 75 patients suffering from arterial obstructive disease in at least one leg, participated in the study. The age of the 62 males and 25 females ranged from 43 to 95 years, with a mean value of 71 years. Their symptoms were intermittent claudication, rest pain and/or ulceration. The patients were divided into five groups (see table 3.1), according to their Ankle-to-Brachial pressure Index (ABI). This $A B I$ varied from $0 \%$ to $123 \%$, being the lowest in group $E$ and the highest in group A. Fifteen of the 25 patients with rest pain experienced relief of pain by depending their legs. They all had an ABI of $50 \%$ or less and clinically belonged to Fontaine stage 3 or 4 . Smoking habits and drug treatment, especially those interfering with vasoconstriction, are shown in table 3.2.

Table 3.1 Patient groups

\begin{tabular}{|c|c|c|c|c|c|c|c|c|}
\hline Group & $\begin{array}{l}\mathrm{ABI} \\
(8)\end{array}$ & N & $\begin{array}{l}\text { Age } \\
\text { (Range) }\end{array}$ & $\begin{array}{l}\text { Ankle } \\
\text { pressure }\end{array}$ & $\begin{array}{l}\text { Fon } \\
0^{\circ}\end{array}$ & taine & 3 & 4 \\
\hline A & $96-123 \%$ & 12 & $67(51-82)$ & 150 & 12 & 00 & 0 & 0 \\
\hline B & $60-95 \%$ & 16 & $65(45-76)$ & 97 & 0 & 214 & 0 & 0 \\
\hline $\mathrm{C}$ & $40-59 \%$ & 23 & $70(43-95)$ & 75 & 0 & 019 & 1 & 3 \\
\hline $\mathrm{D}$ & $20-39 \%$ & 24 & $72(53-81)$ & 52 & 0 & 015 & 5 & 4 \\
\hline $\mathrm{E}$ & $0-19 \%$ & 12 & $81(77-89)$ & 16 & 0 & 00 & 5 & 7 \\
\hline
\end{tabular}


Of the twelve subjects in group A, two received medication for cardiac angina, one for hypertension, one for a recent myocardial infarction and one for atherosclerotic symptoms of the leg not investigated here. These twelve subjects had a normal arterial system in the investigated leg. This was judged not only by the ABI, which in this leg was higher than $95 \%$, but also by the analysis of the Doppler signals of the major leg arteries. These showed no pathology, as opposed to the arterial Doppler signals of the patients in groups $B$ through $E$. The reader is referred to section 2.1 for the criteria to consider Doppler tracings to be pathologic.

Table 3.2 Patient characteristics

\begin{tabular}{ccccccccc} 
Group & N & Relief & Diabetes & Smokers & \multicolumn{4}{c}{ Vasoactive arugs } \\
\hline A & 2) & 3) \\
\hline A & 12 & 0 & 2 & 3 & 3 & 1 & 1 \\
B & 16 & 0 & 1 & 7 & 6 & 2 & 5 \\
C & 23 & 3 & 8 & 6 & 9 & 5 & 5 \\
D & 24 & 5 & 2 & 8 & 4 & 2 & 4 \\
E & 12 & 7 & 5 & 2 & 11 & 3 & 3 \\
\hline
\end{tabular}

1) includes arterial and venous dilators. One patient in group $B$ and one in group D used an ACE-inhibitor

2) B blocking agents

3) Calcium antagonists

Subjects with insulin-dependent diabetes mellitus were excluded from the study, since this disease per se influences microcirculatory autoregulation mechanisms ${ }^{54,148}$. However, eighteen non-insulin dependent diabetics did participate in this study. Their findings were interpreted separately to assess possible differences in microvascular reactivity between diabetic and non-diabetic patients. At the time of the investigation, they were all wellregulated. Peripheral neuropathy was ruled out when patients stated not to experience paresis or loss of sensibility and skin tactile sensibility showed no abnormalities during clinical examination. Patients refrained from smoking and did not take caffeine or alcohol at least one hour before examination. 


\section{Methods}

All patients were investigated using capillary microscopy of the nailfold of the great toe. This was performed in both the sitting and the supine position. The experimental protocol used in this study, as well as the equipment used and the analysis of the parameters measured by means of capillary microscopy were already mentioned in section 2.2 .

Systolic ankle and brachial blood pressure were measured in the supine position by means of a cuff and an $8 \mathrm{MHz}$ Doppler probe to assess $A B I$. Brachial blood pressure was also measured with the Riva Rocci method to calculate mean arterial pressure $(2 / 3 x$ diastolic pressure $+1 / 3 x$ systolic pressure). Finally, systolic ankle blood pressure was measured in the sitting position to calculate the orthostatic pressure increase after the change in posture.

\section{Statistics}

Because in each ABI-group the results of all parameters obtained were not symmetrically distributed, medians are presented to characterize group values. The non-parametric Kruskal-Wallis test was used to evaluate differences between the five patient groups for statistical significance. The paired Wilcoxon signed-ranks test was used for the statistical analysis of differences between the two positions.

\subsection{RESULTS}

Mean arterial blood pressures did not differ significantly between the patient groups. Systolic ankle pressure was on the average $48 \mathrm{~mm} \mathrm{Hg}$ higher in the sitting than in the supine position, due to the increase in orthostatic pressure. This was a consistent finding and was independent of ankle blood pressure in the supine position. In each group the capillary microscopic parameters in the diabetics did not differ significantly from those in the non-diabetics in both positions and, therefore, the diabetic and non-diabetic data were pooled.

The individual data on RBC perfused capillary density are presented in figure 3.1. In the supine position, the densities were similar in groups A 
through $D$. In group $E$, however, the median density was only $8 / \mathrm{mm}^{2}$, which was significantly lower than the median density of $27 / \mathrm{mm}^{2}$ in group D ( $\mathrm{p}<0.005$ ). RBC-perfused capillary density was lower in the supine than in the sitting position in all groups ( $p<0.05$, but not significant in group B). This was especially noticeable in group $E$ (supine: $8 / \mathrm{mm}^{2}$; sitting $34 / \mathrm{mm}^{2}$ ). In the sitting position, the densities did not differ significantly between all groups and ranged from $34 / \mathrm{mm}^{2}$ in group $\mathrm{E}$ to $62 / \mathrm{mm}^{2}$ in group D.

Figure 3.1 Scatterplot of individual and group median capillary densities in sitting and supine positions plotted against their ankle-to-brachial index values.

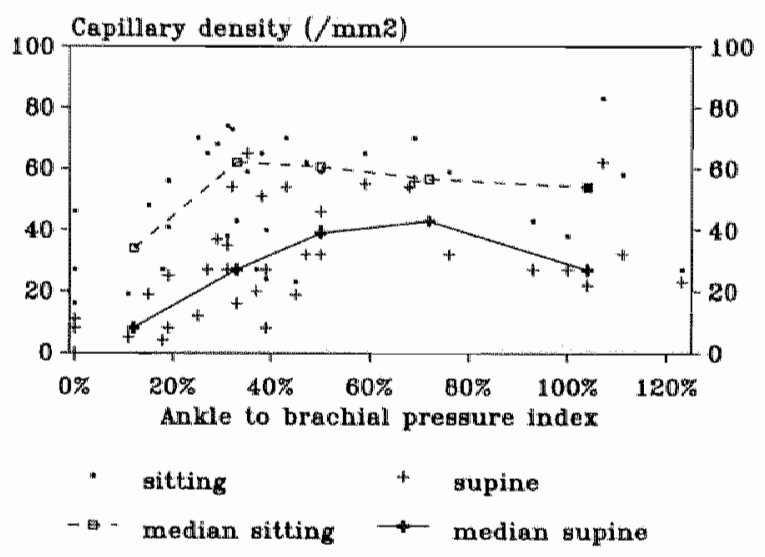

In figure 3.2 the individual data on capillary diameter are shown. In all groups, the diameter was significantly smaller in the supine than in the sitting position $(\mathrm{p}<0.05)$. Capillary diameters did not change significantly between the groups, but tended to increase with a decrease in ABI.

Figure 3.2 Scatterplot of individual and group median capillary diameters in sitting and supine positions plotted against their ankle-to-brachial index values. The arrow indicates a stray value.

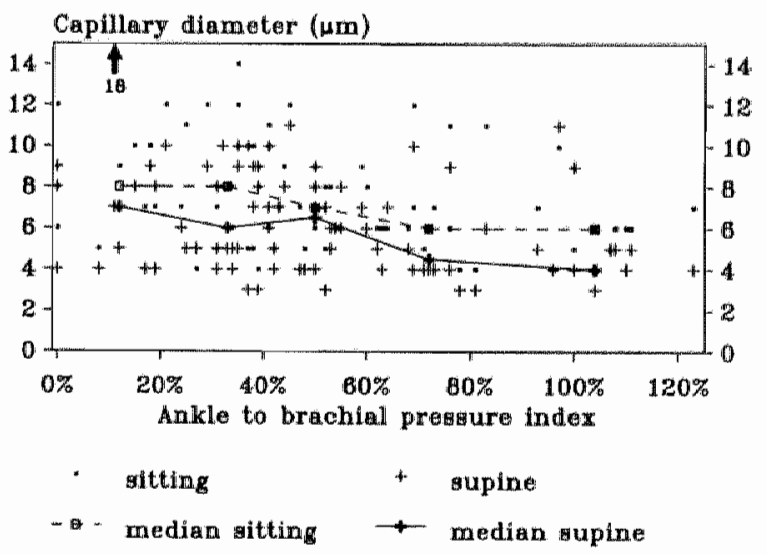


The individual data on capillary Restw are presented in figure 3.3. Induction of reactive hyperaemia did not lead to an increase of the Restv in the capillary examined subsequently, indicating sufficiently long time intervals. In the supine position, Restv was fairly similar in the groups A through $\mathrm{D}$. In group $\mathrm{E}$, however, the median velocity $(17 \mu \mathrm{m} / \mathrm{s})$ was significantly $(p<0.001)$ lower than the median values in group $A$ through $D$ $(168 \mu \mathrm{m} / \mathrm{s})$. The Restv's in the sitting position were not significantly different between the five groups.
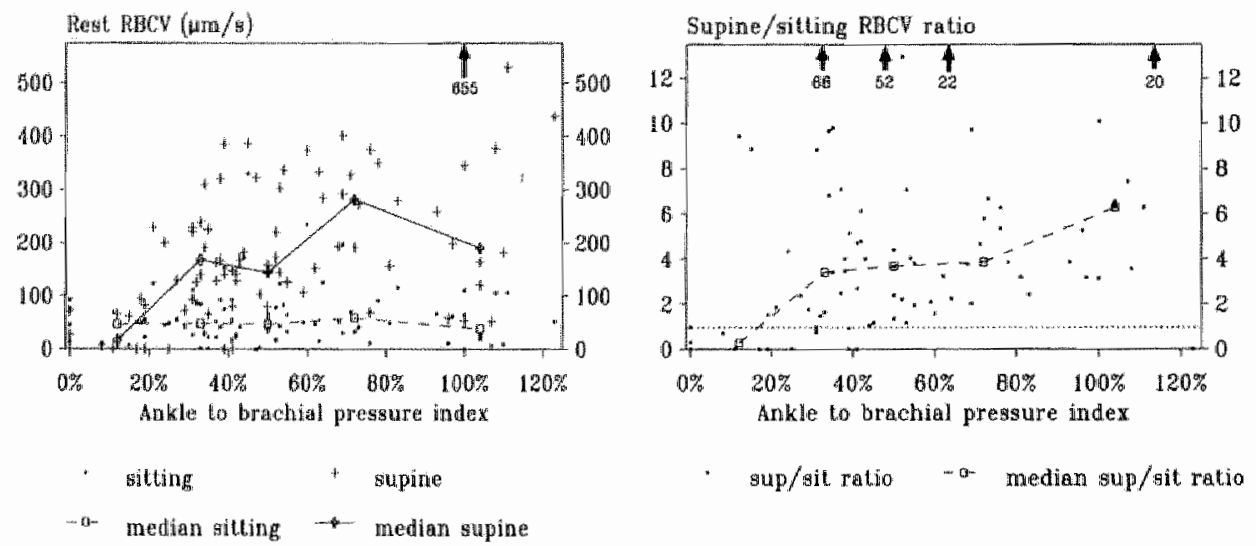

Figure 3.3 Scatterplots of the individual and group median red blood cell velocities at rest in sitting and supine positions (left pranel) and supine-tositting ratios (right panel) plotted against their ankle-to-brachial index values. The dotted line at a ratio of 1 in the right pand indicates an equal velocity in both positions. Arrows indicate stray walues.

As can be seen in the right panel of figure 3.3 , the individual capillary Restv's were about 4-6 times higher in the supine than in the sitting position in the groups A through $D(p<0.005)$, illustrating effective arteriolar vasoconstriction in the sitting position. In contrast, Restv in group E increased upon dependency, leading to ratios below unity. However, this increase in Restv did not reach the level of significancy.

In addition, the relation between Restv and supine-to-sitting RBCV ratios and the individual systolic ankle pressure was investigated, as the 
absolute ankle pressure might be a more indicative parameter of the arterial perfusion pressure in patients with severe ischaemia. This yielded results comparable to those when Restv and its ratios were related to the ABI (see figure 3.4). Also, the results of the parameters Peakv and Volflow (vide infra) plotted against the ankle pressure were similar to those plotted against the $\mathrm{ABI}$.
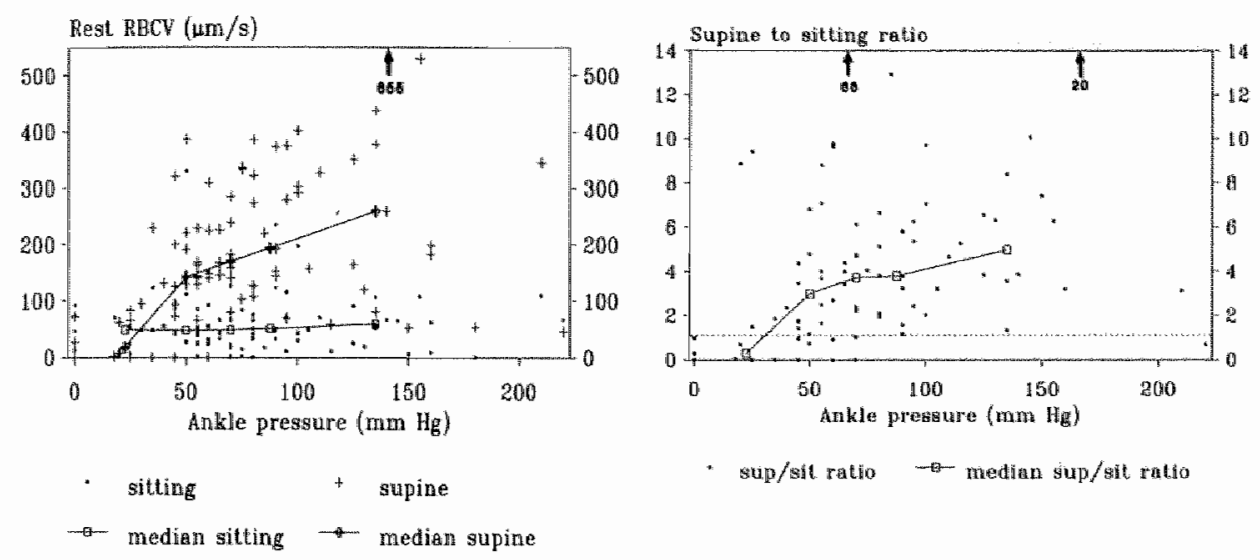

Figure 3,4 Scatterplots of the individual and group median red blood cell velocities at rest in sitting and supine positions (left panel) and supine-to-sitting ratios (right panel) plotted against their systolic ankle blood pressures. The dotted line at a ratio of 1 in the right panel indicates an equal velocity in both positions. Arrows indicate stray values.

In both positions, the trends in Peakv (figure 3.5) were similar to those in Restv. In the supine position, median Peakv was very low in group E (55 $\mu \mathrm{m} / \mathrm{s}$, as compared to $175 \mu \mathrm{m} / \mathrm{s}$ in group D). In the groups $\mathrm{D}$ and $\mathrm{E}$, Peakv appeared to be only slightly higher than the Restv, indicating the absence of reactive hyperaemia. In the sitting position, Peakv decreased slightly from a median of $120 \mu \mathrm{m} / \mathrm{s}$ in group $A$ to a median of $59 \mu \mathrm{m} / \mathrm{s}$ in group $\mathbb{E}$ and was 2-4 times higher in the supine than in the sitting position in groups A through $D$. 


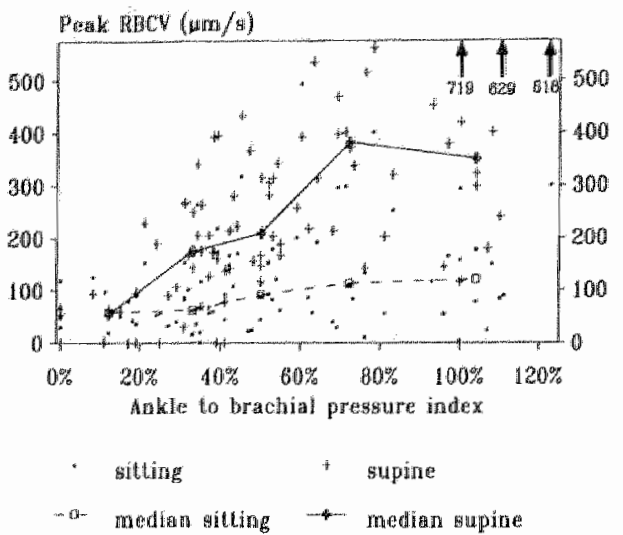

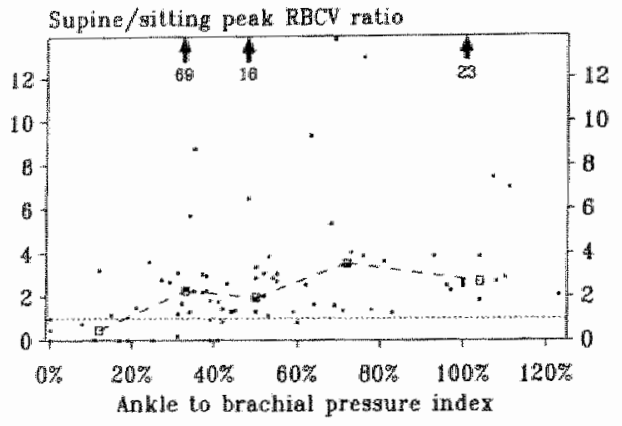

shup/sit ratio - - me median sup/sit ratio

Figure 3.5 Scatterplots of individual and group median peak red blood cell velocities in sitting and supine positions (left panel) and supine-to-sitting ratios (right ponel) plotted against their ankle-to-brachial index values. The dotted line at a ratio of 1 in the right panel indicates an equal velocity in both positions.

In the groups $A$ through $C$, Volflow (figure 3.6) was persistently lower in the sitting than in the supine position. In group $\mathrm{E}$, however, in the supine position, Volflow was markedly reduced ( $\mathrm{p}<0.005$ ), as compared to the other groups, and increased significantly in the sitting position $(p<0.05)$, most probably due to capillary recruitment.

Figure 3.6 Scatterplot of the individual and group median zolume flow per square micrometre of nailfold skin in sitting and supine position plotted against their ankle-tobrachial index walues.

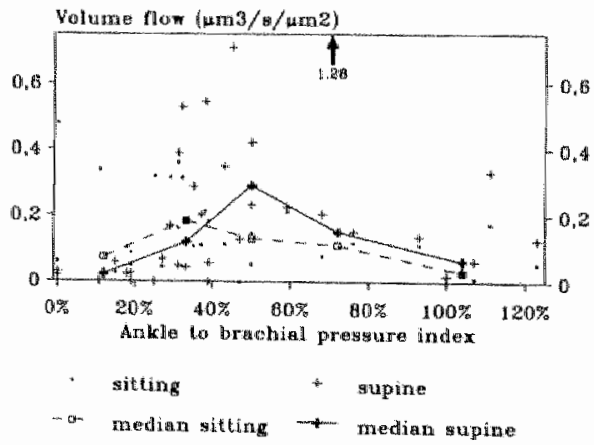


All patients with relief on dependency had an $\mathrm{ABI} \leq 50 \%$. In this $\mathrm{ABI}$ range, the median $A B I$ between patients with and without relief did not differ significantly. The data are shown in table 3.3 .

Table 3.3 Median capillary microscopic data of patients with an $A B I \leq 50 \%$, subdivided in those with and without pain relief on dependency.

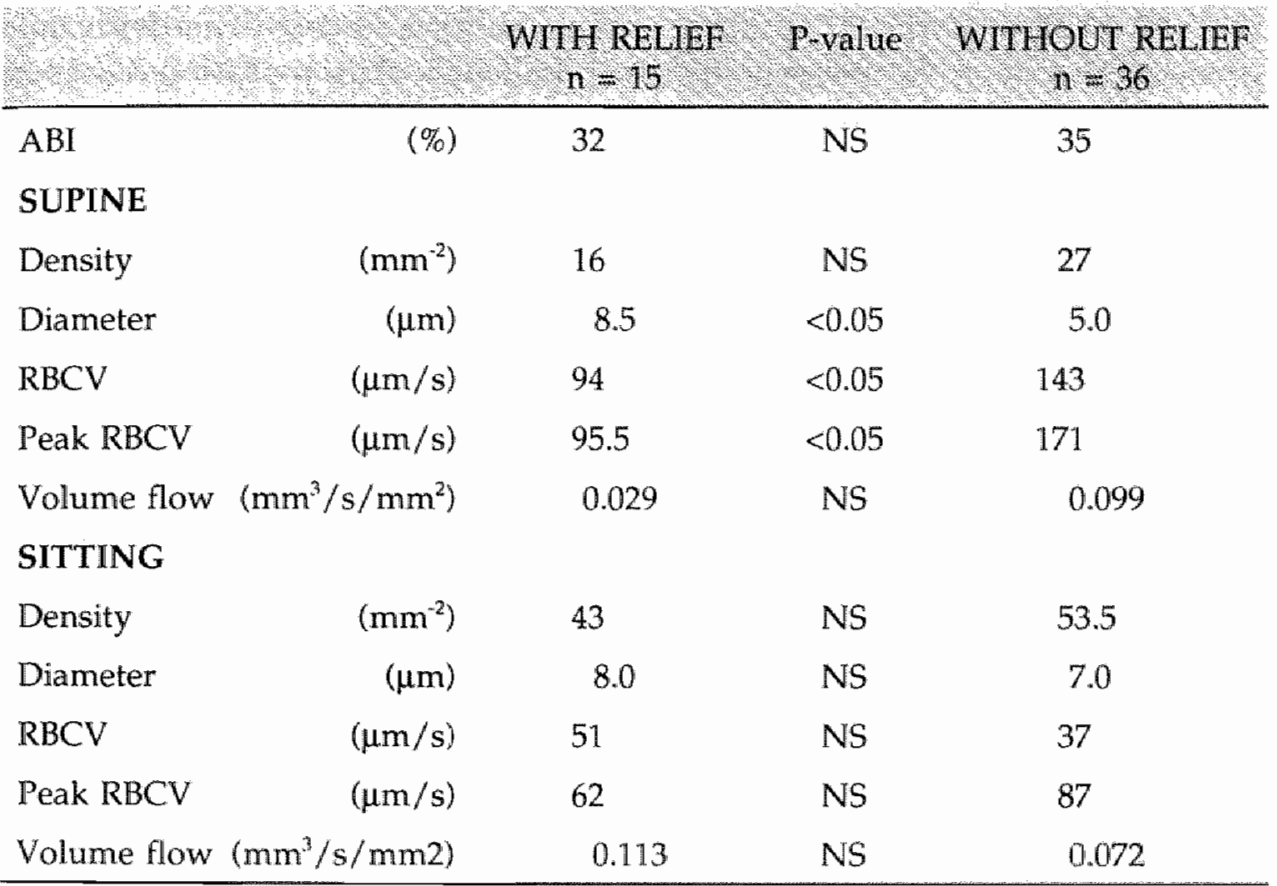

Patients with relief had a considerable worse nutritive perfusion and showed a significantly $(\mathrm{p}<0.05)$ larger capillary diameter and a lower RBCV and Peak RBCV in the supine position, and a lower vasoconstriction index (1.21 and 3.48, respectively) than in patients without relief. However, capillary density in patients with pain relief increased $(p<0.002)$ when changing from the supine to the sitting position and tended to be more than the increase $(p<0.005)$ in patients without pain relief $(2.7$ versus 2 fold increase). Similar changes were found for Volflow. The patients with pain relief showed a 4 fold increase, while those without pain relief showed a decrease. 


\subsection{DISCUSSION}

The findings in the present study show that in limb threatening ischaemia, associated with ankle-to-brachial pressure indices below $20 \%$, skin capillary perfusion is significantly impaired and cannot cope anymore with increasing demands, while the number of $R B C$ perfused capillaries is significantly reduced. A change in posture from the supine to the sitting position leads to reduced skin perfusion in asymptomatic subjects and patients with mild disease. However, in severely diseased patients, skin perfusion tends to increase with this change in posture. These findings indicate that in subjects with a normal or only limitedly compromised circulation the dependencyinduced arteriolar vasoconstriction is still intact, but that this mechanism is disturbed in patients with severe ischaemia. This disturbance is likely to be local in origin, but it is unknown whether it is caused by diminished contractile properties of the smooth muscle cells in the arteriolar wall or by disturbances in local reflex mechanisms.

It is an interesting observation that in both the asymptomatic subjects and the patients with mild or severe peripheral vascular disease, red blood cell-perfused capillary density increased significantly upon dependency, thereby enlarging the surface area for exchange. This increase in density can possibly be explained by a rise in transmural pressure, because the effective perfusion pressure does not change upon dependency. The increase in transmural pressure upon dependency is also indicated by the tendency of the capillary diameter to increase under these circumstances.

The observation that not in all patients with rest pain dependency leads to pain relief, despite the fact that capillary density and blood flow increase when changing to the sitting position, may be explained by the progressed state of the disease in several of these patients. In some of them, rest pain was present in both the supine and the sitting position, while they reported to have experienced pain relief on dependency in the past. This is of important clinical diagnostic value, as it indicates a terminal stage of the disease in which the nutritional circulation will be insufficient in either position, inevitably resulting in tissue necrosis. The same can be said concerning the severely diseased patients showing absence of a reactive hyperemic response, i.e. loss of flow reserve. Further reduction of the arterial perfusion pressure with progression of the disease will not lead to a compensatory microvascular dilatation and thus induce tissue loss. 
In this study, postural microvascular reactivity in patients with noninsulin dependent diabetes mellitus could not be discerned from non-diabetics. This small group of diabetics apparently did not influence the microcirculation differently. It is also possible that in both types of patients atherosclerosis is the dominating disease.

It is concluded that in the clinic, posturally induced arteriolar vasoconstriction, leading to diminished leg perfusion upon dependency, can be assessed with the use of capillary video microscopy. The findings in this study show that patients with limb threatening ischaemia (ankle-to-brachial pressure index $<20 \%$ ) show disturbed arteriolar vasoconstriction, resulting in enhanced capillary recruitment and increased nutritive red blood cell velocity. The relief of pain upon dependency may be explained by an increase in red blood cell-perfused capillary density, thereby enlarging the surface area for exchange, rather than an increase in capillary perfusion. 



\section{Chapter 4}

\section{Posturally induced microvascular constriction in patients with different stages of lower limb ischaemia: effect of local skin heating*}

\subsection{INTRODUCTION}

Patients suffering from severe arterial obstructive disease of the leg tend to lower the leg to alleviate nocturnal or rest pain. This seems paradoxical, because in normal limbs, blood flow is reduced on dependency $\mathrm{y}^{78}$ by central sympathetic reflexes ${ }^{40,77,155}$ and local myogenic or veno-arteriolar constriction mechanisms ${ }^{66,81,84}$ to protect against oedema formation ${ }^{84,152}$.

The microvascular constriction, as seen after leg dependency in healthy subjects $^{41,77,152}$, is abolished in patients with leg ischaemia ${ }^{40,79,127}$, possibly due to a disturbance of the veno-arteriolar response ${ }^{5,6}$, finally resulting in enhanced perfusion of the capillaries ${ }^{180}$ and deeper vessels of the $\operatorname{skin}^{29}$. Local skin heating ${ }^{131,185}$, especially in combination with postural changes ${ }^{31,32 \text {, }}$ 113 is a useful test to determine the integrity of microvascular constriction mechanisms in leg ischaemia. However, it has not been investigated whether local or central mechanisms prevail in the disturbance of these mechanisms. Furthermore, it is still unknown at which level of arterial pressure reduction microvascular constriction upon dependency will be impaired. For this purpose, we investigated skin microcirculation in patients with various degrees of arterial obstructive disease of the legs, using laser Doppler fluxmetry and transcutaneous oximetry, before and after a change

The work described in this chaprer has been published in Climical Science: 1991:

81: $43-49$. 
in posture. In each position the measurements were performed at rest and during reactive hyperaemia, and at different local skin temperatures.

\subsection{PATIENTS AND METHODS}

\section{Patients}

Twelve asymptomatic controls and seventy-six patients suffering from atherosclerotic arterial obstructive disease of one or both legs, cooperated after informed consent. The age of the 62 males and 26 females ranged from 43 to 95 years, with a mean value of 71 years. Clinically, their complaints varied between intermittent claudication, rest pain and ulceration. The patients were divided into five groups (table 4.1), according to their Ankleto-Brachial systolic blood pressure Index $(A B I)$. $A B I$ varied from $0 \%$ to $123 \%$, being the lowest in group $\mathrm{E}$ and the highest in group $\mathrm{A}$.

Table 4.1 Patient groups

\begin{tabular}{|c|c|c|c|c|c|c|c|c|}
\hline Group & $\mathrm{ABI}$ & $\mathrm{N}$ & Age & $\mathrm{MAP}^{\circ}$ & Fon & taine & & \\
\hline & $(\%)$ & & (Range) & $(\mathrm{mm} / \mathrm{H})$ & $0^{*}$ & 12 & 3 & 4 \\
\hline A & $96-123 \%$ & 12 & $67(51-82)$ & 96 & 11 & 10 & 0 & 0 \\
\hline B & $60-95 \%$ & 16 & $65(45-76)$ & 92 & 0 & 214 & 0 & 0 \\
\hline $\mathrm{C}$ & $40-59 \%$ & 23 & $70(43-95)$ & 101 & 0 & 019 & 1 & 3 \\
\hline$D$ & $20-39 \%$ & 24 & $72(53-81)$ & 105 & 0 & 015 & 5 & 4 \\
\hline $\mathrm{E}$ & $0-19 \%$ & 13 & $82(77-89)$ & 97 & 0 & $\begin{array}{ll}0 & 0\end{array}$ & 5 & 7 \\
\hline
\end{tabular}

" $\mathrm{AAP}=$ mean arterial pressure

* ${ }^{\prime}{ }^{\prime}=$ no arterial disease

Smoking habits and drug treatment, especially those interfering with vasoconstriction, are shown in table 4.2 . 
Table $4.2 \quad$ Patient characteristics

\begin{tabular}{|c|c|c|c|c|c|c|}
\hline \multirow[b]{2}{*}{ Group } & \multirow[b]{2}{*}{$\mathrm{N}$} & \multirow[b]{2}{*}{ Diabetes } & \multirow[b]{2}{*}{ Smokers } & \multicolumn{3}{|c|}{ Vasoactive druge } \\
\hline & & & & 1) & 2 & 3) \\
\hline A & 12 & 2 & 3 & 3 & 1 & 1 \\
\hline B & 16 & 1 & 7 & 6 & 2 & 5 \\
\hline C & 23 & 8 & 6 & 9 & 5 & 5 \\
\hline D & 24 & 2 & 8 & 4 & 2 & 4 \\
\hline $\mathrm{E}$ & 13 & 6 & 2 & 11 & 3 & 3 \\
\hline
\end{tabular}

1) includes arterial and venous dilatators. One patient in group D and one in group B used an ACE-inhibitor

2) B blocking agents

3) Calcium antagonists

Of the twelve subjects in group $\mathrm{A}$, two received medication for cardiac angina, one for hypertension, one for a recent myocardial infarction and one for atherosclerotic symptoms of the leg not investigated here. The patients in this group had a presumed normal arterial system in their investigated leg, not only because their ABI was higher than 95\%, but also because analysis of the Doppler signals of the major leg arteries showed no pathology, as opposed to the arterial Doppler signals of the patients in groups B to $E$. The mean age in group A (67 years) did not differ significantly from the mean age in groups B through D (69 years). The mean age in group $\mathrm{E}_{\text {, }}$ however, was higher ( 82 years). Hence, patients in group A were considered age-matched controls only for the groups $B$ to $D$.

Subjects with insulin-dependent diabetes mellitus were excluded from the study, since this disease per se influences microcirculatory autoregulation mechanisms ${ }^{148}$. However, nineteen non-insulin dependent diabetics did participate in this study (table 4.2). At the time of the investigation, they were all normoglycaemic and none of them had clinically manifest peripheral neuropathy. Their findings were interpreted separately to assess possible differences in microvascular reactivity between diabetic and nondiabetic patients.

Patients refrained from smoking and did not take caffeine or alcohol at least one hour before examination. 


\section{Methods}

Measurements were performed following a 20 minute period of acclimatization in a room with a temperature between $23^{\circ}$ and $24^{\circ} \mathrm{C}$. Laser Doppler fluxmetry (LDF) and transcutaneous oximetry $\left(\mathrm{TcpO}_{2}\right)$ - see subsection on equipment - were performed simultaneously, as shown in table 4.3 .

Table 4.3 Experimental protocol. Investigation sequence from I to VIII.

$$
\text { TRANSCUTANEOUS OXIMETRY }
$$

$\frac{37^{\circ} \mathrm{C}}{1 \quad \text { at rest }}$ VIII reactive hyperaemia

SUPINE

\begin{tabular}{lll} 
II reactive hyperaemia & VII at rest \\
\hline III at rest & VI reactive hyperaemia
\end{tabular}

SITTING

IV reactive hyperaemia V at rest

unheated skin temperature $\quad 36{ }^{\circ} \mathrm{C}$

\section{LASER DOPPLER FLUXMETRY}

Microvascular reactivity was tested with LDF at unheated skin temperature (about $29^{\circ} \mathrm{C}$; see results), and at $36^{\circ} \mathrm{C}$ and with tcpO $\mathrm{O}_{2}$ at $37^{\circ} \mathrm{C}$ and at $44^{\circ} \mathrm{C}$. LDF recordings at unheated skin temperature were made, in order to assess the integrity of the constriction mechanisms under control conditions during the first part of the investigations (parts I to IV in table 4.3). Subsequently (parts $\mathrm{V}$ to VIII in table 4.3), LDF was performed at $36^{\circ} \mathrm{C}$ to study the degree of microvascular constriction after limited impairment of local vasoconstricting mechanisms, as was the case with the tcpO $\mathrm{O}_{2}$ measurements performed at an electrode temperature of $37^{\circ} \mathrm{C}$ (part I to IV in table 4.3). At this temperature, there is only slight dilatation of the superficial arterioles and the recorded $\mathrm{tcpO}_{2}$ depends on arteriolar flow rather than arteriolar $\mathrm{pO}_{2}{ }^{44,119}$. TcpO 2 was performed at $44{ }^{\circ} \mathrm{C}$, to overrule local vasoconstriction completely (part V to VIII in table 4.3). In this state, the $\mathrm{tcpO}_{2}$ recorded depends only on the arteriolar $\mathrm{pO}_{2}$ and is flow-independent ${ }^{119}$. 
LDF and tcp $\mathrm{O}_{2}$ were assessed at rest, as well as during reactive hyperaemia following the release of a three minute arterial occlusion, which was achieved by inflating a supramalleolar cuff. The induction of reactive hyperaemia in the foot in this standard manner was applied not only to reduce measurement variability at rest, but also to assess whether the larger vessels between ankle and skin had any additional effect on microvascular reactivity upon dependency.

Further details of the experimental protocol, the equipment used and the parameters measured is described in chapter 2, section 2.3 and 2.4.

\section{Statistics}

Data are plotted as a function of $\mathrm{ABI}$. To facilitate comparison, the patient data were handled per ABI-group. Because in each group the results of all parameters obtained were not symmetrically distributed, medians are presented to characterize group values. The non-parametric Kruskal-Wallis test was used to test for significant differences between the five groups. For the analysis of differences between the sitting and the supine position the paired Wilcoxon signed-ranks test was used. Differences were regarded significant when $\mathrm{P}<0.05$.

\subsection{RESULTS}

In general, mean arterial blood pressure was slightly higher in groups $C$ and D. Differences in systolic ankle blood pressure between the sitting and the supine position were on the average $48 \mathrm{~mm} \mathrm{Hg}$, being higher in the sitting position. This was a consistent finding, not related to the $A B I$ in the supine position. In each group the laser Doppler and $\mathrm{tcO}_{2}$ parameters in both positions did not significantly differ in non-insulin dependent diabetics and non-diabetics and, therefore, the data were pooled.

\section{Laser Doppler fluxmetry}

Figure 4.1 presents the median laser Doppler rest flux data for each $\mathrm{ABI}$ group, at unheated skin temperature (4.1a and c) and at $36^{\circ} \mathrm{C}(4.1 \mathrm{~b}$ and d), for both positions. Vasoconstriction indlices at these temperatures are shown in the figures $4.1 \mathrm{c}$ and $4.1 \mathrm{~d}$, respectively. 
A: Unineated aldi temperature

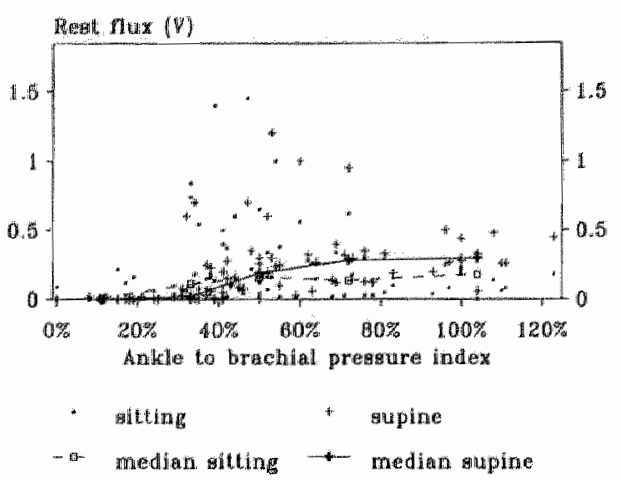

C: Uahated shin tamperature

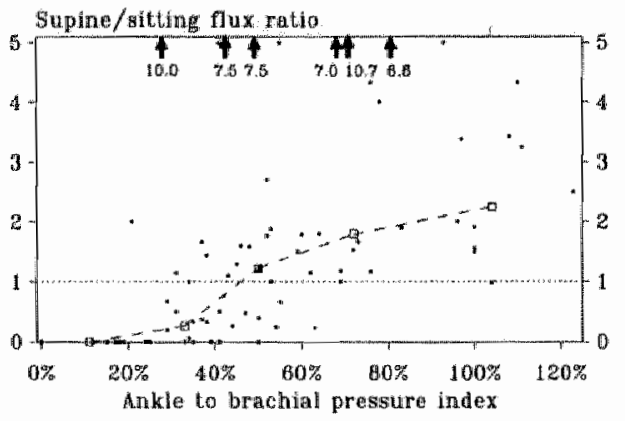

- $\quad$ up/sit mar median
B: $360^{\circ} \mathrm{C}$

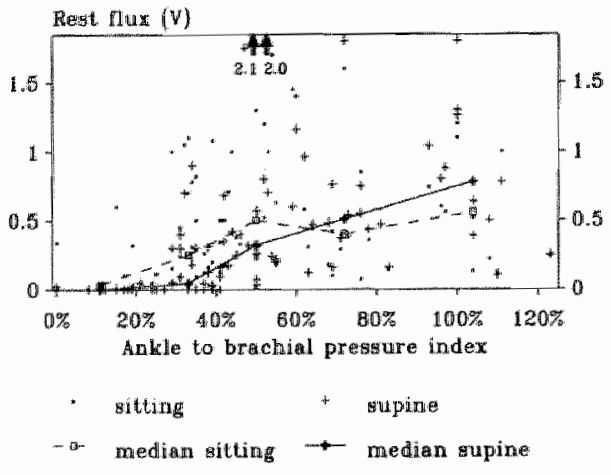

D: $36 \cdot \mathrm{C}$

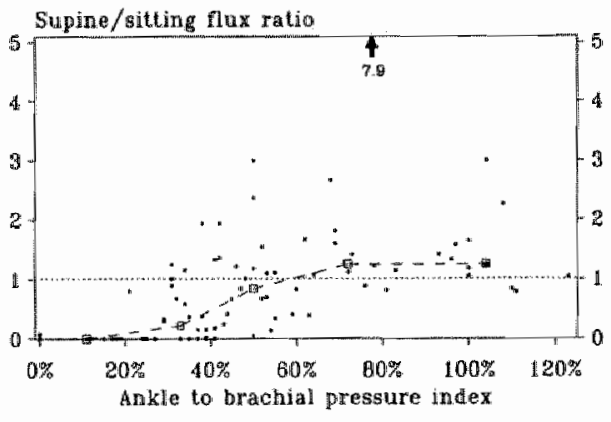

- sup/sit - medion

Figure 4.1 Scatterplots of laser Doppler rest flux ( $a$ and $b$ ) in the supine and sitting positions, and the supine-to-sitting flux ratios ( $c$ and $d$ ), at unheated skin temperature ( $a$ and c) and at $36^{\circ} \mathrm{C}(b$ and $d)$, respectively. Group rest flux medians in sitting position are connected by a dotted line; those in supine position by a solid line. Dashed lines ( $c$ and $d$ ) connect group ratio medians. The dotted lines at a ratio of 1 ( $c$ and $d$ ) indicate equal flux in both positions. Arrows indicate stray values.

Median unheated skin temperature in both positions $\left(29^{\circ} \mathrm{C}\right.$, range 27 $29{ }^{\circ} \mathrm{C}$ ) differed significantly between the five groups $(\mathrm{P}<.005)$ and was lowest in the supine position in group $\mathrm{E}\left(27^{\circ} \mathrm{C}\right)$. Changing from the sitting to the supine position caused a non-significant decrease in unheated skin temperature. At this temperature, median Rest fluxes (figure 4.1a) appeared to decrease with decreasing $\mathrm{ABI}$ (supine: from 0.3 Volts in group $\mathrm{A}$ to 0 Volts in group E; sitting: from 0.18 to 0.01 Volts). This decrease was sig- 
nificant in the supine position $(\mathbb{P}<0.001)$. In group $A$ and $B$, rest fluxes in the supine position were higher than those in the sitting position $(P<0.01)$, but the opposite was seen in group $\mathrm{D}$ and $\mathrm{E}(\mathrm{P}<0.05)$. In these groups, vasoconstriction indices were generally below unity (figure $4.1 \mathrm{c}$ ). All patients (except one) with an $A B I$ less than $30 \%$ had an index below one. All patients (except one) with an $\mathrm{ABI}$ above $55 \%$ had indices above one. Between an ABI of $30 \%$ and $55 \%$, it could be decided on the basis of LDF measurements whether or not vasoconstrictive mechanisms were intact, according to their vasoconstriction indices.

Local skin heating to $36^{\circ} \mathrm{C}$ enhanced Rest flux in the higher $\mathrm{ABI}$ groups $(\mathrm{P}<0.05$ in groups $\mathrm{A}$ through $\mathrm{D})$ in both positions (figure $4.1 \mathrm{~b}$ ). However, the flux differences between the supine and sitting position, as seen at unheated skin temperature, were now reduced. This is illustrated in figure $4.1 \mathrm{~d}$, showing vasoconstriction indices only slightly exceeding unity in group A and B. Rest fluxes as well as flux indices in group D and E persisted to be very low and were virtually unaltered by skin heating: median Rest flux in the sitting position remained higher than in the supine position $(\mathrm{P}<0.05$, groups $\mathrm{C}$ through $\mathrm{E}$ ) and again below an $\mathrm{ABI}$ of $30 \%$, every patient had a vasoconstriction index lower than one.

Peak flux and Rest flux data were similarly related to the ABI: at both temperatures, median Peak flux decreased significantly $(\mathbb{P}<0.001)$ with a reduction of the $A B I$ (at unheated skin temperature from about 0.85 Volts in group $A$ to 0.03 Volts in group $E$, and at $36^{\circ} \mathrm{C}$ from 1.15 to 0.03 Volts, respectively). A difference, however, was found between Rest and Peak flux data in group A and B at unheated skin temperature: median Peak flux values in the sitting position were virtually identical to those in the supine position, resulting in vasoconstriction indices of about one. In patients with lower ABl's, the median vasoconstriction indices were lower than one, indicating that Peak flux was higher while sitting. In group I, local skin heating to $36{ }^{\circ} \mathrm{C}$ did not have any influence on Peak flux. Also, the vasoconstriction indices did not show a significant change upon increasing temperature in any of the groups.

Time to peak flux (Ttpflux) and time to reach $50 \%$ of the rest flux ( $\mathrm{T} 50 \% \mathrm{f}$ ) increased monotonously with decreasing $\mathrm{ABI}$ at both temperatures and in both positions $(P<0.005)$. At unheated skin temperature, Ttpflux in the sitting position rose from 8 seconds in group $A$ to $165 \mathrm{~s}$ in group $E$ and in the supine position from $32 \mathrm{~s}$ in group $\mathrm{A}$ to $237 \mathrm{~s}$ in group D. In group E, 
Ttpflux could not be assessed, because of the no-flow state. After local skin heating, Ttpflux values rose from 11 to $131 \mathrm{~s}$ while sitting and from 59 to 126 s while supine.

\section{Transcutaneous oximetry}

Figure 4.2 shows the individual and group median tcpO $\mathrm{O}_{2}$ data at rest at $37^{\circ} \mathrm{C}(4.2 \mathrm{a}$ and $\mathrm{c})$ and $a t 44^{\circ} \mathrm{C}(4.2 \mathrm{~b}$ and $\mathrm{d})$, for both positions. Figure $4.2 \mathrm{c}$ and $\mathrm{d}$ present the vasoconstriction indices at rest at both temperatures, respectively.

A: $39+\mathrm{C}$

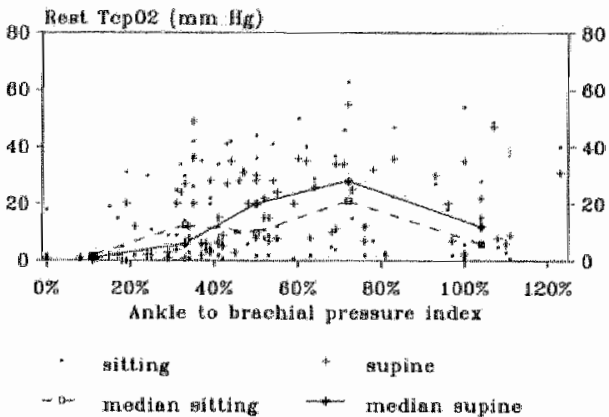

C: ant $C$

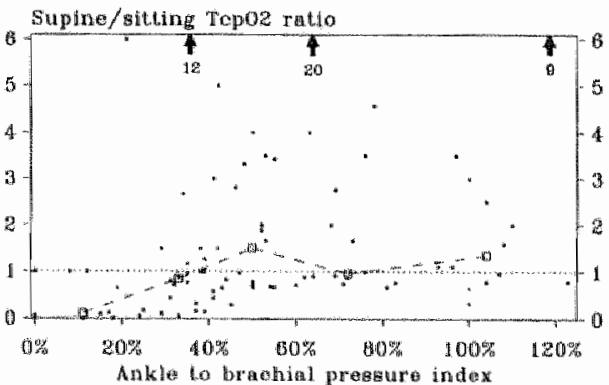

sup/eit. - ovedin

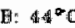

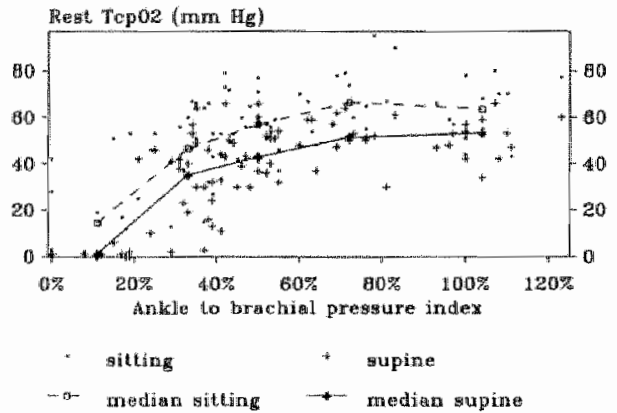

D: 4 재 ${ }^{\circ} \mathrm{C}$

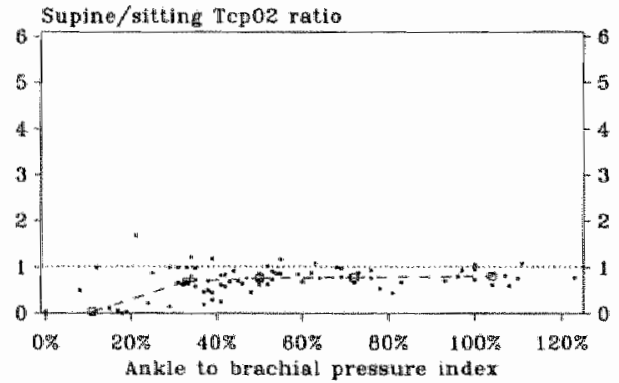

sup/sta - median

Figure 4.2 Satterplots of reat $\operatorname{tcpO}_{2}(a$ and $b$ ) in the supine and sitting positions, and the supine-to-siting topO $\mathrm{O}_{2}$ ratios ( $c$ and $d 1$, at $37^{\circ}$ ( $a$ and $c$ ) and $44^{\circ} \mathrm{C}(b$ and $d$ ), respectively. Group rest tcp $\mathrm{O}_{2}$ medions in sitting position are connected by a dotted line; those in supine position by a solid line. Dashed lines ( $c$ and d) connect group ratio medians. The dotted lines at a ratio of 1 ( $c$ and d) indicale equal $\mathrm{tcpO}_{2}$ in both positions. Arrows indicate stray walues. 
Tissue oxygenation $\left(37^{\circ} \mathrm{C}\right)$ is higher in the supine than in the sitting position in the patients with the highest ABI's (see figure 4.2a). Below an ABI of $70 \%$, oxygenation decreased gradually towards median values of 1 $\mathrm{mm} \mathrm{Hg}$ (supine) and $2 \mathrm{~mm} \mathrm{Hg}$ (sitting) in group $\mathrm{E}$. In this group, tcpO was higher in the sitting than in the supine position $(\mathrm{P}<0.05)$, as can be seen more clearly in figure $4.2 \mathrm{c}$, which shows ratios below unity in group $\mathrm{E}$. Again, all patients having an $\mathrm{ABI}$ below $30 \%$ had a vasoconstriction index lower than one.

Heating of the skin (figure $4.2 \mathrm{~b}$ ) caused a four to sevenfold increase in oxygenation in the patients with higher $\mathrm{ABI}^{\prime} \mathrm{s}(\mathrm{P}<0.005)$, but the oxygenation in group $E$ was virtually unaltered. In all groups oxygenation was now found to be persistently lower in the supine than in the sitting position $(\mathrm{P}<0.005$, except group $\mathrm{E}$ ): figure $4.2 \mathrm{~d}$ shows that all individual ratios, which were above unity in figure $4.2 \mathrm{c}$, are now close to, or below unity.

The PeakpO $\mathrm{O}_{2}$ results were very similar to the $\mathrm{RestpO} \mathrm{O}_{2}$ results: median values at $37{ }^{\circ} \mathrm{C}$ were comparable: in group A through D about $20 \mathrm{~mm} \mathrm{Hg}$ in the supine position and about $16 \mathrm{~mm} \mathrm{Hg}$ in the sitting position and in group $\mathrm{E}$ decreasing to $1 \mathrm{~mm} \mathrm{Hg}$ and $9 \mathrm{~mm} \mathrm{Hg}$, respectively. Local skin heating induced an increase in $\mathrm{PeakpO}_{2}$ (to $60 \mathrm{~mm} \mathrm{Hg}$ ) only in the upper four $\mathrm{ABI}-$ groups $(\mathrm{P}<0.005)$. The vasoconstriction indices were also alike.

TtppO $\mathrm{O}_{2}$ and $\mathrm{T} 50 \% \mathrm{pO}_{2}$ were prolonged at lower perfusion pressure: the median $\mathrm{TtppO}_{2}$ in the supine position at $37^{\circ} \mathrm{C}$ varied from $106 \mathrm{~s}$ (A) to 212 $\mathrm{s}(\mathrm{E})$ and at $44^{\circ} \mathrm{C}$ from $180 \mathrm{~s}$ (A) to $366 \mathrm{~s}$ (D). In the sitting position at $37^{\circ} \mathrm{C}$, these values varied from $120 \mathrm{~s}$ in group $\mathrm{A}$ to $284 \mathrm{~s}$ in group $\mathrm{E}$ and at $44^{\circ} \mathrm{C}$ from $141 \mathrm{~s}$ in group A to $250 \mathrm{~s}$ in group $\mathrm{E}$.

Figure 4.3 Median vasoconstriction indices per group as obtained by laser Doppler fluxmetry and transcutaneows oximetry, both at different skin temper. atures. The dotted line at a ratio of 1 indicates equal flux or tcpO $\mathrm{O}_{2}$ in both positions.

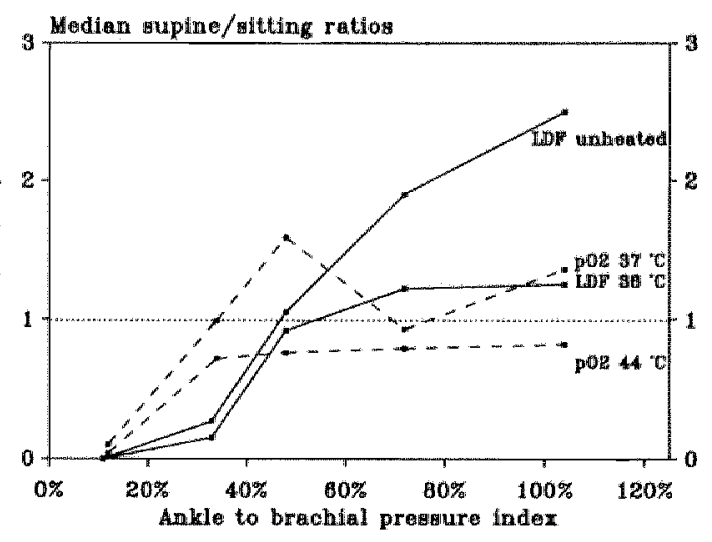


Finally, LDF and tcpO data were combined in order to compare both techniques and to obtain an overall view of the influence of local skin heating (figure 4.3). $\mathrm{LDF}$ indices tended to decrease prior to the tcpO $\mathrm{O}_{2}$ indices with decreasing $\mathrm{ABI}$. A clear overlap was found in the highest $\mathrm{ABI}$-groups between the vasoconstriction indices of $\mathrm{LDF}$ at $36^{\circ} \mathrm{C}$ and $\mathrm{tcpO} \mathrm{O}_{2}$ at $37^{\circ} \mathrm{C}$, although these instruments measure quite different parameters.

\subsection{DISCUSSION}

Skin perfusion and oxygenation are markedly reduced and posturally induced microvascular constriction mechanisms cease to function when arterial disease of the legs progresses beyond a certain limit, as was found in all patients with an ankle-to-brachial systolic blood pressure index (ABI) below approximately $30 \%$. In these patients, local vasoconstriction mechanisms are overruled, as an increase in local skin temperature does not improve skin perfusion and oxygenation at rest, while these parameters increase upon dependency.

Microvascular reactivity was similar in patients with mild ischaemic disease of the legs and in asymptomatic control legs. In all patients with an $\mathrm{ABI}$ of $55 \%$ or more, skin perfusion and oxygenation were reduced after changing from the supine to the sitting position. Thus, disturbances of posturally induced vasoconstriction are confined to critically low blood pressure levels. In the present study, ABI could not predict the effectiveness of microvascular constriction mechanisms below a value of $60 \%$. In this range, laser Doppler fluxmetry, especially when measured without local heating of the skin, is a useful tool to assess the presence or absence of microvascular constriction upon dependency by calculating the vasoconstriction index (i.e. the supine to sitting ratio) from measurements in the supine and the sitting position. Transcutaneous oximetry at $37^{\circ} \mathrm{C}$ also appeared to be able to test the effectiveness of postural vasoconstriction. However, using this technique, the transition from intact to disturbed vasoconstriction is not so clear-cut, because vasoconstriction mechanisms are already suppressed by the required heating of the skin.

In patients with severe leg ischaemia $(A B I<30 \%$ ), skin perfusion was low, but always slightly enhanced when changing to the sitting position, 
indicating disturbed microvascular constriction mechanisms. This is in accordance with previous investigations using laser Doppler fluxmetry and transcutaneous oximetry ${ }^{29}$. By means of capillary video-microscopy vasoconstriction responses at the capillary level were found to be disturbed below an $\mathrm{ABI}$ of $20 \%$. This suggests that in patients with an $\mathrm{ABI}$ below $30 \%$, capillary perfusion is sustained at the cost of the perfusion in deeper skin layers, in an attempt to preserve nutritional blood flow. These findings may explain the relief of pain on dependency as is seen in some of these patients.

Stepwise local skin heating (unheated $\left(29^{\circ}\right)-36^{\circ} / 37^{\circ}-44{ }^{\circ} \mathrm{C}$ ) in patients without or with mild ischaemia causes a stepwise counteraction of microvascular constriction on dependency, resulting in a progressively higher perfusion and oxygenation in the sitting than in the supine position; a situation similar to that in severely diseased patients before heating of the skin. In these patients perfusion and oxygenation at rest cannot be improved anymore by a temperature increase or the induction of reactive hyperaemia, obviously because the microvessels are already completely dilated. This is supported by the finding that local skin heating did not enhance reactive hyperaemia in these patients.

The larger arteries of the foot between ankle and toe (e.g. $>500 \mu \mathrm{m}$ ) are not likely to have any regulatory influence on microvascular perfusion, because the induction of reactive hyperaemia showed no additional increase in perfusion or oxygenation as compared to the increase observed during local skin heating, indicating that local mechanisms prevail in this regulation.

In this study, the small number of diabetics per ABI-group apparently did not influence microcirculatory reactivity differently. It is also conceivable that in both types of patients atherosclerosis is the dominating disease.

$\mathrm{TcpO}_{2}$ measurements were performed on the dorsum of the foot, whereas the laser Doppler instrument was applied to the pulp of the great toe, in which arteriovenous anastomoses are more numerous. Despite this difference, there is a close resemblance between the results obtained with $\mathrm{LDF}$ at $36^{\circ} \mathrm{C}$ and $\mathrm{TcpO}$ at $37^{\circ} \mathrm{C}$ in the highest $\mathrm{ABl}$-groups. This suggests that $\mathrm{TcpO}_{2}$ measurements, even at this temperature, do not only provide information about the capillary perfusion ${ }^{32,11}$, but also about the perfusion of deeper layers of the skin². However, reduction of skin perfusion, as measured with laser Doppler fluxmetry, occurred at a higher ABI than the 
reduction of skin oxygenation, which is more in accordance with capillary microscopy findings ${ }^{180}$. This indicates that transcutaneous oximetry does not measure in the skin layers that can be reached by laser Doppler fluxmetry.

Because of the clear inverse correlation between the Time to peak, as measured by both instruments, and the ABI, these parameters appear to be more informative about the macrocirculation than the microcirculation.

In conclusion, the ABI is widely used in clinical vascular practice as an objective parameter to assess peripheral vascular disease. The findings in the present study show that an $\mathrm{ABI}$ higher than $55 \%$ concurs with intact microvascular reactivity in patients with mild leg ischaemia. However, below $55 \%$, the ABI can not portend the existence of disturbed constriction mechanisms. Therefore, in more severe leg ischaemia, only the examplified comparison of skin microcirculatory perfusion in the supine versus the sitting position using laser Doppler fluxmetry (at unheated skin temperature) and transcutaneous oximetry (at $37^{\circ} \mathrm{C}$ ) is useful to investigate to which extent microvascular constriction responses upon dependency are disturbed. Therapeutically, this disturbance indicates that the limb is in jeopardy of becoming critically ischaemic and therefore urges the necessity of improving arterial circulation. In future longitudinal studies, it remains to be proven whether disturbed posturally induced microcirculatory reactivity is of prognostic value. The possibility of counteracting microvascular constriction by only a local stimulus suggests that these constriction mechanisms are mainly local phenomena. 


\section{Chapter 5}

\section{Microvascular reactivity differences between the two legs of patients with unilateral lower limb ischaemia*}

\subsection{INTRODUCTION}

A change in posture from the supine to the sitting position results in a reduction of skin blood flow in the legs. This microvascular reactivity upon postural changes is considered to be influenced by centrall (sympathetic ${ }^{7}$ ) or local (veno-arteriolar ${ }^{66}$ or myogenic ${ }^{81,84}$ ) mechanisms. This reactivity enables the microcirculation to adapt its perfusion to postural changes ${ }^{2,78}$ and to avert the occurrence of orthostatic oedema ${ }^{2,152}$. In patients with lower limb ischaemia, these mechanisms have been found to be disturbed ${ }^{31,32,180}$, ultimately resulting in enhanced rather than decreased perfusion in the upright position.

This disturbance may theoretically be due to derailed vasoconstriction mechanisms of either local or central origin. In patients with unilateral leg ischaemia, a locally disturbed mechanism would only alter the reactivity in the diseased leg, whereas a central cause for the disturbed adaptation mechanism would affect both legs. Therefore, the posturally induced microcirculatory reactivity was investigated in both legs of patients with unilateral leg ischaemia. An additional advantage of this type of study is that in this way inter-individual differences in smoking habits and medication, factors influencing microcirculatory reactivity, are excluded. A second group of subjects with normal leg circulation served as control, as the "asymptomatic"

The work described in this chapter has been published in the European Journal of Vascular Surgery: 1992: 6: .... 
legs of patients might also show atherosclerotic lesions, due to the generalized nature of the disease.

The present study was performed on the great toe with the use of capillary microscopy and laser Doppler fluxmetry. These techniques were used to obtain information about nutritional and total (mainly thermoregulatory) skin microcirculation ${ }^{176}$, respectively. This allowed us to assess whether these microcirculatory levels react differently in case of ischaemia. Microvascular reactivity was tested by changing posture and inducing reactive hyperaemia following the release of an arterial occlusion.

\subsection{PATIENTS AND METHODS}

\section{Patients}

The first group of patients in this study consisted of 21 patients (14 males, 7 females), with a mean age of 71 years (range: $44-83$ years), suffering from unilateral chronic arterial obstructive disease. Their ischaemic complaints varied from intermittent claudication to rest pain, with or without ulceration (Fontaine stages 2, 3 and 4, respectively). Their other leg was asymptomatic, although not in all cases devoid of arterial disease. To assess possible differences between asymptomatic and fully uncompromised legs, a second group of 11 age-matched (mean age 67; range: 51-82 years) patients was investigated as controls. In this group at least one leg was normal as far as the arterial circulation was concerned.

An estimation of the severity of macrocirculatory obstructions was obtained by assessing the systolic ankle-to-brachial pressure index (ABI). In the first group, the ABI varied between 0 and $48 \%$ (mean: 29\%) in the more diseased legs and between 35 and 123\% (mean: 69\%) in the asymptomatic legs. Six patients had undergone unsuccessful vascular reconstructive surgery in the diseased leg. None of the patients had been treated with lumbar sympathectomy. Ten patients still smoked more than 5 cigarettes daily. Eight patients received at least one vasoactive drug to treat their atherosclerotic disease: 5 used calcium antagonists, 4 B-blocking agents, 4 vasodilatators and 1 an ACE-inhibitor. Subjects with insulin-dependent diabetes mellitus were excluded from the study, since this disease per se may influence microcirculatory autoregulation mechanisms in both legs 54,148 , and, 
hence, could mask differences in microcirculatory reactivity between the two legs. However, 3 non-insulin dependent diabetics without clinically manifest peripheral neuropathy were included in the study. At the time of the investigation they were normoglycaemic. Neuropathy was ruled out when investigation of the skin sensory function showed no abnormalities.

In the second group, the ABI of all legs investigated was $>95 \%$ (mean $104 \%$ ). Two patients were non-insulin dependent diabetics, 3 were smokers. Five patients used medication for atherosclerotic symptoms of the heart or the leg not investigated: 3 received a vasodilatator, $\mathbb{1}$ a $B$-blocking agent and 1 a Calcium antagonist.

\section{Methods}

Measurements were performed following 20 minutes of acclimatization in a room with a temperature between $23^{\circ}$ and $24^{\circ} \mathrm{C}$. Patients were subjected to capillary microscopy of the nailfold of each great toe in the sitting position and after a ten minute adaptation interval reinvestigated in the supine position to assess the integrity of postural vasoconstriction. Subsequently, laser Doppler fluxmetry was performed in the pulp of the great toes, again in both positions. Of the patients in the second group, only one (healthy) leg was investigated. The equipment and experimental protocol used are described in chapter 2 , sections 2.2 and 2.4 . Finally, brachial and ankle systolic blood pressures were measured by means of a cuff and an $8 \mathrm{MHz}$ Doppler probe, with the patients in the supine position, to calculate the ABI.

\section{Statistics}

Because the results of the parameters obtained were not symmetrically distributed, medians are presented to characterize group values. For the analysis of differences between the two positions the paired Wilcoxon signed-ranks test, and for the differences between the legs and the patient groups the Mann-Whitney U-test was used.

\subsection{RESULTS}

In both groups the results obtained in diabetics did not differ from those in non-diabetics and therefore these data were pooled. 


\section{Capillary microscopy}

The data obtained in the first (asymptomatic and diseased legs) and the second patient group (control legs), as recorded in both positions, are summarized in table 5.1.

Table 5.1 Capillary microscopy data from both legs in supine and sitting position

\begin{tabular}{|c|c|c|c|c|}
\hline $\begin{array}{l}\text { Dens Diam } \\
\left(\mathrm{mm}^{2}\right)(\mu \mathrm{m})\end{array}$ & $\mathrm{TCl}^{\circ}$ & $\begin{array}{l}\text { Rest RBCV } \\
(\mu \mathrm{m} / \mathrm{s})\end{array}$ & $\begin{array}{l}\text { Volume flow } \\
(\mu \mathrm{m} / \mathrm{s})\end{array}$ & $\begin{array}{cc}\text { Peak RBCV } & \text { Ttp } \\
(\mu \mathrm{m} / \mathrm{s}) & (\mathrm{s})\end{array}$ \\
\hline
\end{tabular}

SUP $1 \mathrm{NE}$

$\begin{array}{lrrrrrrr}\text { Control } & 30 & 4 & 484 & 182 & .048 & 323 & 8 \\ \text { Asymptomatic } & 32 & 5 & 687 & 200 & .111 & 275 & 14 \\ \text { Diseased } & 27 & 7 & 1015 & 127 & .056 & 123 & 22\end{array}$

S I T T IN G

\begin{tabular}{lrllllll} 
Control & 56 & 6 & 1579 & 25 & .020 & 90 & 15 \\
Asymptomatic & 51 & 8 & 2444 & 51 & .087 & 87 & 12 \\
Diseased & 42 & 8 & 2390 & 46 & .092 & 54 & 15 \\
\hline
\end{tabular}

" = Transport Capacity Index

\section{Supine position}

Capillary densities did not differ significantly between control, asymptomatic and diseased legs. Capillary diameter was larger $(p<0.01)$ in the diseased legs as compared to the controls. Rest and peak RBCV were significantly higher in the control and asymptomatic legs than in the diseased legs (RBCV at rest: $p<0.05$ and $p<0.01$; Peak RBCV: $p<0.001$ and $p<0.005$, respectively). Reactive hyperaemia was only seen in the control and asymptomatic legs. Ttpv was longer in asymptomatic $(\mathrm{p}<0.05)$ and diseased legs ( $p<0.0005$ ) than in controls. TCI did not differ significantly between the three leg groups. Volume flow was higher in the asymptomatic legs ( $p$ $<0.001$ ) as compared to the control legs. The other morphological and $\mathrm{dy}$ namic parameters in the control legs did not differ significantly from those in the asymptomatic legs. The diseased legs could be discerned from the asymptomatic legs by the lower rest and peak RBCV and the absence of reactive hyperaemia. 


\section{Sitting position}

Again, capillary densities did not differ significantly between the three leg groups. Capillary diameters were larger in the asymptomatic and diseased legs as compared to the controls ( $\mathrm{p}<0.01)$. TCI was higher in the diseased legs than in the controls $(\mathrm{p}<0.05)$. RBCV at rest and Ttpv did not differ between the three leg groups. Peak RBCV was lower in the diseased legs as compared to the asymptomatic $(p<0.005)$ and control legs $(p<0.001)$. Reactive hyperaemia was most prominent in the control legs. Volume flow was lower in the control legs than in the asymptomatic $(p<0.001)$ and diseased legs ( $p<0.005$ ). Control legs could be discerned from asymptomatic legs by means of the smaller capillary diameter and lower volume flow. The diseased legs could only be discriminated from the asymptomatic legs by the lower Peakv and a poor reactive hyperaemia.

\section{Postural changes}

Changing from the supine to the sitting position clearly increased capillary density (control: $p<0.05$; symptomatic and diseased: $p<0.0005$ ), and capillary diameter (control and diseased: $p<0.05$; asymptomatic: $p$ $<0.005$ ), thereby improving nutritional transport capacity (control: $\mathrm{p}<0.05$; asymptomatic and diseased: $p<0.0005)$. $R B C V$ at rest and during reactive hyperaemia decreased significantly in all three groups (RBCV at rest: control: $p<0.005$; asymptomatic: $p<0.0005$; diseased: $p<0.001$; Peak RBCV: control: $\mathrm{p}<0.005$; asymptomatic: $\mathrm{p}<0.0005$; diseased: $\mathrm{p}<0.005$ ).

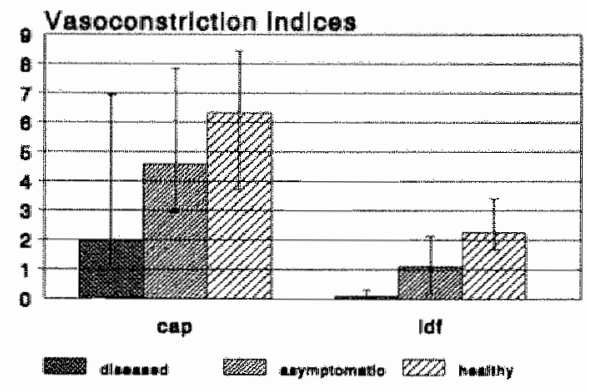

The supine-to-sitting RBCV ratios at rest were 6.32 for the control, 4.59 for the asymptomatic and 1.94 for the diseased legs. Figure 5.1 shows the
Figure 5.1 Median vasoconstriction indices obtained from capillary red blood cell velocities (CAP) and LDF values in the legs of patients with one diseased and one asymp. tomatic leg and in the healthy legs of control subjects. Error bars indicate the $25^{\text {th }}$ and $75^{\text {th }}$ percentile intervals. 
median vasoconstriction indices obtained from capillary RBCV (CAP) and laser Doppler flux values (LDF) of all three patient groups, including the $25^{\text {th }}$ and $75^{\text {th }}$ percentile intervals. The latter ratio was significantly lower ( $p$ $<0.05$ ) than the ratio in the control legs, but still higher than 1 . However, the volume flow ratio was 0.91 for the diseased legs (asymptomatic: 1.27; control legs: 2.12), which indicates a tendency towards disturbed vasoconstriction at the nutritional level of the microcirculation.

\section{Laser Doppler fluxmetry}

The data from both groups and positions are presented in table 5.2. Biological zero never exceeded $0.01 \mathrm{~V}$.

Table 5.2 Laser Doppler fluxmetry data from both legs in supine and sitting position.

\begin{tabular}{llll} 
Rest flux & $\begin{array}{l}\text { Peak flux } \\
\text { (Volts) }\end{array}$ & $\begin{array}{c}\text { Ttpf } \\
\text { (Volts) }\end{array}$ \\
\hline S U P I N E & & & \\
Control & 0.29 & 0.85 & 32 \\
Asymptomatic & 0.22 & 0.72 & 44 \\
Diseased & 0.00 & 0.00 & 98
\end{tabular}

\section{SIT T ING}

\begin{tabular}{llll} 
Control & 0.16 & 0.72 & 8 \\
Asymptomatic & 0.20 & 0.56 & 55 \\
Diseased & 0.07 & 0.17 & 80 \\
\hline
\end{tabular}

\section{Supine position}

Median Restf and Peakf were zero in the diseased legs and lower than in the asymptomatic ( $p<0.001$ and $p<0.005$, respectively) and control legs $(p<0.0005$ and $p<0.0005$, respectively). The control and asymptomatic legs showed a clear reactive hyperaemia response. Ttpf was shorter in the control legs than in the asymptomatic $(p<0.05)$ and diseased legs $(p<0.01)$. Ttp could be assessed in only seven diseased legs, because of the no-flow state. 


\section{Sitting position}

In this position no significant differences could be observed between Restf in the three groups. Peakf was lower in the diseased legs than in the control $(p<0.005)$ and asymptomatic legs $(p<0.05)$. Reactive hyperaemia was most conspicuous in the control legs. The asymptomatic legs showed a longer Ttpf than the control legs $(p<0.001)$, and a shorter Ttpf than the diseased legs $(p<0.01)$.

\section{Postural changes}

After changing to the sitting position, Restf decreased in control legs ( $p$ $<0.005)$, rendering a median supine-to-sitting ratio of 2.25 . Restf remained unchanged in asymptomatic legs (ratio: 1.00) and increased $(p<0.001$ ) in the diseased legs (see figure 5.1). Peakf was enhanced only in the diseased legs ( $p$ $<0.01$ ). However, these values were still much lower than in the asymptomatic legs. This indicates a disturbed vasoconstriction response at this level of the microcirculation in diseased legs, which is much more evident than at the nutritional level. The median ratio in these legs was zero, because Restf in the supine position was zero.

\subsection{DISCUSSION}

The findings in the present study indicate that at this stage of lower limb ischaemia, i.e. an average ankle-to-brachial index (ABI) of $29 \%$, posturally induced microvascular constriction is abolished at the level of total skin (mainly thermoregulatory) blood flow, leading to an increase in flow when changing from the supine to the sitting position. The posturally induced microvascular constriction at: the nutritional skin blood flow level is maintained in these patients, albeit that the degree of constriction decreases with the severity of the disease. The maintenance of posturally induced vasoconstriction at the nutritional level is in accordance with the previous observation that this vasoconstriction response does not disappear before an $\mathrm{ABI}$ of $20 \%$ is reached ${ }^{179}$, 180 . The present findings support the hypothesis that the (disturbed) posturally induced microvascular constriction in severe leg ischaemia is induced locally. If a central mechanism were involved, the vasoconstriction disturbance at the thermoregulatory level would have been present in both legs of the same patient and not only in the most diseased leg.

Under normal conditions, smooth muscle cells in arterioles, arteriovenous (AV) anastomoses and precapillary vessels constrict upon a postural increase in blood pressure, resulting in reduced skin blood flow, as illustrated in figure 5.2. 
SUPINE

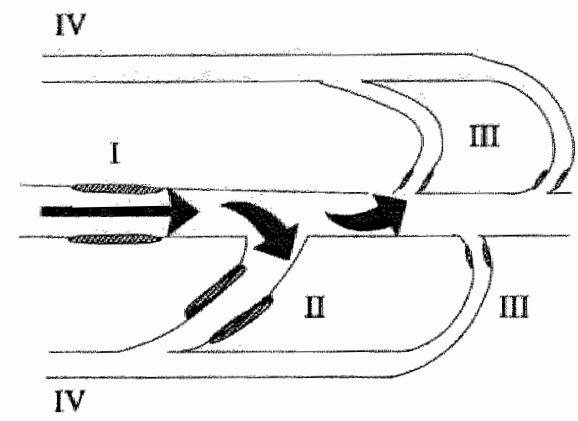

SITTING

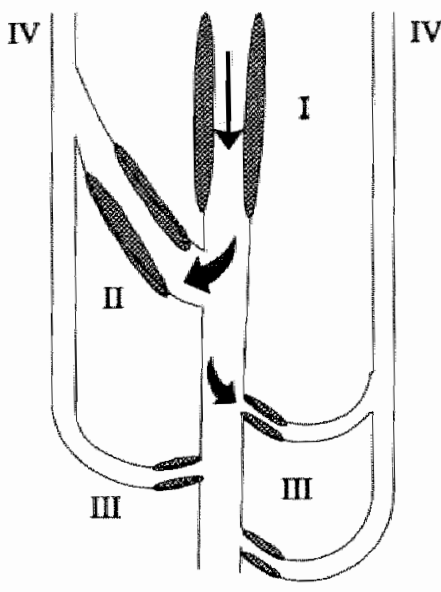

Figure 5.2 Posturally induced skin microvascular constriction in healthy subjects

I: Arteriolar smooth muscle cells

II." Smooth muscle cells at arteriovenous anastomoses

III: Precapillary smooth muscle cells

IV: Subpapillary plexus

Note the increase in smooth muscle cell activity when changing from the supine to the sitting position and the subsequent reduction in blood flow.

Smooth muscle cells in arterioles and AV anastomoses are considered to be activated by sympathetic nerves ${ }^{184}$ and by a blood pressure increase in the foot upon orthostasis, which leads to myogenic arteriolar contraction ${ }^{84}$. An increase in venous pressure also results in arteriolar constriction ${ }^{66}$. 
Smooth muscle cells in precapillary vessels are likely to be controlled by local factors, e.g. vasoactive metabolic substances accumulating during ischaemia and tissue oxygenation. It is unlikely that in the more severely diseased patients, sympathetic nerves are involved in the disturbed postural vasoconstriction at the level of $\mathrm{AV}$-anastomoses, as unilateral ischaemia does not reduce sympathetic stimulation in the contralateral, asymptomatic legs. Sympathetic activity is probably merely elicited by activation of the central receptors detecting blood pressure and temperature changes, although the sympathetic influence on the smooth muscle cells in AV-anastomoses during ischaemia needs further investigation. Apparently, skin ischaemia results in a locally induced relaxation of the smooth muscle cells in arterioles and precapillary vessels to balance the reduction of perfusion pressure, thereby overriding a possible sympathetic activity. This idea is supported by the observation that capillary diameter in the supine position is larger at more severe stages of ischaemia, leading to maintenance of nutritional perfusion, as expressed by volume flow. Capillaries run parallel to, and have a lower total resistance (due to their overall larger cross-sectional surface area) than AV-anastomoses. This may explain the finding that in the diseased legs (see figure 5.3), capillary perfusion in the supine position is maintained while AV-perfusion is immeasurably low.

Changing to the sitting position induces a slightly enhanced skin perfusion in the diseased legs, as measured by laser Doppler fluxmetry, illustrating disturbed smooth muscle cell contraction in $\mathrm{AV}$-anastomoses. This rise in perfusion of $\mathrm{AV}$-anastomoses is in accordance with previous findings ${ }^{182}$, but in disagreement with the reduced RBCV at the level of the nutritional capillaries. Apparently, smooth muscle cell contraction in precapillary vessels is still active at a much lower pressure level $(A B I \geq 20 \% 179$, 180 ) than in AV-anastomoses ( $\mathrm{ABI} \geq 60 \%{ }^{182}$ ) (see figure 5.3 ). This is plausible, taking into consideration that capillary pressure is to be maintained around $20 \mathrm{~mm}$ $\mathrm{Hg}$ to ensure adequate transcapillary fluid exchange and to prevent oedema formation. 


\section{SUPINE}

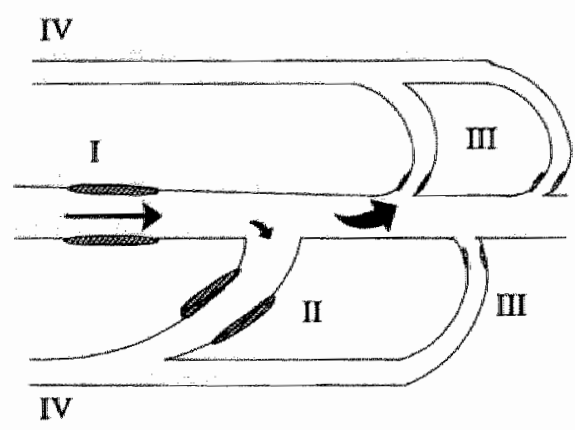

SITTING

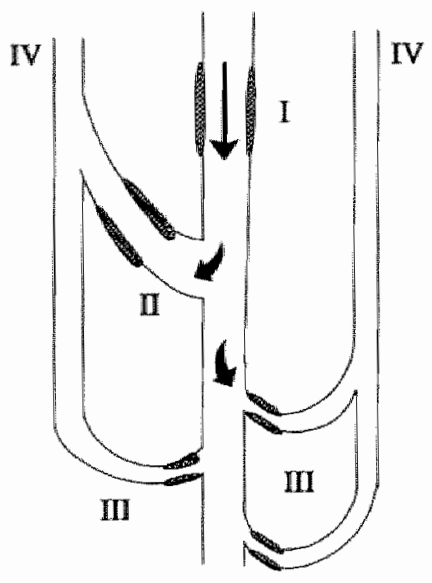

Figure 5.3 Posturally induced skin microvascular constriction in severe lower limb ischaemia

I: Arteriolar smooth muscle cells

II: Smooth muscle cells at arteriovenous anastomoses

III: Precapillary smooth muscle cells

IV: Subpapillary plexus

Note the increase in arteriovenous perfusion and the enhanced precapillary smooth muscle cell activity, resulting in a decrease in capillary blood flow, after changing from the supine to the sitting position.

The lower nutritional $R B C V$ in the supine position and the presence of some vasoconstrictive capacity upon dependency could jeopardize skin viability. However, changing to the sitting position caused a marked capillary recruitment and dilatation - especially in the asymptomatic and diseased legs - supposedly induced by the higher transmural pressure. The 
advancement of lower limb ischaemia, characterized by an additional disappearance of vasoconstriction of precapillary vessels upon dependency ${ }^{179}$, will inevitably lead to oedema formation, necrosis and/or gangrene. This relation between the loss of constriction of precapilary vessels and oedema formation may elucidate the oedema formation after vascular reconstructive surgery in patients with severe limb ischaemia ${ }^{45}$. When their capillaries are exposed to the restored arterial blood pressure in the absence of vasoconstriction mechanisms in precapillary vessels, transmural pressure at the capillary level will increase and lead to an enhanced transcapillary fluid transport to the extravascular compartment.

It is conceivable that a difference in local skin temperature between the two legs might have influenced the differences in skin perfusion as found in this study. However, a previous study concerning patients with different stages of lower limb ischaemia ${ }^{182}$ showed that local skin temperature differed $2{ }^{\circ} \mathrm{C}$ between asymptomatic and severely diseased patients. We doubt whether this temperature difference can give rise to a different vasoconstrictive response. Nor do we know to which extent a potential subphysiological temperature in severely diseased legs influences postural vasoconstriction. If so, differences in vasoconstriction indices measured between asymptomatic legs (with a relatively higher temperature) and diseased legs would have been masked.

The zero skin perfusion, as measured by the laser Doppler instrument in the presence of perfused capillaries, illustrates the small contribution of capillary perfusion to the laser Doppler signal, especially when measured in the pulp of a digit, where AV-anastomoses are numerous. This implies that laser Doppler fluxmetry may be less sensitive to detect disturbances in skin perfusion than capillary microscopy, which can focus on the perfusion of a single capillary.

In conclusion, this study shows that in severe lower limb ischaemia, which is accompanied by a reduction of arterial pressure and compensatory arteriolar dilatation, skin thermoregulatory and nutritional flow act differently. In the severely ischaemic foot, posturally induced regulation of thermoregulatory perfusion is disturbed, as indicated by the abolished vasoconstriction response upon dependency, while this regulation is still (partly) intact at the nutritional level. The difference in the microvascular constriction response, as found between asymptomatic and diseased legs in the same patient indicates that this disturbance is mainly of local origin. 



\section{Chapter 6}

\section{The relevance of posturally induced micro- vascular constriction after revascularisation in patients with chronic leg ischaemia*}

\subsection{INTRODUCTION}

Microvascular constriction mechanisms in the leg are activated when a person changes from the supine to the sitting position to counteract the orthostatic pressure increase and thereby oedema formation ${ }^{78,81}, 152$. In patients with severe chronic lower limb ischaemia, these vasoconstriction responses are disturbed, leading to an increased instead of a reduced perfusion on dependency ${ }^{6,31}, 182$. This disturbance can either be caused by ischaemic damage to the pressure sensing cells or the structures inducing vasoconstriction, or because the myogenic vasoconstriction response is no longer activated due to the critically reduced arterial pressure, even in the dependent position.

In patients with severe lower limb ischaemia vascular reconstructive surgery is the therapy of choice to improve arterial perfusion pressure 63,70 , 99,160 . However, the frequent occurrence of early postoperative oedema indicates that significant disturbances in the microcirculation occur. Knowledge regarding the effects of this therapy on the microcirculation is scanty, particularly of the possible recovery of vasoconstrictive mechanisms following revascularisation. The latter is important because restoration of vasoconstriction upon dependency may prevent oedema formation in case of successful reconstructive vascular surgery leading to increased arterial pressure. 
In the present study we investigated whether successful vascular reconstuctive surgery restores posturally induced microvascular constriction and, if so, how long after surgery. These findings were related to the postoperative occurrence of oedema. Measurements were performed using 1) laser Doppler fluxmetry (LDF), which is a useful technique for the early assessment of disturbances in postural vasoconstriction in total skin microcirculation $^{122}$, and 2) capillary video-microscopy, which is the method of choice to assess disturbances in skin nutritional perfusion ${ }^{179}$.

\subsection{PATIENTS}

During the study period, all consecutive patients admitted for arterial reconstructive surgery, because of chronic lower limb ischaemia, were investigated preoperatively. From these, we selected for follow-up those patients in whom vascular reconstruction was successful. This was defined as a reconstruction resulting in a patent bypass during the follow-up period of up to 37 days. Thus, 31 patients participated in the study. The mean age of the 16 men and 15 women was 71 years, ranging from 36 to 89 years. All patients suffered from atherosclerotic disease. According to the clinical Fontaine (F) classification, 6 belonged to F2b (severe claudication), 9 to F3 (rest pain) and 16 to $\mathrm{F} 4$ (ulceration or gangrene). Their mean preoperative ankle-to-brachial systolic blood pressure index (ABI) was $40 \%$ (range: $0-84 \%$ ). None of the patients had preexistent ankle oedema or venous insufficiency, which was ruled out by physical examination. Nine patients suffered from diabetes mellitus, one of whom was insulin-dependent.

Twenty-seven of the 31 patients underwent a peripheral arterial revascularisation. In 4 patients the reconstruction was performed at the aorto-iliac level. The localisation of the reconstruction is summarized in table 6.1. 
Table 6.1 Localisation of the different arterial reconstructions performed in 31 patients

\begin{tabular}{lc} 
Type of reconstruction & N \\
\hline Aorto-iliac & 4 \\
Supragenual femoropopliteal & 1 \\
Infragenual femoropopliteal & 21 \\
Femorocrural & 5 \\
\hline
\end{tabular}

\subsection{METHODS}

\section{Laser Doppler fluxmetry}

This technique to measure skin perfusion was already described in chapter 2, section 2.4. The following parameters were measured:

* Rest flux (Volts)

* Peak flux (Volts) during reactive hyperaemia, following the release of a 3-minute arterial occlusion, induced by inflating a cuff around the ankle

* Time to reach peak flux (seconds)

* Vasoconstriction index, as measured with laser Doppler fluxmetry (VIL), defined as the individual supine / sitting Rest flux ratio

A vasoconstriction index $<1$ indicates a higher perfusion in the sitting than in the supine position and, thus, a disturbed vasoconstriction response. Normal vasoconstriction indices in asymptomatic subjects are about 2.25 , as was found in a previous study (see chapter 5$)^{181}$.

The measurements were performed the day before vascular surgery and daily thereafter, up to 37 days. In each session, measurements were performed in the supine (the first few days after surgery the patient remained in bed) and the sitting position (whilst the patient was sitting upright and depending his lower leg). Also, perfusion was measured at rest and during reactive hyperaemia. In the first week postoperatively, we obviously desisted from provoking reactive hyperaemia in patients with a femorocrural bypass, since this would imply compression of the bypass itself. 


\section{Capillary microscopy}

For the capillary microscopic equipment and method used, the reader is referred to chapter 2 , section 22. Capillary microscopy was performed on the day before and some day between 10 to 14 days after surgery, but always before dismission from the hospital. This investigation was not performed daily in the post-operative period, since the patients were not yet mobilized and mainly confined to bed, and the method requires patients to be seated in an investigation chair. The parameters measured were:

* Capillary diameter ( $\mu \mathrm{m})$

* Capillary density $\left(\mathrm{mm}^{-2}\right)$ : the number of perfused capillaries per square millimetre of nailfold skin

* Red blood cell velocity $(\mathrm{RBCV})$ at rest $(\mu \mathrm{m} / \mathrm{s})$

* Peak $R B C V(\mu \mathrm{m} / \mathrm{s})$ during reactive hyperaemia, following the release of an 1-minute arterial occlusion, induced by inflation of a cuff around the ankle

* Time to Peak RBCV (s)

* Vasoconstriction index, as measured with capillary microscopy (VIC; individual supine / sitting RBCV ratio)

A normal value for the VIC in asymptomatic subjects is about 6.3 , as. described in the previous chapter ${ }^{181}$.

\subsection{RESULTS}

Mean $A B 1$ rose significantly $(p<0.0001)$ from $40 \%$ before surgery to $82 \%$ after. One patient, however, showed a very limited raise in ABI from 32 to $40 \%$. Median follow-up duration was 12 days (range $3-37$ days). Thirteen patients developed ankle oedema during the postoperative period. Most patients were discharged a fortnight after surgery. Consequently, the number of patients investigated hereafter was reduced to 10 .

\section{Laser Doppler fluxmetry}

In the supine position, pre-operative laser Doppler flux values at rest were very low, as was the reactive hyperaemic response (see table 6.2). The median vasoconstriction indices VIL was both below 1 . These findings 
indicate the presence of severe lower limb ischaemia with disturbed postural vasoconstriction. Eight patients, however, still had an intact vasoconstriction response, as indicated by a VIL value exceeding 1. Strikingly, VIL in these patients was reduced and lower than 1 on the first postoperative day, indicating disturbed vasoconstriction due to the surgical procedure.

Table 6.2 Median laser Doppler fluxmetry findings before, shortly after and 12 days after revascularisation in patients with restored postural aasoconstriction, defined as a rise of the vasoconstriction index above 1 during the follow-up period. $P=$ significance as compared to pre-operative results. NS $=p \geq 0.05$.

\begin{tabular}{|c|c|c|c|c|c|}
\hline SUPINE & $\begin{array}{l}\text { Before } \\
\text { surgery }\end{array}$ & $\begin{array}{l}\text { Shortly } \\
\text { after }\end{array}$ & $\mathrm{p}$ & $\begin{array}{l}12 \text { days } \\
\text { after }\end{array}$ & p \\
\hline Rest flux (V) & 0.00 & 0.05 & $<0.05$ & 0.09 & $<0.005$ \\
\hline Peak flux (V) & 0.00 & 0.11 & NS & 0.28 & $<0.001$ \\
\hline Time to peak flux (s) & 114 & 72 & NS & 61 & $<0.05$ \\
\hline \multicolumn{6}{|l|}{ SITTING } \\
\hline Rest flux (V) & 0.05 & 0.21 & $<0.001$ & 0.04 & NS \\
\hline Peak flux (V) & 0.09 & 0.33 & $<0.005$ & 0.10 & NS \\
\hline Time to peak flux (s) & 46 & 55 & NS & 27 & NS \\
\hline Vasoconstriction index & 0.00 & 0.43 & NS & 2.00 & $<0.05$ \\
\hline
\end{tabular}

In 24 out of the 31 patients, vasoconstriction restored during the follow-up period: the median value of VIL became greater than 1 on day 8 postoperatively. The progress of the postural vasoconstriction response in patients in whom this response recovered is shown in figure 6.1. Restoration of vasoconstriction did not correlate with the pre-operative Fontaine stage, $\mathrm{ABI}$, type of revascularisation or the presence of diabetes mellitus. Of the remaining 7 patients, one persistently showed an immeasurable perfusion, due to pronounced hyperkeratosis of the skin in the area to be measured, so 
that recovery of vasoconstriction could not be recognized. The remaining 6 patients did not show recovered vasoconstriction. Four of these showed persistent post-operative oedema. In the remaining 2 patients, oedema formation could not be observed. One patient had a limited post-operative ABI increase of only $8 \%$. The other had a very short follow-up because of death on the third post-operative day. Thus, at least 4 out of 6 patients developed persistent ankle oedema, whereas only 9 out of the 24 patients with restored vasoconstriction developed oedema. Apparently, the absence of vasoconstriction mechanisms coincided with postoperative oedema formation.

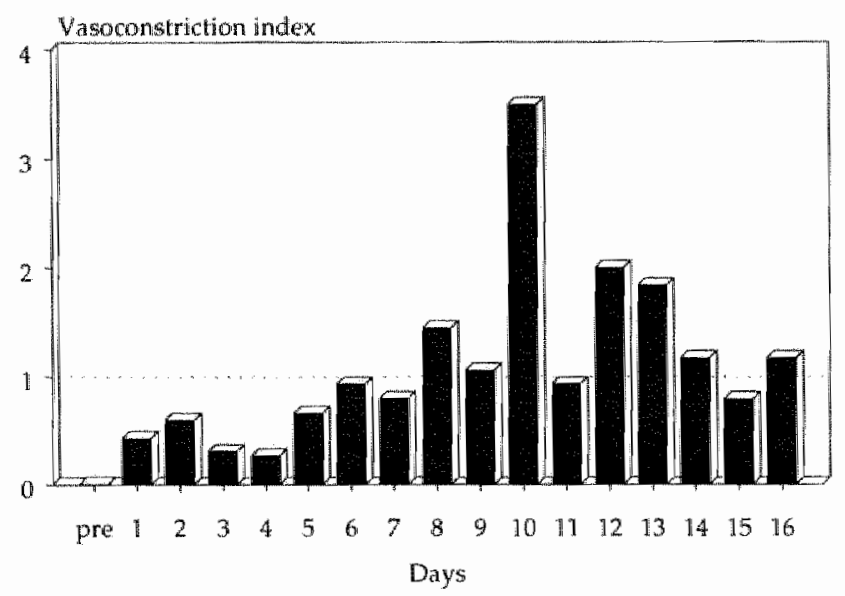

Figure 6.1 Median vasoconstriction indices as measured with laser Doppler fluxmetry in patients in whom postural vasaconstriction recovered following arterial revascularisation.

No significant differences were observed in LDF perfusion before and shortly after surgery between patients with and without restoration of postural vasoconstriction. However, the 24 patients with restored vasoconstriction showed an increase in Rest and Peak flux shortly after surgery when measured while sitting, but not while supine (see table 6.2), indicating that vasoconstriction had not yet recovered. On day 12, however, their LDF values in the supine position were significantly higher as compared to those before surgery, but not in the sitting position, illustrating the recovery of 
vasoconstrictive reactivity. In contrast, in the remaining 7 patients no improvement of LDF parameters could be detected shortly after and on day 12 after surgery. This implies that an increased skin perfusion is accompanied by restoration of vasoconstriction.

Excluding the 2 patients with early death and the one with hyperkeratosis, 13 of the remaining 29 patients developed persistent oedema postoperatively. The LDF parameters of these patients did not improve shortly after surgery. This is in contrast with the significant improvement of the Rest and Peak flux (from $0.05 \mathrm{~V}$ to $0.24 \mathrm{~V}, \mathrm{p}<0.0005$, and from $0.09 \mathrm{~V}$ to $0.50 \mathrm{~V}, \mathrm{p}<0.001$, respectively) in the 16 patients without oedema, when measured in the sitting position. In only 1 of the latter patients postural vasoconstriction did not improve. This was the patient with a limited $A B I$ increase. Thus, virtually no disturbances in postural vasoconstriction were seen in patients without postoperative oedema.

\section{Capillary microscopy}

The capillary microscopy protocol could not be completed properly in 10 patients because of ulceration in the area of investigation ( 5 patients), movement artifacts due to tremor or ischaemic pain (3 patients) or followup difficulties (1 patient with cardiac failure, 1 patient died shortly postoperatively). However, the 21 remaining patients had pre-operative characteristics comparable to those investigated only with the use of laser Doppler fluxmetry.

Before revascularisation, capillary microscopy findings in the supine position showed a limited hyperaemic response (RBCV: $177 \mu \mathrm{m} / \mathrm{s}$; Peak RBCV: $205 \mu \mathrm{m} / \mathrm{s}$ ). Posturally induced vasoconstriction indices at the nutritional level were subnormal, but not seriously disturbed (VIC: 2.76).

After surgery, capillary microscopic parameters improved in both positions, but especially in the supine position, illustrating the effect of the arterial pressure increase also on nutritional skin microcirculation (see table 6.3). Vasoconstriction indices tended to increase (VIC: 3.86 ), albeit not statistically significant. 
Table 6.3 Median capillary microscopy findings in all patients investigated before and between 10-14 days after revascularisation

\begin{tabular}{lccc} 
SUPINE & Before & After & p-value \\
\hline Diameter $(\mu \mathrm{m})$ & 8 & 7 & $<.05$ \\
Density $\left(\mathrm{mm}^{-2}\right)$ & 30 & 30 & NS \\
Rest RBCV $(\mu \mathrm{m} / \mathrm{s})$ & 177 & 245 & $<.01$ \\
Peak RBCV $(\mu \mathrm{m} / \mathrm{s})$ & 205 & 329 & $<.001$ \\
Time to peak RBCV (s) & 17 & 10 & $<.05$ \\
sirring & & & \\
\hline Diameter $(\mu \mathrm{m})$ & 9 & 8 & NS \\
Density $\left(\mathrm{mm}{ }^{-2}\right)$ & 43 & 46 & NS \\
Rest RBCV $(\mu \mathrm{m} / \mathrm{s})$ & 57 & 84 & NS \\
Peak RBCV $(\mu \mathrm{m} / \mathrm{s})$ & 113 & 160 & $<.05$ \\
Time to peak RBCV (s) & 19 & 12 & NS \\
& & & \\
\cline { 1 - 1 } Vasoconstriction index & 2.76 & 4.13 & NS \\
\hline
\end{tabular}

Patients who showed a recovered postural vasoconstriction postoperatively, as measured with LDF, had a significant increase in capillary perfusion, particularly in the supine position: $\mathrm{RBCV}$ rose from 177 to 245 $\mu \mathrm{m} / \mathrm{s}(\mathrm{p}<0.01)$ and Peak RBCV from 205 to $329 \mu \mathrm{m} / \mathrm{s}(\mathrm{p}<0.001)$. This in contrast to the findings in those without improvement of vasoconstriction (RBCV from 178 to $165 \mu \mathrm{m} / \mathrm{s}$; Peak RBCV from 211 to $215 \mu \mathrm{m} / \mathrm{s}$ ).

Patients with persistent oedema did not show an increase in nutritional perfusion, as opposed to the patients without oedema, in whom RBCV at rest improved significantly in the supine position from 121 to $243 \mu \mathrm{m} / \mathrm{s}$ ( $\mathrm{p}$ $<0.05$ ). In addition, Peak RBCV in the latter patients increased from 146 to $494 \mu \mathrm{m} / \mathrm{s}$ while supine ( $<<0.01$ ), and from 89 to $145 \mu \mathrm{m} / \mathrm{s}$ while sitting ( $\mathrm{p}$ $<0.05)$. 


\subsection{DISCUSSION}

This study shows that 1) vascular reconstructive surgery not only enhances arterial inflow, but also improves microcirculatory perfusion, as measured by laser Doppler fluxmetry and capillary microscopy, 2) posturally induced microvascular constriction, as judged in the thermoregulatory part of skin microcirculation, can be regained in approximately eight days following the revascularisation procedure, and 3) postoperative oedema formation may be fostered by the absence of postural vasoconstrictive mechanisms.

Reinstatement of arterial perfusion pressure usually restores not only total but also nutritional skin perfusion, as was also found by Jacobs et aliin". However, this does not necessarily result in restoration of orthostatic vasoconstriction responses. Our observation that this restoration does not occur within a week after revascularisation, indicates that the absence of postural vasoconstriction is due to structural changes rather than inactivation because of the low arterial pressure. This notion is supported by our finding that revascularisation results in a temporary disturbance of postural vasoconstriction, even in patients with an active vasoconstriction before surgery. Besides, the veno-arteriolar reflex ${ }^{6}$, one of the mechanisms leading to arteriolar constriction upon dependency, would still be activated even in case of severely reduced arterial pressure, because it is activated by an orthostatic pressure increase in the venules. The relatively long delay before restoration suggests that the disturbed constriction capacity needs a period of structural regeneration before the increased arterial pressure can be sufficiently counteracted. This regeneration could possibly be protein synthesis in the media of the arterioles. An improved microvascular perfusion appears to be a prerequisite for this regeneration.

The observation that the median values of the vasoconstriction indices, as measured with laser Doppler fluxmetry, were not persistently greater than 1 after restoration of postural vasoconstriction may be explained by the fact that the patients remained mostly in bed or in a chair the first week postoperatively. In this situation, only the increased arterial pressure will activate arteriolar smooth muscle cell regeneration. After this period, mobilisation of the patients will increase the duration and magnitude of the orthostatic raise in blood pressure in the leg microcirculation, which has not yet developed sufficient postural vasoconstrictive capacity. This gives rise to an ostensible relapse in vasoconstrictive activity before postural vasocon- 
striction regenerates completely in a few more days. Also, patients with a rapid recovery and intact vasoconstriction were discharged between 10 and 14 days after surgery, leaving those with not yet completely recovered wasoconstriction. This causes a shift towards lower median vasoconstriction indices, as found in this study.

Postural vasoconstriction appeared to be less affected at the nutritional level of skin microcirculation. This is in accordance with previous findings showing that postural vasoconstriction at the thermoregulatory level is already disturbed when $A B I$ is less than $60 \% 181,182$, but is not disturbed at the nutritional level until ABI becomes lower than $20 \%$. In the patients in the latter study, vasoconstrictive capacity was lower as compared to asymptomatic subjects. This already suggests some disturbance of postural vasoconstriction. However, only a more severe disturbance of the vasoconstriction, indicated by an index below 1, is pertinent to oedema formation, as shown in this study. This can be explained by the fact that in this situation, the degree of arteriolar vasoconstriction has deteriorated to such an extent that it causes a clearly higher skin perfusion while sitting. Hence, the orthostatic increase in capillary and thus, transmural pressure in the dependent position will be insufficiently counteracted. This in turn will lead to an enhanced transcapillary fluid transport.

The pathogenesis of persistent postoperative limb oedema is multifactorial. Disruption of the lymphatic vessels during surgery is an established cause $^{1,37,38,843}$. This is supported by the finding that the incidence of postreconstructive oedema is markedly higher in distal reconstructions ${ }^{142}$, in which larger incisions are to be made and more vessels are to be manipulated. An additional argument for lymphatic involvement is the finding that post-operative oedema accumulates mainly in subcutaneous tissue, as is the case in patients suffering from lymphoedema ${ }^{75,170}$. Furthermore, a dysfunction of the intrinsic lymph propulsion mechanism has been proposed ${ }^{137}$. It is likely that in all patients undergoing a peripheral vascular reconstruction, damage to the lymphatic vessels occurs to some extent. However, an impeded lymph drainage cannot be the sole cause, since in our study only 13 out of the 27 patients who underwent a peripheral revascularisation developed persistent oedema. The notion that other factors (see figure 6.2) are important in addition to disrupted lymph drainage, is also illustrated by the patient who had a limited $\mathrm{ABl}$ increase $(8 \%)$ after surgery. This patient 
underwent a peripheral arterial reconstruction, but did not develop oedema post-operatively.

Some investigators have demonstrated that disturbances in arteriolar constriction upon an increased orthostatic pressure can play a role ${ }^{36,164}$. These disturbances may be caused by 1) the ischaemic disease, causing destruction of pressure sensing structures, and 2) the reduced arterial pressure, resulting in atrophy of the arteriolar smooth muscle cells. In these cases, capillary hyperperfusion and oedema cannot be avoided when arterial pressure is restored after revascularisation. In our study, every patient with a continuous disturbance of postural vasoconstriction mechanisms showed persistent postoperative oedema, yet not vice versa. In addition, virtually no disturbances in postural vasoconstriction were observed in patients without post-operative oedema. This indicates that this disturbance is at least a facilitative factor in the development of postoperative oedema. When capillaries are exposed to an increased pressure due to the restored arterial blood pressure in the absence of vasoconstriction mechanisms in precapillary vessels, transmural pressure at the capillary level will increase and lead to an enhanced transcapillary fluid transport to the extravascular compartment (see figure 6.2). This is substantiated by the findings in one patient in our study undergoing an aorto-iliac procedure, which is thought to hardly ever compromise lymph vessels. This patient showed a persistently disturbed postural vasoconstriction and subsequently, persistent oedema during a follow-up period of 26 days.

Furthermore, oedema formation may be exaggerated as the consequence of an increased capillary permeability, when the capillary endothelial barrier has been damaged either because of pre-operative ischaemia or due to reperfusion ${ }^{105}$. Venous thrombosis is an alleged cause for the development of post-operative oedema through an increase in capillary pressure, but it is rare ${ }^{130}$.

We could not pre-operatively betoken patients at risk for the development of post-operative oedema by means of microcirculatory investigation, as was found in earlier studies ${ }^{95,105}$. However, in order to avoid or attenuate post-operative oedema formation, not only the application of elastic stockings to enhance tissue pressure and thus, to reduce transmural pressure, but also the testing of microvascular constriction appears relevant. Mobilisation of patients after vascular reconstructive surgery should preferably not be initiated until postural vasoconstriction has recovered. 


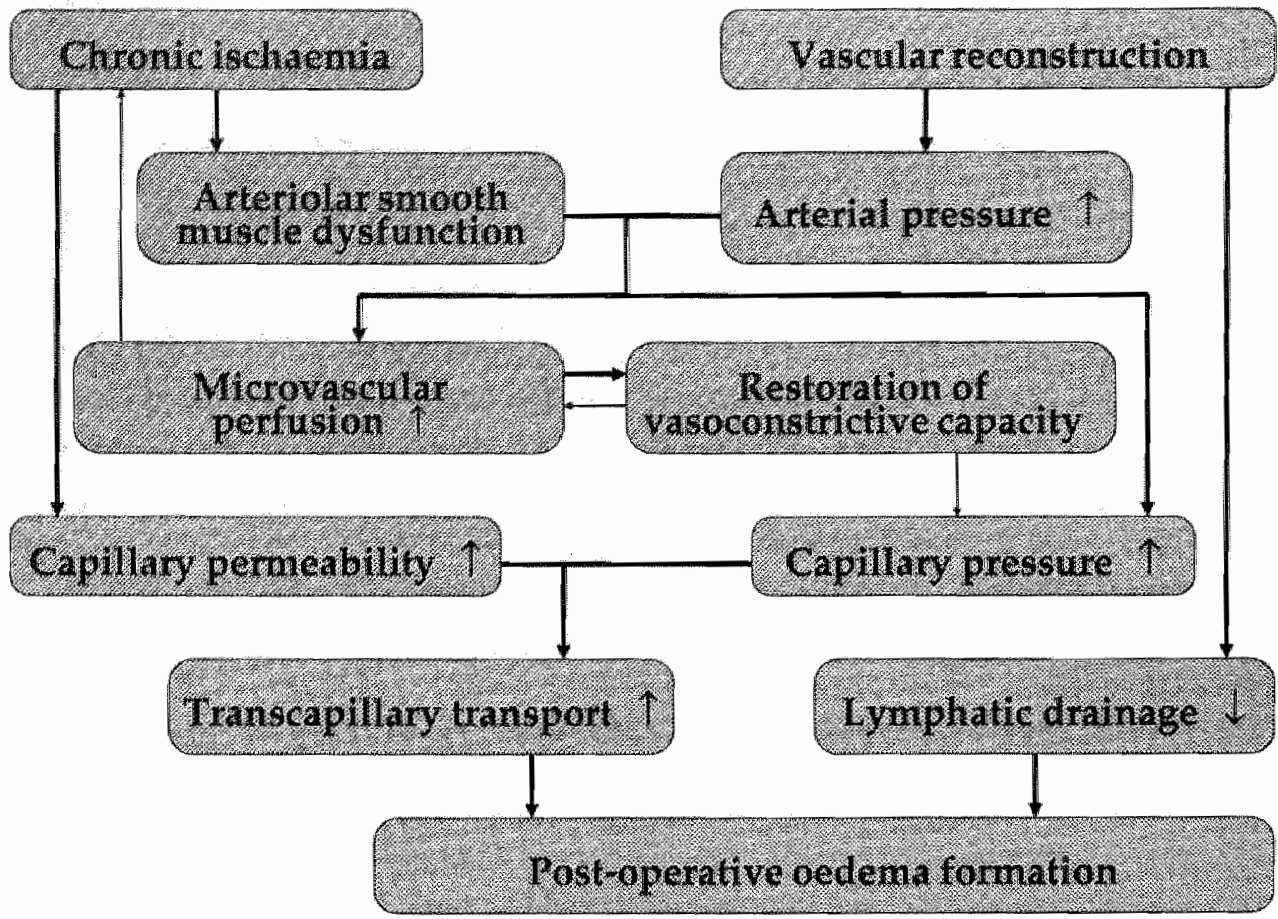

Figure 6.2 Flow chart of the pathophysiological mechanisms leading to leg oedema following arterial revascularisation. Counteracting phenomena are indicated by light arrows.

In conclusion, the findings in this study demonstrate that the disturbance of posturally induced microvascular constriction mechanisms in patients with chronic lower limb ischaemia can be reversed after vascular reconstructive surgery. The restoration of these mechanisms appears not to be simply a matter of reactivation but rather a regeneration of structural vasoconstrictive components, initiated by an improvement of microvascular perfusion. If orthostatic vasoconstriction does not recover after revascularisation, the formation of oedema is prompted. 


\section{Chapter 7}

\section{The usefulness of capillary microscopy, laser Doppler fluxmetry and trans- cutaneous oximetry in the assessment of the severity of lower limb ischaemia ${ }^{*}$}

\subsection{INTRODUCTION}

Skin nutritive perfusion is of utmost importance for limb viability. The changes in perfusion that compromise skin viability can only be determined by using methods that measure skin haemodynamics. To date, capillary microscopy, transcutaneous oximetry $\left(\mathrm{TcpO}_{2}\right)$ and laser Doppler fluxmetry (LDF) are techniques frequently used to obtain information about skin microcirculation in patients suffering from lower limb ischaemia. Each of these methods has its specific reproducibility, merits and disadvantages. Also, with each technique numerous parameters can be measured to quantify microcirculatory perfusion ${ }^{45,134,135,174}$. A variety of parameters has been used to non-invasively investigate and assess lower limb ischaemia ${ }^{23,32,110,114,}$ 115 , but to our best knowledge only a few studies have been performed to determine which microcirculatory technique(s), method(s) and parameter(s) and which investigatory position are best suited for a better evaluation of the severity of vascular disease in addition to clinical or macrocirculatory parameters, and for a better discrimination between the different stages of lower limb ischaemia. Therefore, we performed a study to evaluate which 
microcirculatory parameters can best be used to distinguish between patients suffering from lower limb ischaemia of different severity.

\subsection{PATIENTS}

One hundred and thirty subjects consented to participate in the study. The mean age of the 88 males and 42 females was 73 years (range 36-96 years). According to the clinical stages of Fontaine $(F) 1$ through 4 , they were either asymptomatic or suffered from intermittent claudication, rest pain without or with ulceration, respectively, in at least one leg. The patients were divided into four groups (table 7.1), according to their Ankle-to-Brachial pressure Index $(\mathrm{ABI})$. Group A consisted of asymptomatic subjects, serving as controls. Smoking habits and drug treatment, especially those interfering with vasoconstriction, were similar in each group. Patients refrained from smoking and did not take caffeine or alcohol at least one hour before examination.

Table 7.1 Patient groups

\begin{tabular}{|c|c|c|c|c|c|c|c|c|c|}
\hline Group & ABI & $\mathrm{N}$ & Agr (range) & Toe & Ankle & & onta & & \\
\hline & (8) & & & pressure & pressure & 1 & 2 & & 4 \\
\hline A (asymptomatic) & $96-123 \%$ & 16 & $70(52-83)$ & 100 & 150 & 16 & 0 & 0 & 0 \\
\hline B (mild) & $51-95 \%$ & 34 & $69(36-81)$ & 50 & 90 & 0 & 26 & 3 & 5 \\
\hline $\mathrm{C}$ (moderate) & $26-50 \%$ & 58 & $73(43-96)$ & 30 & 55 & 0 & & 2 & 13 \\
\hline D (severe) & $0-25 \%$ & 22 & $79(44-90)$ & 0 & 20 & 0 & 2 & 9 & 11 \\
\hline
\end{tabular}

Classification of patients, based on ankle-to-brachial systolic blood pressure index $(\mathrm{ABI})$, including their mean age and range (years), median systolic toe and ankle blood pressures (in $\mathrm{mm} \mathrm{Hg}$ ) and clinical stages according to Fontaine. 
The 16 asymptomatic subjects in group $A$ were preferred as controls above healthy subjects. It is more likely that they match the diseased patients, because some of them used (vasoactive) medication and presented other signs of atherosclerotic disease. These subjects had a normal arterial system in the investigated leg, not only because the $A B I$ in this leg was higher than $95 \%$, but also because analysis of the Doppler signals of the major leg arteries showed no pathology, as opposed to the arterial Doppler signals of the patients in groups B through D. A description of the Doppler criteria to assess arterial pathology can be found in chapter 2 , section 2.1 .

Subjects with insulin-dependent diabetes mellitus were excluded from the study, since this disease per se influences microcirculatory autoregulation mechanisms ${ }^{148}$.

However, 33 non-insulin dependent diabetics did participate in this study. Their findings were interpreted separately to assess whether the presence of diabetic patients would influence differences in microvascular skin perfusion between the groups. The diabetics were all well-regulated at the time of the investigation. Only those patients were included in the study who stated not to experience paresis or loss of sensibility and whose skin tactile sensibility showed no abnormalities during clinical examination, to rule out the presence of peripheral neuropathy. As shown by table 7.1, 8 patients in group B (mildly diseased) belonged to $F 3$ or 4 . Five of them suffered from diabetes mellitus, which may have caused overestimation of the ABI due to vessel wall sclerosis. "Their systolic toe pressures ranged between 45 and $60 \mathrm{~mm} \mathrm{Hg}$. The other 3 had toe pressures $\leq 30 \mathrm{~mm} \mathrm{Hg}$, indicating the presence of very peripheral vascular disease.

\subsection{METHODS}

All measurements were performed by the same investigator, thus avoiding inter-observer variability.

\section{Capillary microscopy}

This is an established technique to assess nutritional skin circulation of patients with arterial occlusive disease ${ }^{12}$, by investigating both capillary 
morphology and red blood cell velocity (RBCV) in the nailfold of the great toe. The methods and equipment used have been described in detail before $^{15,16,165,176}$ (see chapter 2, section 2.2).

In this study, capillary microscopy was performed following $15 \mathrm{~min}$ utes of acclimatization in a room with a temperature between $22^{\circ}$ and $23^{\circ} \mathrm{C}$. The patients were investigated firstly in the sitting and then in the supine position. For a detailed description of the investigatory protocol and parameters measured, the reader is referred to chapter 2 , subsection 2.2 . In both positions, capillary density was investigate first. Then, capillary diameter and RBCV were measured in usually four, but at least three capillaries (generally in group D). In either position, the same capillaries could usually be investigated, because identification of each capillary is easy due to its almost unique morphology. RBCV was measured not only at rest, but also during reactive hyperaemia following the release of a one minute arterial occlusion, achieved by inflating a supramalleolar cuff, to assess to which extent the capillaries are able to react with an increased perfusion upon an increased demand. This hyperemia procedure was performed in each of the three or four capillaries investigated in both positions. To ensure that the previous hypaeremic response had subsided, the measurements in the different capillaries were performed with an interval of at least three minutes, which is longer than the duration of reactive hyperaemia ${ }^{52}$. The average values of the diameters and velocities of the three or four capillaries observed in both positions, were taken as the patient's readings.

\section{$T_{c p} O_{2}$ and $L D F$}

Transcutaneous oximetry ( $\mathrm{TcpO}_{2}$; $\mathrm{TCM} 2$, Radiometer, Kopenhagen, including a Clark-type electrode ${ }^{25}$ ) and laser Doppler fluxmetry (LDF; Periflux Pf3, Perimed, Stockholm) were performed simultaneously and directly following capillary microscopy. $\mathrm{TcpO}_{2}$ measures skin oxygenation, LDF measures mainly thermoregulatory flow ${ }^{13,176}$. The tcpO $\mathrm{O}_{2}$ measuring electrode was attached to the dorsum of the foot in the first intermetatarsal space by an adhesive fixation ring containing contact liquid. The laser Doppler probe holder was attached to the pulp of the great toe with doublesided adhesive tape. This site was chosen, because in this area arteriovenous anastomoses involved in thermoregulation are numerous. The experimental protocol was according to that mentioned in chapter 2, sections 2.3 and 2.4. 
The reproducibility of these two techniques has been investigated thoroughly and documented earlier $2,24,27,30,32,39,44,53,72,113,120,173,175$.

\section{Parameters measured}

In summary, the following parameters were measured:

\section{PRESSURE MEASUREMENTS}

* Brachial systolic blood pressure (in $\mathrm{mm} \mathrm{Hg}$ ), using the Riva Rocci method, with the patients in the supine position.

* Ankle systolic blood pressure (in $\mathrm{mm} \mathrm{Hg}$ ), using a cuff and an $8-\mathrm{MHz}$ Doppler probe. These data were used to calculate systolic ABI in the supine position.

* Digital systolic pressure $(\mathrm{mm} \mathrm{Hg}$ ) in the great toe, using a photoplethysmograph.

\section{CAPILLARY MICROSCOPY}

* Capillary density, per square millimetre of nailfold skin.

* Capillary diameter (in $\mu \mathrm{m}$ ), represented by the RBC column width ${ }^{121}$ in the arteriolar limbs of the capillary loops in microns, measured halfway between the visible base and the crest of the loop.

* Restv (RBCV at rest, in $\mu \mathrm{m} / \mathrm{s}$ ) and Peakv (RBCV at peak reactive hyperaemia).

* Hyperaemic increase in RBCV (HIV in $\mu \mathrm{m} / \mathrm{s}$ ), i.e. Peakv minus Restv, as a measure of nutritive reserve flow.

* Time to peak $R B C V$ (in s): the time needed to reach Peak velocity.

* Capillary transport capacity index (TCI), being $\pi \times$ (average capillary radius) $)^{2} x$ density.

* Capillary volume flow (Volflow, in $\mu \mathrm{m}^{3} / \mathrm{s} / \mu \mathrm{m}^{2}$ ) at rest, as calculated from the average Restv x TCI.

* Vasoconstriction index: the supine to sitting velocity ratios, obtained by dividing $\mathrm{RBCV}$ in both positions in each patient. This ratio was used to obtain better insight into the individual changes in perfusion due to changes in posture as it is an index for the effectiveness of the postural vasoconstrictive mechanisms. This approach was taken because the median of the ratios for a group may be different from the ratios calculated from the group median values. When RBCV was zero in both the supine and the sitting position, the ratio was also regarded as zero. 
$\mathrm{TCPO}_{2} \mathrm{AND}$ LDF

* Rest $\mathrm{pO}_{2}$ (in mm Hg) and Restf (in Volts): TcpO, and LDF at rest, and at peak reactive hyperaemia $\left(\mathrm{PeakpO}_{2}\right.$ and Peakf, respectively).

* $T 50 \% \mathrm{pO}_{2}$ and $\mathrm{T} 50 \% \mathrm{f}$ (in s): time to reach half of the RestpO $\mathrm{O}_{2}$ and Restf, respectively, following a three minute occlusion period.

* TtppO $\mathrm{O}_{2}$ and $T \operatorname{tpf}$ (in s): time to reach PeakpO and Peakf, respectively, during reactive hyperaemia.

* Hyperaemic increase in $\mathrm{TcpO}_{2}$ (HIT, in $\mathrm{mm} \mathrm{Hg}$ ) and LDF (HIF, in Volts), respectively, again defined as peak minus rest values, as a measure of thermoregulatory flow and oxygenation reserve capacity, respectively.

* Vasoconstriction index, derived from the RestpO $\mathrm{O}_{2}$ and Restf in supine and sitting position (see above).

\section{Statistics}

The statistical procedures used for the analysis of the data obained are already described in chapter 2.5. In addition, the following values and methods were used:

* For the best discriminating individual parameters, the cut-off values were calculated that render the highest predictive values. These values show the probability that patients with a value lower than the cut-off value are correctly classified as having clinically or macrocirculatory severe ischaemia, and those with a higher value as not severely ischaemic patients.

* In addition to the predictive values, $\kappa$ (kappa) was calculated as a chance-corrected measure of agreement between macro and microcirculatory parameters on the one hand and the stages of lower limb ischaemia on the other. The value of $k$ can range from -1 to 1 . The higher the value, the better the agreement. A $\kappa$ of greater than approximately 0.75 indicates excellent agreement, a value of less than about 0.40 poor agreement. The $\kappa$ takes into account the prevalence of the different stages of ischaemia in this study. Thus, it may be considered as a better parameter to describe diagnostic accuracy ${ }^{26,15 \%}$. Discriminant analysis was performed to identify the combination of parameters with the best discriminative property to discern whether a patient belongs to F $1-2$ or $3-4$, or to the groups with an $A B I<$ or $\geq 30$ 
$\%$. For this purpose, the discriminant procedure using the Wilks' $\lambda$ stepwise method provided by the SPSS computer programme was applied ${ }^{136}$. This type of multivariate analysis is used to maximize statistical separation of the patient groups through a linear function model that weighs and combines the discriminating parameters. To this end, the 'à priori" chance is required, i.e. the probability that a patient belongs either to Fontaine $1-2$ or Fontaine $3-4$, or ABI group $<$ or $\geq 30 \%$ before microcirculatory investigation is performed, because this chance influences the outcome of the test. In this study, the "à priori" chance was calculated from the proportion of cases actually falling into each group. The analysis yields a combination of parameters that leads to the highest percentage of correctly à posteriori classified cases. Thus, the additive value of combining all three microcirculatory techniques in the objectivation of critical ischaemia is assessed. This combination may then be useful to classify newly investigated cases. Discriminative capacity to discern between all four groups could not be calculated accurately, because this would have required more patients in each group investigated.

\subsection{RESULTS}

The median age in the severely diseased patients was significantly higher than in the other groups ( $p<0.05$ ), obviously because ageing is associated with progression of vascular disease.

\section{Pressure measurements}

Median ankle and toe blood pressures differed significantly ( $\mathrm{p}<0.001)$ between the four patient groups, yet with some overlap (see figure 7.1), although hardly any overlap existed between asymptomatic subjects and diseased patients. By means of these two parameters the different Fontaine stages could not be distinguished accurately (see table 7.1 and 7.6). The number of diabetics per group did not differ significantly. 
Figure 7.1 Median toe systolic blood pressures, mersured in the supine position, for each patient group investigated, including the $25^{\text {th }}$ and $75^{\text {th }}$ percentile intervals

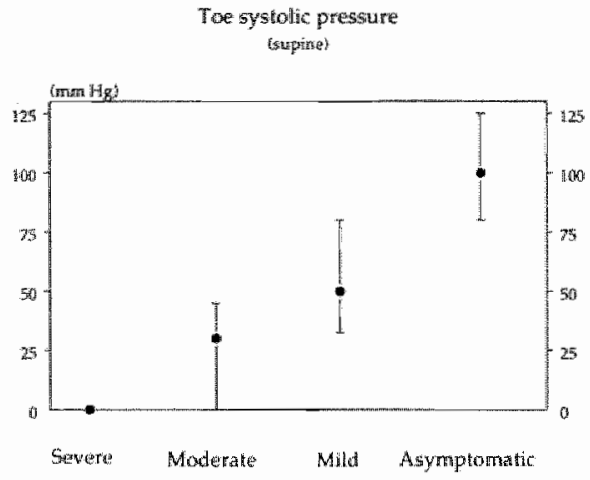

\section{Capillary microscopy}

The coefficient of variation (CV) calculated from the data obtained in healthy subjects was 0.09 for the capillary density and diameter. Restv showed a CV of 0.59 , Peakv of 0.25 and Ttpv of 0.19 . A CV of about 0.3 is comparable to the $\mathrm{CV}^{\text {s }}$ for laser Doppler fluxmetry ${ }^{120}, 173,175$ and transcutaneous oximetry ${ }^{39,} 120$ parameters. The $\mathrm{CV}$ for Restv, however, was evidently higher. This is supposedly due to the great physiologic variation in skin perfusion, in part due to the presence of flowmotion in these healthy persons, and illustrates the usefulness of postocclusive reactive hyperaemia parameters.

The CV's for Restv and Peakv were fairly similar between the beginning and experienced investigator (Restv: 0.68 and 0.86; Peakv: 0.54 and 0.66 , respectively). The higher $\mathrm{CV}^{\prime}$ 's scored by the experienced investigator may imply that he could measure a wider range of RBCV's. The RBCV's and derived parameters measured by the experienced and beginning investigator showed correlations $\geq 0.90$ ( $\mathrm{p}<0.005$ ). Hence, this technique was considered reliable in the investigation of these patients.

Statistical analysis of the differences observed between the adjacent patient groups is shown in table 7.2 . 
Table 7.2 Discrimination between $A B I$ groups when using capillary microscowy

\begin{tabular}{|c|c|c|c|c|c|c|c|}
\hline SITTING & A & p & B & P & 6 & p & 1 \\
\hline Diameter & 6 & - & 7 & - & 8 & - & 8 \\
\hline Density & 54 & $=$ & 43 & - & 43 & - & 36.5 \\
\hline Restv & 57 & - & 51 & - & 47.5 & - & 46 \\
\hline Peakv & 120 & - & 92.5 & - & 84.5 & - & 53.5 \\
\hline Time to peakv & 17 & - & 12 & - & 19 & - & 15.5 \\
\hline Hyperaemic increase in $\mathrm{RBCV}$ & 46 & - & 42 & * & 21.5 & - & 25 \\
\hline Transport capacity index & 1630 & - & 1655 & - & 2715 & - & 2121 \\
\hline Volume flow & .082 & - & .117 & - & 154 & - & .075 \\
\hline \multicolumn{8}{|l|}{ SUPINE } \\
\hline Diameter & 5 & - & 5.5 & $\infty$ & 7 & - & 7 \\
\hline Density & 29 & - & 30 & - & 27 & *** & 11 \\
\hline Restv & 190 & - & 214 & * & 146.5 & $* * *$ & 34 \\
\hline Peaky & 349.5 & - & 297 & ** & 168 & $* * *$ & 51 \\
\hline Time to peakv & 10 & * & 16 & - & 20.5 & - & 23.5 \\
\hline Hyperaemic increase in RBCV & 80.5 & - & 52 & w:* & 10 & - & 0 \\
\hline Transport capacity index & 628 & - & 1060 & - & 1028.5 & * & 551 \\
\hline Volume flow & .126 & - & .150 & - & 133 & $* *$ & .025 \\
\hline Vasoconstriction index & 5.80 & - & 3.22 & - & 2.69 & * & .97 \\
\hline
\end{tabular}

Capillary microscopic data of the asymptomatic (A) subjects and mildly (B), moderately (C) and severely (D) diseased patients investigated in both the sitting and the supine position, including statistical analysis of the differences between adjacent groups.

$-=$ not significant; * $=p<0.05 ; * *=p<0.005 ; * * *=p<0.001$. 
Virtually all parameters deteriorated with increasing severity of the disease, particularly in the supine position. Vasoconstriction indices showed some vasoconstrictive activity upon dependency even in the severely diseased patients. It is clearly visible that in the sitting position, patients from each group could not be discerned from those in a adjacent group. However, in the supine position, the different stages of lower limb ischaemia could be separated on the basis of either morphological or dynamic parameters, e.g. Peakv completely separated group C and D and was significantly higher in group B than in group C. This is illustrated in figure 7.2.

Figure 7.2 Median peak red blood cell velocities during reactive hyperaemia, in each patient group investigated in the supine position, including the $25^{\text {th }}$ and $75^{\text {th }}$ percentile intervals

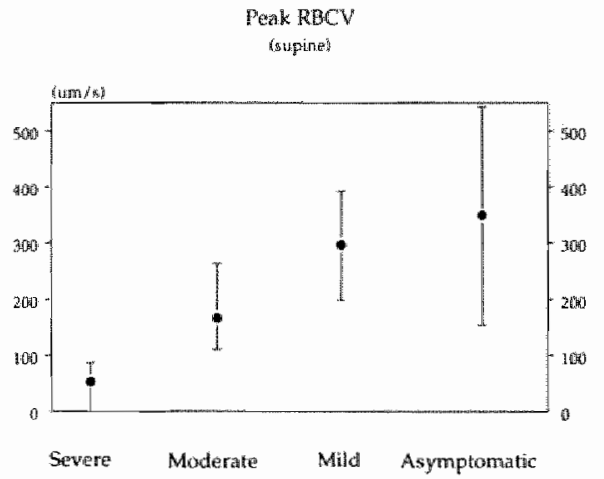

Peakv as measured in the supine position showed the best $\kappa$ value. This Peakv and, to a lesser extent, capillary density in either position showed the highest predictive values in the assignment of patients either to $F 1-2$ or $3-4$ (table 7.6). Hence, these parameters were involved in the discriminant analysis (table 7.7). Capillary microscopy alone appeared to have a lesser discriminative power to discern patients belonging to different Fontaine stages than did the combination of macrocirculatory parameters, but a higher discrimination was seen when patients with an $\mathrm{ABI}<30 \%$ were to be discerned (table 7.7).

The presence of diabetic patients did not influence the differentiation between the patient groups. The only parameter showing different results was Restv in the sitting position, which was lower $(p<0.05)$ in group D than in group $C$ patients with diabetes, but did not differ significantly in those without diabetes. 


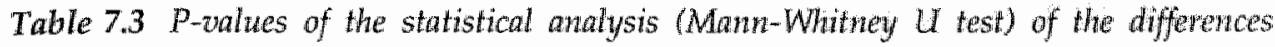
between the patient groups, when only 1 capillary is investigated, or 2,3 or 4 capillaries per patient are aweraged

\begin{tabular}{|c|c|c|c|c|c|c|c|c|c|c|c|c|}
\hline \multirow[b]{2}{*}{ SITING } & \multicolumn{4}{|c|}{ Asymptomatie + Mild } & \multicolumn{4}{|c|}{ Mild \& Mroderate } & \multicolumn{4}{|c|}{ Moderate r) ciavero } \\
\hline & 1 & 2 & 3 & 4 & 1 & 2 & 3 & 4 & 1 & 2 & 3 & 4 \\
\hline Diameter & .02 & .01 & .06 & .05 & .53 & .94 & .32 & .26 & .88 & .73 & .68 & .35 \\
\hline Resty & .69 & .31 & .42 & .16 & .08 & .07 & .21 & .17 & .87 & .68 & .99 & .80 \\
\hline $\begin{array}{l}\text { Peakv } \\
\text { SUPINE }\end{array}$ & .36 & .75 & .61 & .49 & .03 & .06 & .03 & .05 & 61 & .82 & .67 & .49 \\
\hline Diameter & .21 & .09 & .08 & .13 & .11 & .39 & .28 & .13 & .56 & .86 & 71 & .93 \\
\hline Restv & 71 & .37 & .57 & .67 & .017 & .0009 & .0060 & .0054 & .0025 & .0037 & .0007 & .0008 \\
\hline Peaklky & .51 & .96 & .66 & .91 & .0012 & .0000 & .0008 & .0001 & 0060 & .0234 & .0010 & .0008 \\
\hline
\end{tabular}

The validity of taking the average of four capillaries to assess capillary diameter and dynamics was tested by repeating the calculations mentioned above using the values of diameter, Restv and Peakv of only the first, and those obtained by averaging the first two and the first three capillaries investigated in each patient. These values yielded exactly the same differences between the patient groups as those shown in table 7.2 , although statistical significance decreased when the values of only one capillary per patient were used (see table 7.3). This indicates that intercapillary diameter and $\mathrm{RBCV}$ differences already decrease by taking a sufficient number of patients in each group investigated, without concealing inter-group differences.

\section{Transcutaneous oximetry}

\section{AT $37^{\circ} \mathrm{C}$}

Transcutaneous oximetry data and statistical analysis of the differences between the patient groups investigated at $37^{\circ} \mathrm{C}$ is presented in table 7.4. This table shows that the three stages of leg ischaemia could easily be differentiated. 
When diabetics were excluded from the calculations, the median $\mathrm{TtppO}_{2}$ at $37^{\circ} \mathrm{C}$ showed no significant difference between group $\mathrm{B}$ and $\mathrm{C}$, as was the case with the vasoconstriction index at $37^{\circ} \mathrm{C}$ between the groups $\mathrm{A}$, $\mathrm{B}$ and $\mathrm{C}$. RestpO $\mathrm{O}_{2}$ at $37^{\circ} \mathrm{C}$ was now significantly lower in group $\mathrm{C}$ as compared to group $B$.

Table 7.4 Discrimination between $A B I$ groups when using transcutaneous oximetry at $37^{\circ} \mathrm{C}$

\begin{tabular}{|c|c|c|c|c|c|c|c|}
\hline SITTING & A & 1 & B & P & C & p & D \\
\hline $\operatorname{RestpO}_{2}$ & 12 & - & 10 & -+ & 12 & $*$ & 3.5 \\
\hline PeakpO & 15 & - & 17 & 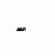 & 17 & * & 10 \\
\hline $\mathrm{T} 50 \% \mathrm{pO}_{2}$ & 36 & $-^{+}$ & 34 & $* *$ & 68 & * & 109 \\
\hline TtppO & 120 & - & 130 & $* 0$ & 174 & * & 230 \\
\hline HIT & 1 & - & 2 & - & 1 & - & 0 \\
\hline \multicolumn{8}{|l|}{ SUPINE } \\
\hline RestpO 2 & 17.5 & - & 18 & -+ & 9 & $* * *$ & 1 \\
\hline PeakpO & 19.5 & - & 21 & * & 16 & $* * *$ & $\mathbb{1}$ \\
\hline $\mathrm{T}_{50} \% \mathrm{pO}_{2}$ & 48 & - & 48 & - & 82 & - & 120 \\
\hline $\mathrm{TtppO}$ & 115 & - & 158 & * & 172 & - & 223 \\
\hline HIT & 4 & - & 2 & - & 0 & - & 0 \\
\hline Vasoconstriction index & 1.04 & - & 1.67 & * & 90 & $* *$ & .12 \\
\hline
\end{tabular}

Transcutaneous oximetry data of the asymptomatic (A) subjects and mildly (B), moderately (C) and severely (D) diseased patients investigated in both the sitting and the supine position, including statistical analysis of the differences between adjacent patient groups.

$-=$ not significant; $*=p<0.05^{* * *}=\mathrm{p}<0.005_{*}^{* * *}=\mathrm{p}<0.001$.

$+\quad=$ Significant difference $(\mathrm{p}<0.05)$ when measured at $44^{\circ} \mathrm{C}$.

$\mathrm{o} \quad=$ No significant difference when measured at $44^{\circ} \mathrm{C}$.

$T 50 \% \mathrm{pO}_{2}=$ Time to reach $50 \%$ of rest $\mathrm{pO}_{2}$ during reactive hyperaemia

TtppO $\mathrm{O}_{2}=$ Time to reach peak $\mathrm{tcpO}_{2}$ during reactive hyperaemia

$\mathrm{HIT}=\mathrm{TcpO}_{2}$ increase during reactive hyperaemia 


\section{AT $44^{\circ} \mathrm{C}$}

Discrimination between the different stages was hardly enhanced by further heating of the skin to $44^{\circ} \mathrm{C}$ (see table 7.4). However, RestpO at this temperature could discriminate better between $F 3-4$ and $F 1-2$ patients than at $37^{\circ} \mathrm{C}$, particularly in the supine position (cut-off value sitting $40 \mathrm{~mm} \mathrm{Hg}$; supine $30 \mathrm{~mm} \mathrm{Hg}$ ). This is demonstrated in figure 7.3, showing complete separation of the groups $\mathrm{C}$ and $\mathrm{D}$. To a lesser degree, the same was true for $\mathrm{T} 50 \% \mathrm{pO}_{2}$ in the sitting position. Restp $\mathrm{O}_{2}$ could discriminate well between $\mathrm{F}$ $3-4$ and F 1-2 patients when cut-off values of 40 and $30 \mathrm{~mm} \mathrm{Hg}$ were used in the sitting and supine position, respectively. Corresponding predictive and $\kappa$ values are presented in table 7.6. Transcutaneous oximetry per se, performed at this temperature, appeared to have a better discriminative power than macrocirculatory techniques (table 7.7).

Figure 7.3 Median transcutaneous axygen pressures at rest, for each patient group investigated, including the $25^{\text {th }}$ and $75^{\text {s.t }}$ percentile intervals

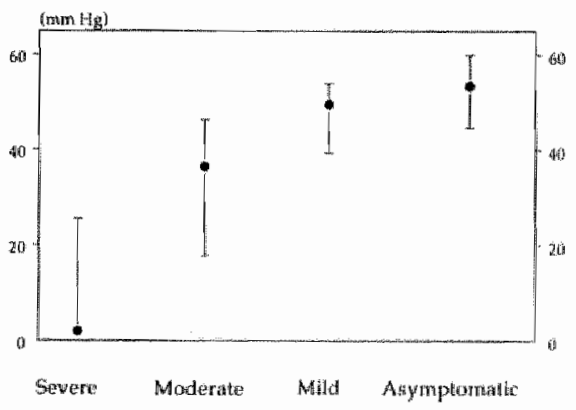




\section{Laser Doppler fluxmetry}

\section{AT UNHEATED SKIN TEMPERATURE}

Median unheated skin temperature was $28^{\circ} \mathrm{C}$ and did not vary significantly among the four groups. Laser Doppler flux data including statistical analysis of the differences between the patient groups is shown in table 7.5. From this data it is manifest that all patient groups could be discerned using LDF parameters at rest and during reactive hyperaemia. Figure 7.4 presents the median T50\% for each group in the sitting position, showing little overlap between the groups. Predictive and $\kappa$ values were calculated for the best discriminating LDF parameters (table 7.6). Combining these parameters did not result in a better discrimination of patients as compared to macrocirculatory parameters (table 7.7).

Figure 7.4 Median times to reach half of the laser Doppler rest flux value during reactive hyperaemia at unheated skin temperature, for each patient group indestigated, including the $25^{\text {th }}$ and $75^{\text {th }}$ percentile interaals

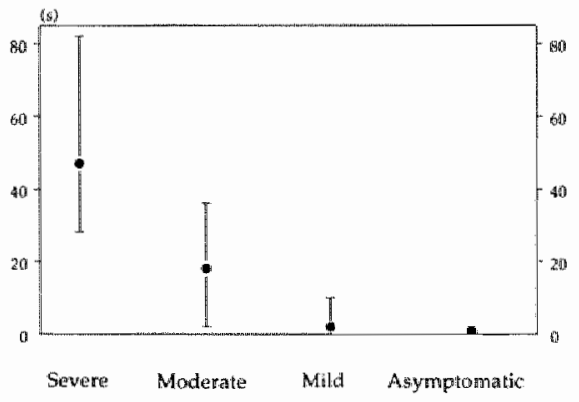


Table 7.5 Discrimination between ABl groups when using laser Doppler fluxmetry at unheated skin temperature

\begin{tabular}{lccccccc} 
SIrTING & A & P & B & P & C & p & D \\
\hline Rest flux & 16 & - & 16 & - & 12 & $* * *$ & 1 \\
Peak flux & 63.5 & - & 45 & $*$ & 25 & $* * *$ & 3 \\
T50\%f & 1 & $* *$ & 2 & $* *$ & 18 & $* *$ & 47 \\
Ttpf & 8 & $* *$ & 32 & $* * *$ & 64.5 & - & 104 \\
HIF & 45.5 & $*$ & 17 & $*$ & 8 & $*$ & .5 \\
SuPINE & & & & & & & \\
Rest flux & 29 & - & 24 & $* * *$ & 5 & $* * *$ & 0 \\
Peak flux & 79.5 & $*$ & 43 & $* * *$ & 15 & $* * *$ & 0 \\
T50\%f & 2 & $* * *$ & 19 & $*$ & 50 & $*$ & $x$ \\
Ttpf & 26.5 & $* * *$ & 70 & $* *$ & 128 & $*$ & $x$ \\
HIF & 49.5 & $*$ & 19 & $* * *$ & 7.5 & $* * *$ & 0 \\
& & & & & & & \\
Vasoconstriction index & 2.25 & - & 1.67 & $* * *$ & 0.5 & $* * *$ & 0 \\
\hline
\end{tabular}

Laser Doppler fluxmetry data obtained of the severely(D), moderately(C) and mildly $(B)$ diseased patients and asymptomatic subjects(A) investigated in both the sitting and the supine position and without local heating of the skin, including statistical analysis of the differences between adjacent groups.

$=$ not significant; $*=p<0.05 ; * *=p<0.005 ; * * *=p<0.001$.

$\mathrm{T} 50 \% \mathrm{f}=$ Time to reach $50 \%$ of rest value during reactive hyperaemia

Ttpf = Time to reach peak flux during reactive hyperaemia

HIF = Flux increase during reactive hyperaemia

$x \quad=$ No-flow state.

When patients with diabetes were excluded from the calculations, significancies between the groups were virtually the same. Without diabetics, only in sitting position T50\% $\mathrm{f}$ was not significantly different between group $C$ and $D$ at unheated skin temperature and between group $A$ and $B$ at $36^{\circ} \mathrm{C}$. 


\section{AT $36^{\circ} \mathrm{C}$}

Local skin heating to $36^{\circ} \mathrm{C}$ did not improve the discriminative capacity of laser Doppler fluxmetry, as it did not cause more parameters to be significantly different between the groups. Moreover, vasoconstriction indices were reduced in group $A$ and $B$, due to the suppression of microvascular constriction when the skin is heated.

Table 7.6 Optimal cut-off and predictive values in the discrimination between Fontaine 1-2 and 3-4 patients, using different measuring techniques, including the $\mathrm{K}$ value, as a measure of diagnostic accuracy.

\begin{tabular}{|c|c|c|c|c|c|}
\hline Parane lor & Cuto & off value & $\begin{array}{l}\text { P Tedicll } \\
\text { Measurement above cut-off: } \\
\text { patient belongs to } \mathrm{F} 1.2\end{array}$ & $\begin{array}{l}\text { Y e v a l a es } \\
\text { Measurement below cut-off: } \\
\text { patient belongs to F3-4 }\end{array}$ & $\mathrm{k}$ val \\
\hline Systolic ankle pressure & 50 & $\mathrm{~mm} \mathrm{Hg}$ & $79 \%$ & $79 \%$ & .42 \\
\hline Ankle/brachial index & 30 & $\%$ & $80 \%$ & $86 \%$ & .46 \\
\hline Systolic toe pressure & 30 & $\mathrm{~mm} \mathrm{Hg}$ & $85 \%$ & $60 \%$ & .67 \\
\hline Cap, density (sitting) & 25 & $\mathrm{~mm}^{-2}$ & $59 \%$ & $74 \%$ & .19 \\
\hline Cap. density (supine) & 42 & $\mathrm{~mm}^{-2}$ & $65 \%$ & $77 \%$ & .11 \\
\hline Peak RBCV (sitting) & 50 & $\mu \mathrm{m} / \mathrm{s}$ & $76 \%$ & $59 \%$ & .24 \\
\hline Peak RBCV (supine) & 120 & $\mu \mathrm{m} / \mathrm{s}$ & $78 \%$ & $80 \%$ & .54 \\
\hline RestpO $\mathrm{O}_{2}\left(44^{\circ} \mathrm{C}\right.$, sitting $)$ & $40^{1}$ & $\mathrm{~mm} \mathrm{Hg}$ & $79 \%$ & $83 \%$ & .47 \\
\hline RestpO $_{2}\left(44^{\circ} \mathrm{C}\right.$, supine $)$ & 301 & $\mathrm{~mm} \mathrm{Hg}$ & $91 \%$ & $88 \%$ & .70 \\
\hline $\mathrm{T}_{50} \% \mathrm{pO}_{2}\left(44^{\circ} \mathrm{C}\right.$, sitting $)$ & 70 & $\mathrm{~s}$ & $74 \%$ & $71 \%$ & .56 \\
\hline $\mathrm{T} 50 \% \mathrm{pO}_{2}\left(44^{\circ} \mathrm{C}\right.$, supine $)$ & 170 & $s$ & $75 \%$ & $44 \%$ & .32 \\
\hline T50\% Flux (sitting) & 30 & $\mathrm{~s}$ & $81 \%$ & $60 \%$ & .38 \\
\hline T50\%flux (supine) & 70 & $s$ & $83 \%$ & $57 \%$ & .33 \\
\hline $\begin{array}{l}\text { Hyperaemic flux } \\
\text { increase (sitting) }\end{array}$ & 0.05 & V & $78 \%$ & $74 \%$ & .47 \\
\hline $\begin{array}{l}\text { Hyperaemic flux } \\
\text { increase (supine) }\end{array}$ & 0.03 & $\mathrm{~V}$ & $74 \%$ & $73 \%$ & .57 \\
\hline Supine/sitting flux ratio & 0.2 & & $79 \%$ & $76 \%$ & .53 \\
\hline
\end{tabular}

\section{Microcirculatory techniques combined}

The merit of combining the best discriminative parameters of each microcirculatory technique used is shown in table 7.7. When measurements 
of capillary Peakv, RestpO $\mathrm{O}_{2}$ at $44{ }^{\circ} \mathrm{C}$ and the T50\% flux were combined, $90 \%$ of the patients in this study could be correctly objectified as having clinically severe ischaemia. A major part of the classifying properties of the combination of microcirculatory techniques could be ascribed to transcutaneous oximetry.

Table 7.7 Results of discriminant analysis to identify the best discriminatioe combination of macrocirculatory and microcirculatory parameters

\begin{tabular}{|c|c|c|c|c|}
\hline TEAHNIOUES & PRRAMTLRS & W & $\begin{array}{l}\text { a posteritgr } \\
\text { Fontane }\end{array}$ & 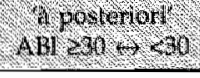 \\
\hline Clinical & Fontaine stage & 130 & & $72.3 \%$ \\
\hline Doppler & $\mathrm{ABI}$ & 130 & $67.9 \%$ & \\
\hline Plethysmography & Toe pressure & 117 & $78.6 \%$ & $75,2 \%$ \\
\hline Doppler + plethysmography & $A B I+$ Toe pressure & 117 & $77.8 \%$ & \\
\hline Capillary microscopy & $\begin{array}{ll}\text { Capillary density } & \text { (sitting) } \\
+ \text { Peak RBCV } & \text { (supine) }\end{array}$ & 78 & $62.8 \%$ & $79.5 \%$ \\
\hline Laser Doppler fluxmetry & $\begin{array}{l}\text { (sitting) } \\
\text { (supine) }\end{array}$ & 115 & $81.2 \%$ & 79.70 \\
\hline Transcoutaneous oximetry & $\begin{array}{ll}\text { Rest } \mathrm{pO}_{2} & \left(44^{\circ} \mathrm{C} \text {, supine }\right) \\
\text { +Rest } \mathrm{pO}_{2} & \left(44^{\circ} \mathrm{C} \text {, sitting }\right)\end{array}$ & 91 & $86.8 \%$ & $90.1 \%$ \\
\hline $\begin{array}{l}\text { Capillary microscopy }+ \\
\text { Transcutaneous oximetry }\end{array}$ & $\begin{array}{lr}\text { Peak RBCV } & \text { (supine) } \\
& + \text { Rest } \mathrm{PO}_{2} \quad\left(44^{\circ} \mathrm{C} \text {, supine) }\right.\end{array}$ & 84 & $88.1 \%$ & $92.9 \%$ \\
\hline $\begin{array}{l}\text { Capillary microscopy + } \\
\text { Transicutaneous oximetry + } \\
\text { Laser Doppler fluxmetry }\end{array}$ & 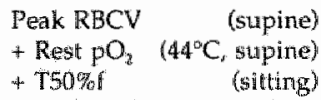 & 73 & $89.6 \%$ & $93.2 \%$ \\
\hline
\end{tabular}

For each investigatory technique or combination of techniques the best discriminating parameter combinations, the number of patients in that particular analysis, and the percentage of correctly "a posteriori" classified patients, using Fontaine stage or $\mathrm{ABI}$ as grouping variable.

$\mathrm{ABI}=$ Ankle-to-brachial systolic pressure index

$\mathrm{RBCV}=$ Red blood cell velocity

HIF = Hyperaemic increase in flux (Peak flux minus Rest flux value)

$\mathrm{T} 50 \% \mathrm{f}=$ Time to reach $50 \%$ of Rest flux during reactive hyperaemia 


\subsection{DI5CUSSION}

This study shows that capillary microscopy, transcutaneous oximetry and laser Doppler fluxmetry are useful techniques to distinguish different stages of lower limb ischaemia. The latter technique could even differentiate between mildly diseased and asymptomatic subjects. Combination of these techniques, using capillary peak $\mathrm{RBCV}$ during reactive hyperaemia, when the patient is recumbent, resting $\mathrm{TcpO}_{2}$ at $44^{\circ} \mathrm{C}$, assessed in the supine position, and the Time to reach $50 \%$ of resting laser Doppler flux while sitting, resulted in a high discernment $(90 \%)$ of clinically severe ischaemia. Transcutaneous oximetry performed alone appeared to have a higher diagnostic accuracy in the objectivation of severe ischaemia than investigation of the macrocirculation (predictive values $87 \%$ and $78 \%$, respectively). The presence of some patients suffering from non-insulin dependent diabetes mellitus did not disturb the possibility to differentiate the various patient groups.

Capillary microscopy did not show any significant differences between the various groups when performed with the patient in the sitting position. Red blood cell perfusion was low in all patient groups. In the moderately and mildly diseased patients and asymptomatic subjects, this low perfusion appears to be caused by the intact postural vasoconstriction mechanisms ${ }^{179}$, and in the severely diseased patients this is obviously due to the critical reduction in arterial perfusion pressure, despite a disturbed postural vasoconstriction. Therefore, this technique should be used whith the patient in the supine position, to avoid posturally induced vasoconstrictive responses. Moreover, the elimination of orthostatic blood pressure, and hence, transmural pressure, will facilitate the discrimination between the severely and moderately diseased patients, as capillary recruitment occurs upon dependency ${ }^{179}$. Apart from the measurement of morphological parameters, red blood cell velocity parameters, particularly during reactive hyperaemia, can be used to facilitate discrimination between the different patient groups. For this purpose, the measurement of more than one capillary is advocated to account for the variation in perfusion between different capillaries. Furthermore, measurement variability is reduced by inducing reactive hyperaemia. When performed in this manner, capillary microscopy appears to be a good method to assess nutritive skin perfusion and its reactivity, 
especially in critical lower limb ischaema ${ }^{100}$. However, this technique seems to have a limited capacity to discern $F$ (ontaine) 1-2 and 3-4 patients. This can be attributed to the wide $\mathrm{ABI}$ range found in F 3-4 patients. Moreover, explicit disturbances in capillary perfusion do not occur until ABI is severely reduced ${ }^{179}$. Nevertheless, in the latter situation, capillary microscopy can properly distinguish severely from less severely diseased patients (see table 7.7). Hardly any significant differences could be observed between mildly diseased and asymptomatic subjects with the use of intravital microscopic parameters. In the mildly diseased, only a tendency towards a lower red blood cell velocity at rest, a less pronounced reactive hyperaemia and a larger capillary diameter, as compared to the asymptomatic subjects. Studies in our laboratory have shown more evident differences between mildly ischaemic and real healthy subjects.

Transcutaneous oximetry, measured either at an electrode temperature of $37^{\circ} \mathrm{C}$ or $44^{\circ} \mathrm{C}$, could not distinguish mildly diseased from asymptomatic subjects. This may be explained by the presumption that in these groups, even at $37^{\circ} \mathrm{C}$, skin oxygenation is mainly dependent on arteriolar oxygenation (which is likely to be similar in these groups) and not on skin blood flow. However, severely, moderately and mildly ischaemic patients could indeed be distinguished. This is in accordance with the findings of other investigators ${ }^{19,122}$. The induction of reactive hyperaemia enhanced the method's discriminative capacity, especially by assessing the time to peak $\mathrm{pO}_{2}\left(\mathrm{TtppO} \mathrm{O}_{2}\right)$ and the time to reach half of the $\mathrm{pO}_{2}$ at rest $\left(\mathrm{T} 50 \% \mathrm{pO}_{2}\right)$, which is in agreement with previous observations ${ }^{43,61,109}$. Measuring at $44^{\circ} \mathrm{C}$ increases discrimination, probably due to reduction of test variability. Thus, transcutaneous oximetry appeared to be a better method than intravital capillary microscopy to classify patients suffering from mild, moderate and severe limb ischaemia. Moreover, this technique is not confined to one measurement site and, thus, not thwarted when ulcers are present in the area of observation. Performing the measurements while the patient is recumbent seems preferable, judged from the higher predictive values in this position. Combining capillary microscopy with transcutaneous oximetry augments discriminating power. The diagnostic value of these two methods may further be enhanced by using a combined ellectrode, by which both techniques can be applied to the same skin areas ${ }^{60,91}$.

Laser Doppler fluxmetry could distinguish all patient groups investigated, when measurements were performed both at rest and during reac- 
tive hyperaemia. Earlier studies seem to point in the same direction ${ }^{6,111,146 .}$ Local heating of the skin appeared to be superfluous for this purpose. Other investigators ${ }^{31}$ found a higher reproducibility and more obvious differences between the patient groups when the skin was heated to $37^{\circ} \mathrm{C}$, but their measurements were performed on the dorsum of the foot. Here, arteriovenous (A.V) anastomoses are scanty, which may have reduced inter-group differences in ischaemia, because with progression of the disease AV flow decreases before nutritive flow ${ }^{18 !}$. This is also an important factor explaining the differences in discriminative power between capillary microscopy and laser Doppler fluxmetry. When patients with severe ischaemia are investigated, we recommend applying laser Doppler fluxmetry while the patient is sitting, because this technique appeared less sensitive to detect low-flow states, which occurs particularly in the supine position. Investigation in both positions, however, can offer useful additive information about the integrity of posturally induced microvascular constriction by calculating the vasoconstriction index. Laser Doppler fluxmetry is a technique that can detect disturbed vasoconstriction at an early stage of ischaemic disease ${ }^{5,179,181}$, probably because under physiological conditions, skin blood flow is usually in excess of the actual metabolic needs ${ }^{74}$ and mainly influenced by the demands of thermoregulation. Hence, it is plausible that in case of a diminished arterial inflow, a decrease in laser Doppler flux will occur prior to a disturbance in capillary nutritional blood flow. In this study, laser Doppler fluxmetry was found to be the best discriminating method to distinguish between all the stages of lower limb ischaemia, despite its claimed variability and arbitrarity, which is less when parameters other than the flux value itself are used. Its accuracy might even be enhanced by using a diode laser Doppler instrument or a laser Doppler multiprobe, thereby enlarging the skin surface area available for measurements ${ }^{139}$.

To date, continuous wave Doppler analysis and photoplethysmography are the most useful noninvasive tests in the screening of patients to detect larger vessel disease. However, they show considerable overlap between the different clinical stages of vascular disease, showing predictive values generally lower than those of the microcirculatory techniques used in this study. Furthermore, they do not apprise us about skin perfusion. In contrast, the combination of microcirculatory techniques gives information additive to these macrocirculatory measurements as to the viability of the skin in severe ischaemia and the integrity of postural vasoconstriction in mild ischaemia ${ }^{182}$. 
It is still to be proven what the merits of this extra information will be for the management and outcome of these patients. Nonetheless, these techniques already offer the opportunity to study pathophysiological mechanisms occurring in lower limb ischaemia ${ }^{29}{ }^{181}$ and the ability to objectify the efficacy of therapies with the aim of improving peripheral (skin) blood circulation $^{39,97}$. In addition, they are an adjuvans in the classification of the severity of vascular disease, since microcirculatory disturbances in critical limb ischaemia can exist without the presence of severe disturbances in macrocirculatory parameters ${ }^{100}$. In these cases, vascular reconstructive surgery is indicated as well.

We conclude that capillary microscopy appears to be a valuable tool to assess whether skin nutrition is in jeopardy in patients suffering from severe ischaemia. Transcutaneous oximetry is found to be effective as a sensitive and fairly easy method to objectivate lower limb ischaemia. Laser Doppler fluxmetry is indicated for the detection of early disturbances in microcirculatory perfusion and postural vasoconstriction, especially in areas with abundant $\mathrm{AV}$-anastomoses. Finally, the combination of these non-invasive techniques, as described in this study, provides useful information as to the skin microcirculation and reactivity in addition to the macrocirculatory parameters commonly used in patients with and without maturity onset diabetes. 



\section{Chapter 8}

\section{General discussion and conclusions}

The manifestation of peripheral arterial occlusive disease is commonly classified according to the clinical stages of Fontaine. To objectify the presence and severity of lower limb ischaemia in patients with complaints suggestive of ischaemic disease, investigation of the major arteries of the leg is at present a routine diagnostic procedure. However, macrocirculatory investigation cannot give information as to skin microcirculatory perfusion, which is at risk in severe ischaemia. Moreover, these diagnostic tools cannot clarify pathophysiological phenomena as seen after postural changes, e.g., the relief of ischaemic pain by leg dependency, and the importance of postural vasoconstriction in the prevention of post-operative oedema. Furthermore, the Fontaine classification and macrocirculatory investigative techniques are not always accurate in the assessment of the severity of the vascular disease ${ }^{86}, 128,158$. Patients suffering from intermittent claudication (Fontaine stage 2) may have a severely reduced ankle blood pressure, whilst patients with rest pain or ulceration (Fontaine stage 3 or 4 ) can show a but mildly lowered ankle pressure. The latter can, at least partly, be explained by the fact that ischaemic patients, in particular those suffering from concomitant diabetes mellitus, frequently have arterial vessel wall sclerosis which makes these arteries are difficult to compress while measuring the ankle pressure ${ }^{42,67}$. This results in an erroneously high ankle-to-brachial pressure index $(\mathrm{ABI})$. Because of these limitations, investigation of the microcirculation may provide useful additional information in patients suffering from lower limb ischaemia.

When a person changes from the supine to the sitting position, his blood pressure at the level of the foot rises due to an increase in orthostatic pressure. Yet, this cannot explain the increase in skin perfusion, as occasionally observed in critically ischaemic patients when they lower their leg. This is because the higher arterial pressure is accompanied by a parallel rise in 
venous pressure ${ }^{17,80}$, leaving the perfusion pressure at the level of the skin microvessels virtually unaltered ${ }^{116}$.

In this thesis (chapter 3), it was demonstrated with capillary microscopy, measuring directly and exclusively nutritional skin perfusion, that capillary perfusion is maintained until $A B I$ becomes lower than $20 \%$. In critically ischaemic patients with an $A B I$ below this value, the reduced arterial perfusion pressure, as measured in the supine position, leads to a decrease in capillary perfusion. Also, reactive hyperaemia is absent, illustrating the critically ischaemic state of the microcirculation. Furthermore, in the supine position the number of skin capillaries perfused is significantly reduced, thereby causing an extra reduction in skin nutritional transport capacity. When asymptomatic or mildly diseased subjects change to the sitting position, capillary perfusion decreases as the result of pre-capillary vasoconstriction. In contrast, capillary density rises, apparently due to the increase in orthostatic blood pressure and thus, transmural pressure. Patients with an $A B I$ of less than $20 \%$ showed a tendency to an increased capillary perfusion on dependency (see figure 8.1), indicating disturbed microvascular constriction mechanisms, and a significant increase in capillary density. Both findings could explain the relief of pain upon lowering of the leg. Yet, in patients experiencing relief of ischaemic pain on dependency, a significant increase in capillary density was observed, but no rise in red blood cell velocity. This implies that upon leg dependency capillary recruitment, and hence, an improved surface area for transcapillary fluid exchange, rather than enhanced red blood cell velocity is responsible for the pain relief in these patients. Whether the transmural pressure increase is indeed responsible for this recruitment may be further elucidated when data from intracapillary pressure measurements in these patients become available.

Microvascular reactivity in deeper layers of skin microcirculation, comprising arteriolo-venular (AV) shunts and the thermoregulatory part of the microcirculation (chapter 4 and 5), as measured by means of laser Doppler fluxmetry, becomes disturbed at an earlier stage of ischaemic disease than does skin nutritional circulation (see figure 8.1). This difference in reactivity highlights the very different function of the various vascular systems of the skin. This also suggests that the integrity of nutritional perfusion has a higher priority than that of thermoregulatory flow and needs a more effec- 
tive vasoconstrictive reactivity. Disturbance of this feature in case of severe ischaemia makes the skin prone to develop ulceration and necrosis.

Figure 8.1 Median vasoconstriction indices in various stages of lower limb ischaemia measured at different local skin temperatures, using three microcirculatory investigative techniques

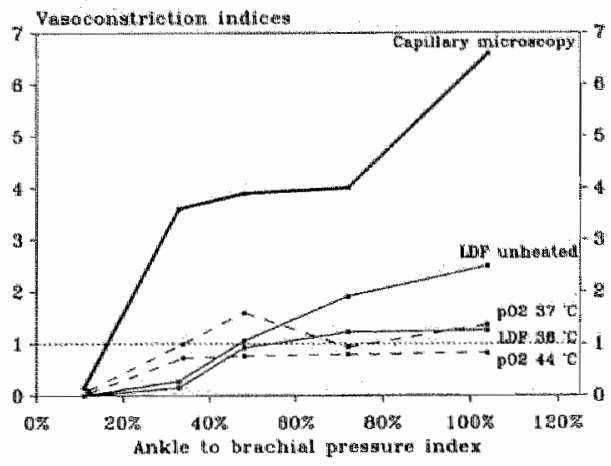

The low thermoregulatory perfusion during ischaemia while supine; in spite of a disturbed vasoconstriction response at that level seems contradictory. However, ischaemia leads to dilatation of the smooth muscle cells in the arterioles that supply both capillaries and AV anastomoses. The larger number of capillaries causes a greater total capillary cross-sectional area and a lower vascular resistance in these capillaries than in the thermoregulatory vessels. This probably explains the preferential perfusion of the capillary bed, in spite of a still active pre-capillary vasoconstriction.

The ABI as a macrocirculatory parameter could only accurately predict the effectiveness of postural microvascular constriction responses when its value was higher than $60 \%$. Thus, when vascular disease progresses to $\mathrm{ABI}$ 's below this value, microcirculatory investigation is needed to perceive the initial disturbances in microvascular reactivity. For this purpose, laser Doppler fluxmetry appeared to be the most suitable method.

Some investigators claim that transcutaneous oximetry measures only capillary oxygenation ${ }^{32}$. In our studies, oximetry was performed in an area where $\mathrm{AV}$ anastomoses are sparse ${ }^{69}$. Nevertheless, the results concerning the integrity of postural vasoconstriction, as measured at $37^{\circ} \mathrm{C}$, were quite alike those obtained by laser Doppler fluxmetry at $36^{\circ} \mathrm{C}$, which was performed in 
an area with numerous $\mathrm{AV}$ anastomoses. In addition, the loss of vasoconstrictive capacity, as observed with oximetry measurements, occurred at an $A B I$ that was in between the $A B I$ 's at which vasoconstriction disturbances occurred at the capillary and thermoregulatory level (see figure 8.1). This intimates that oximetry measures more than mere capillary oxygenation. Subsequently, a disturbed vasoconstriction response, as measured by means of transcutaneous oximetry, indicates that disturbances in skin microcirculation are more pronounced than when laser Doppler fluxmetry shows abnormalities, but less than when nutritional perfusion is compromised. The recently developed triple-probe, incorporating a laser Doppler fibre tip and a transparent transcutaneous oxygen electrode, allowing microscopic investigation of capillaries in the same area of the skin, may further clarify this subject ${ }^{60}$. Although a disturbed posturally induced vasoconstriction indicates that the skin is in danger to become critically ischaemic, the prognostic clinical repercussion of this indication remains to be elucidated.

The change in posture as applied in these studies included both the lowering of the legs and the raising of the head and trunk. This elicits not only local, but also central sympathetic vasoconstrictive responses, which could have obscured the separation of these responses. However, the findings that local heating of the skin can suppress postural vasoconstriction, as seen in severely ischaemic patients, and that microvascular reactivity is disturbed only in one leg in case of unilateral ischaemic disease, advocate the predominantly local origin of this reactivity (chapter 4 and 5). Moreover, patients experiencing relief of pain upon dependency achieve this relief by either lowering the ischaemic leg or assuming the upright position, indicating the minor contribution of central responses.

Non-insulin-dependent diabetic patients did not show a clearly different microvascular reactivity as compared to non-diabetics. However, there is evidence that diabetes does induce disturbances in microcirculatory blood flow, both at the nutritive and the thermoregulatory level ${ }^{55}$. A plausible explanation for this paradox is that, in patients who suffer from both atherosclerosis and diabetes mellitus, the atherosclerosis has a more dominating influence on the abnormalities in microvascular reactivity than diabetes per se. Ergo, the presence of non-insulin-dependent diabetes appears not to interfere with the assessment of the severity of ischaemic disease and disturbances in microvascular reactivity by means of microcirculatory investigation. 
The microvascular constriction mechanisms upon changes in posture are considered to be a defense mechanism against oedema formation. An adequate transcapillary transport is warranted only when capillary pressure is maintained at values of around $20 \mathrm{~mm} \mathrm{Hg}$. When capillary blood pressure is higher while microvascular vasoconstriction is disrupted, the development of oedema can be anticipated. This is observed as a frequent complication after vascular reconstructive surgery (chapter 6). Loss of arteriolar constriction was found to correlate with the occurrence of post-operative oedema. Although important other factors influence post-operative oedema formation, the restoration of postural vasoconstriction appears to be relevant to avoid this oedema. Patients with a low pre-operative ankle pressure, but a still active vasoconstriction response, showed disturbed vasoconstriction directly after reinstatement of the arterial pressure. $\mathrm{Ob}$ viously, vasoconstrictive capacity is proportional to the arterial pressure to be counteracted. The reduced blood pressure apparently results in smooth muscle cell atrophy in the arteriolar wall. This phenomenon was found to be reversible after revascularisation.

Finally, the profit of microcirculatory techniques in the assessment of the severity of peripheral arterial occlusive disease was demonstrated in chapter 7. Capillary microscopy appeared to be a useful and unique method to assess skin nutritional perfusion, particularly in patients with the most severe stages of lower limb ischaemia, since the perfusion at this level of skin microcirculation is maintained until arterial inflow is seriously reduced (see figure 8.1). A prerequisite for optimum discrimination between different stages of leg ischaemia is to investigate the patient in the supine position. In this situation, differences in capillary density are more overt due to the absence of orthostatic blood pressure, which would cause capillary recruitment. Moreover, in this position postural vasoconstriction is not activated and thus, perfusion differences are manifested. Because of the inter-capillary variability in perfusion at rest, provocation of reactive hyperaemia is essential. Transcutaneous oximetry proved to be the most discriminative method among the microcirculatory techniques used here to assess the severity of lower limb ischaemia, as compared with macrocirculatory techniques. Local heating of the skin to $44^{\circ} \mathrm{C}$ was preferable as it reduces measurement variability. On the other hand, it prohibits the assessment of postural microvascular reactivity. The merits of Laser Doppler fluxmetry were the assessment of total skin perfusion, through which the 
different stages of ischaemia, particularly the earlier stages, could be differentiated, and secondly, the detection of initial disturbances in postural vasoconstriction. For both purposes, local heating of the skin proved superfluous. Because the flux measured is but a relative quantity with a limited reproducibility, parameters derived during reactive hyperaemia were preferred.

Combining the three non-invasive microcirculatory techniques proved to be of additional value over macrocirculatory techniques with respect to the accuracy to diagnose ischaemic disease. In this study, the most useful parameters to combine appeared to be the tcpO $\mathrm{O}_{2}$ at rest at $44^{\circ} \mathrm{C}$ and the capillary peak red blood cell velocity, both measured in the supine position, and the time to reach $50 \%$ of the laser Doppler rest flux value during reactive hyperaemia, as obtained in the sitting position. Thus, $90 \%$ of the patients with clinically severe ischaemia could be classified correctly, as opposed to $78 \%$ when using only macrocirculatory techniques. Therefore, this combination constitutes a valuable additive diagnostic tool in a vascular laboratory and is promising as an aid in the management of patients with lower \imb ischaemia.

\subsection{Conclusions}

The findings in this thesis allow the following condusions:

1) Capillary recruitment in the skin of patients with lower limb ischaemia appears to be a passive phenomenon, occurring when orthostatic pressure is elevated. Particularly in patients with critical peripheral ischaemia, this phenomenon is of major importance to improve effectiveness of skin perfusion and thus, to alleviate ischaemic pain.

2) Skin microcirculation in these patients is preserved until the reduction in macrocirculatory perfusion reaches a critical limit. Below this point, microvascular reactivity becomes progressively disturbed. The skin attempts to preserve nutritional perfusion, apparently at the cost of local thermoregulatory blood flow. 
3) Microvascular reactivity to postural changes is an important feature in the regulation of skin perfusion and the prevention of oedema formation, and is predominantly of local origin.

4) Due to the gradual occurrence of disturbances in the various functional domains of skin microcirculation, laser Doppler fluxmetry, which measures total skin perfusion, is the first method to detect microcirculatory derailments, followed by transcutaneous oximetry. Capillary microscopy is an asset to judge skin viability in patients with more severe stages of lower limb ischaemia.

5) The value of a combination of microcirculatory techniques in lower limb ischaemia, in addition to macrocirculatory parameters, consists of a more accurate assessment of the severity of lower limb ischaemia and a more certain diagnosis of a threatened microcirculation. Transcutaneous oximetry appears to be the best advisable stand-alone technique to assess disturbances in skin microcirculation. 



\section{Chapter 9}

\section{Summary}

Patients suffering from chronic lower limb ischaemia due to atherosclerosis show a disturbed blood circulation in the larger blood vessels (i.e. the macrocirculation) of the leg. Subsequently, this also leads to disturbances of the blood flow in the smallest skin vessels, also called skin microcirculation. The importance of microcirculatory derailments is illustrated by the occurrence of ulceration and tissue loss in patients with severe ischaemia.

Clinical techniques routinely performed to investigate the peripheral circulation are resticted to those analyzing the macrocirculation. Techniques investigating skin microcirculation such as those used in this thesis, have several advantages:

1) they non-invasively yield information about the very tissue at risk in severe ischaemia

2) these methods can offer additional information about the peripheral circulation when macrocirculatory measurements, e.g. of the systolic ankle blood pressure, become unreliable in cases where the arteries have become rigid and incompressible due to the sclerotic disease

3) these techniques may contribute to the explanation of pathophysiological mechanisms, such as the disturbances in microvascular reactivity to changes in posture, which occur in lower limb ischaemia. An example of this disturbance is the relief of ischaemic pain experienced by patients when they lower their leg, whereas in healthy persons blood flow in the legs is restricted on dependency due to microvascular constriction responses.

For these reasons, skin microcirculation was investigated in patients with different stages of lower limb ischaemia to assess microcirculatory reactivity to changes in posture and to study the additive value of the three microcirculatory techniques used in the assessment of the severity of lower limb ischaemia. 
Chapter 1 is an introduction to this thesis and offers a concise description of the anatomy and physiology of skin microcirculation and the measuring techniques applied. These techniques are capillary microscopy, visualizing skin capillaries and their erythrocyte perfusion in the nailfold of the great toe, transcutaneous oximetry, measuring the oxygenation of the skin, and laser Doppler fluxmetry, which measures total, mainly thermoregulatory skin perfusion. The aims of this thesis were:

1) the assessment of the microcirculatory disturbances in different stages of chronic lower limb ischaemia

2) the investigation of pathophysiological mechanisms in skin microvascular reactivity, in particular the microvascular response upon a change in posture, and the role of local and central mechanisms

3) the assessment of the putative merits of microcirculatory investigation in addition to macrocirculatory diagnostic techniques to discriminate different degrees of severity in patients with chronic leg ischaemia.

In chapter 2 the techniques and methods used in this thesis to investigate the macro and microcirculation are described. Brachial, ankle and toe systolic blood pressures were assessed as a measure to quantify the severity of vascular disease in the different patient groups beside the clinical stages according to Fontaine. Three non-invasive techniques were used to investigate the nutritive (capillary microscopy) and total skin microcirculation (transcutaneous oximetry and laser Doppler fluxmetry). The investigatory protocol and parameters used are explained. The validation and reproducibility of these techniques are accounted for. Investigations were performed on patients in the supine and the sitting position and transcutaneous oximetry and laser Doppler fluxmetry were performed also at two different local skin temperatures, both in order to test the effectiveness of posturally induced microvascular constriction mechanisms. Measurements were done at rest and during reactive hyperaemia, after the release of a one-minute arterial occlusion, to be informed about the reserve capacity of skin microcirculation. Finally, the statistical analyses used throughout this thesis are described. 
Chapter 3 deals with the microcirculatory changes in capillary morphology and dynamics in different stages of lower limb ischaemia, investigated using capillary microscopy. The findings show that capillary nutritive perfusion appears to be preserved. Postural vasoconstriction at this level seems to be present, except in patients with limb threatening ischaemia (ankle-to-brachial pressure index $(\mathrm{ABI})<20 \%$ ). They show disturbed arteriolar vasoconstriction, enhanced capillary recruitment and increased nutritive red blood cell velocity. The relief of ischaemic pain upon dependency in these patients may be explained by an increase in red blood cell-perfused capillary density, thereby enlarging the surface area for exchange, rather than an increase in capillary perfusion.

Chapter 4 is a description of the investigation of posturally induced microvascular constriction in patients with different stages of ischaemic disease, as measured by means of laser Doppler fluxmetry and transcutaneous oximetry. Postural vasoconstriction was present in all patients with an $A B I$ of greater than $55 \%$. Below this value, the integrity of microvascular reactivity could only be assessed when the patients were investigated using microcirculatory techniques in both the sitting and the supine position. Microvascular constriction appeared disturbed in all patients with an $\mathrm{ABI}$ below $30 \%$. Local heating of the skin could overrule postural vasoconstrictive responses, advocating the local origin of these mechanisms.

Chapter 5 deals with the investigation of the skin microvascular reactivity in patients with unilateral severe leg ischaemia. The purpose of this study was firstly, to assess whether local or central mechanisms prevail in postural vasoconstriction and secondly, to define the differences in microvascular reactivity between the nutritional and thermoregulatory level of skin microcirculation. The finding that the constriction response differed between the asymptomatic and diseased leg of the same patients was evidence for the local origin of this response. The postural regulation of thermoregulatory skin blood flow was found to be disturbed, but still (partially) intact at the nutritive level. Putative mechanisms for the observed differences are discussed. 
Chapter 6 is a study of the effect of arterial revascularisation on postural microvascular reactivity in patients with severe chronic ischaemia. After surgery, microcirculatory perfusion and postural reactivity was restored after approximately eight days. This was not the case in patients who developed oedema post-operatively. These observations suggest structural regeneration of the atrofied arteriolar vessel wall, which takes place only when microcirculatory perfusion has improved. Furthermore, the reinstatement of postural vasoconstriction seems pertinent to the prevention of postoperative oedema formation.

In chapter 7 the usefulness of the three microcirculatory investigative techniques is described as to the discrimination between the different cinical stages of lower limb ischaemia. The best discriminating parameters of transcutaneous oximetry yielded a predictive value of 87 per cent to correctly classify patients with severe ischaemia. Capillary microscopy discerned severely ischaemic patients with and without a severely compromised nutritional perfusion (predictive value $63 \%$ ). Laser Doppler fluxmetry could distinguish every patient group investigated (predictive value $81 \%$ ), particularly mildly diseased and asymptomatic subjects. When the best discriminating parameters of all three techniques were combined, $90 \%$ of the patients could be classified correctly, as opposed to $78 \%$ when only ankle and toe systolic blood pressures were assessed.

In chapter 8 the most prominent findings of this thesis are discussed. It is concluded that:

1) capillary recruitment appears to be an essential phenomenon to improve the effectiveness of skin microvascular perfusion and thus, to alleviate the ischaemic pain experienced by patients when they lower their leg

2) the capillary, nutritional perfusion is preserved until a certain limit is reached. When arterial pressure becomes reduced, it reveives priority above the thermoregulatory perfusion

3) postural microvascular reactivity is predominantly of local origin. It is an important feature in the regulation of skin perfusion and prevention of oedema formation 
4) laser Doppler fluxmetry is the first method to detect disturbances in skin microcirculation when arterial pressure decreases, followed by transcutaneous oximetry. Finally, capillary microscopy is useful to assess the condition of nutritional skin perfusion

5) transcutaneous oximetry appears to be the best stand-alone technique to assess disturbances in skin microcirculation. Combining microcirculatory techniques enhances the accuracy to assess the severity of lower limb ischaemia in addition to macrocirculatory techniques. 



\section{Chapter 10}

\section{Samenvatting}

Patiënten die lijden aan ischemie van de benen ten gevolge van atherosclerose hebben een stoornis in de bloedtoevoer via de grote bloedvaten (de zogenaamde macrocirculatie) naar of in de benen. Dit leidt uiteindelijk tot een verstoorde bloedcirculatie in de kleinste bloedvaten, de microcirculatie. Het ontstaan van slecht genezende wonden (ulceraties) en weefselversterf (necrose) bij patiënten met ernstige ischemie illustreert het belang van stoormissen in de microcirculatie van de huid. Technieken die routinematig in de kliniek gebruikt worden om de perifere circulatie te onderzoeken, meten slechts de macrocirculatie. Het gebruik van de in dit proefschrift beschreven technieken die de microcirculatie meten heeft de volgende voordelen:

1) zij verschaffen op niet-invasieve wijze informatie over de bloedvoorziening van de huid, die juist bij patiënten met ernstige ischemie bedreigd is

2) deze technieken kunnen aanvullende informatie geven over de perifere circulatie wanneer macrocirculatoire metingen, bijvoorbeeld van de enkel- of teen-bloeddruk, onbetrouwbaar zijn. Dit komt voor wanneer de arteriën verkalkt zijn als gevolg van de atherosclerose

3) deze technieken kunnen bijdragen tot het verklaren van patho-fysiologische mechanismen, zoals stoornissen in microvasculaire reactiviteit bij houdingsveranderingen die optreden bij patiënten met ernstige ischemie.

Dehalve werd de microcirculatie van de huid onderzocht bij patiënten lijdende aan diverse stadia van perifere ischemie om met name de microvasculaire reactiviteit bij houdingsveranderingen vast te stellen. Bovendien werd onderzocht wat de toegevoegde waarde van microcirculatoire technieken is bij het onderscheiden van de diverse graden van perifere ischemie. 
Hoofdstuk 1 is de inleiding van dit proefschrift, waarin kort de anatomie en fysiologie van de microcirculatie van de huid wordt beschreven, evenals de drie gebruikte onderzoektechnieken. Deze technieken zijn capillair-microscopie, waarmee de capillairen en hun doorbloeding gevisualizeerd kan worden in de nagelplooi van de grote teen, transcutane oxymetrie, die de oxygenatie van de huid meet, en laser Doppler fluxmetrie, waarmee de totale, met name thermoregulatoire, huiddoorbloeding gemeten kan worden. De doelstellingen van dit proefschrift waren:

1) het vastleggen van de stoornissen in de microcirculatie in de diverse stadia van perifere ischemie

2) het onderzoeken van de pathofysiologische mechanismen als onderdeel van de microvasculaire reactiviteit van de huid, in het bijzonder de microvasculaire reactie op houdingsveranderingen, en de rol van locale en centrale regulatiemechanismen in deze reactie

3) het vaststellen van de mogelijke toegevoegde waarde van microcirculatoir onderzoek naast macrocirculatoire onderzoektechnieken ter onderscheiding van de diverse stadia van chronische ischemie van de benen.

In hoofdstuk 2 worden de technieken en methoden beschreven waarmee de micro- en macrocirculatie is onderzocht. Arm-, enkel- en teen-bloeddrukken werden gebruikt als maat voor de ernst van het vaatlijden in de diverse patiëntengroepen, naast de indeling volgens Fontaine, gebaseerd op klinische verschijnselen. Drie niet-invasieve onderzoektechnieken werden toegepast om zowel de voedende, nutritieve (capillaire-microscopie) als de totale, vooral thermoregulatoire, microcirculatie (transcutane oxymetrie en laser Doppler fluxmetrie) te kunnen objectiveren. Het protocol en de gemeten parameters van het onderzoek worden uitgelegd. De validiteit en reproduceerbaarheid van deze technieken worden besproken. Het onderzoek werd uitgevoerd bij patiënten in zowel zittende als liggende houding. De twee laatstgenoemde technieken werden tevens toegepast bij twee verschillende locale huidtemperaturen. Dit alles met het doel om de effectiviteit van de houdingsafhankelijke vasoconstrictie-mechanismen te testen. De metingen werden bovendien gedaan in rust en tijdens reactieve hyperemie, na een periode van arteriële occlusie. Zodoende kon een indruk verkregen worden omtrent de reserve-capaciteit van de microcirculatie in de huid. 
Tenslotte zijn de statistische methoden toegelicht die in dit proefschift zijn gebruikt.

Hoofdstuk 3 is een beschrijving van de veranderingen in capillaire morfologie en dynamiek in de diverse stadia van perifere ischemie, onderzocht met behulp van capillair-microscopie. De resultaten laten zien dat de nutritieve doorbloeding zo lang mogelijk wordt gespaard. Houdingsafhankelijke vasoconstrictie op dit niveau van de microcirculatie lijkt actief te zijn, behalve in patiënten met kritieke ischemie (enkel-arm index (EAI) < $20 \%$ ). Deze patiënten hebben een gestoorde vasoconstrictie en in zittende houding een toegenomen recrutering van capillairen en een in mindere mate toegenomen capillaire erythrocytensnelheid. De verlichting van ischemische pijn die sommige patiënten ervaren wanneer zijn hun been laten afhangen lijkt verklaard te kunnen worden door de waargenomen toename van het aantal met erythrocyten doorbloede capillairen, waardoor het oppervlak toeneemt waarover uitwisseling kan plaatsvinden.

In hoofdstuk 4 wordt het onderzoek van de houdingsgeinduceerde vasoconstrictie beschreven bij patiënten in verschillende stadia van perifere ischemie, onderzocht met behulp van laser Doppler fluxmetrie en transcutane oxymetrie. Alle patiënten met een EAI hoger dan $55 \%$ vertoonden een intacte vasoconstrictie-respons. Beneden deze waarde kon de integriteit van deze microvasculaire reactiviteit alleen vastgesteld worden door middel van microcirculatie-onderzoek in zittende en liggende houding. De vasoconstrictie-reactie bleek gestoord bij alle patiënten met een EAI van kleiner dan 30 \%. Locale verwarming van de huid bleek een nog aanwezige vasoconstrictie-respons te kunnen onderdrukken. Dit pleit voor het woornamelijk locaal gereguleerd zijn van deze respons.

In hoofdstuk 5 wordt ingegaan op het onderzoek van de houdingsafhankelijke vasoconstrictie bij patiënten met éenzijdige perifere ischemie. Het doel van deze studie was om vast te stellen of locale, dan wel centrale mechanismen een hoofdrol spelen in de regulatie van de microvasculaire reactiviteit en ten tweede om de eventuele verschillen in reactiviteit vast te leggen tussen het nutritieve en thermoregulatoire deel van de microcirculatie in de huid. De constrictie-respons bleek duidelijk te verschillen tussen de asymptomatische en ischemische benen van dezelfde patiënten, wat het 
locaal bepaald zijn van deze reactiviteit ondersteunt. De houdingsafhankelijke regulatie van de thermoregulatoire huiddoorbloeding was gestoord, terwijl die van de nutritieve doorbloeding niet of slechts weinig was gestoord. Mogelijke mechanismen die deze verschillen kunnen verklaren worden besproken.

Hoofdstuk 6 presenteert de effecten van arteriële revascularisatie op de houdingsafhankelijke reactiviteit in de microcirculatie bij patiẻnten met ernstige, chronische ischemie aan de benen. Na operatieve arteriële reconstructie herstelde de microcirculatoire perfusie en vasoconstrictie zich na circa acht dagen. Dit trad niet op bij patiënten die post-operatief oedeem ontwikkelden. Deze bevindingen suggereren dat er een structurele regeneratie optreedt in de geatrofiëerde spierwand van de arteriolen, wat slechts plaatsvindt als de microcirculatie is verbeterd. Bovendien lijkt het herstel van de microvasculaire reactiviteit van belang bij het voorkómen van postoperatieve oedeemvorming.

Hoofdstuk 7 beschrijft het nut van de drie microcirculatoire onderzoektechnieken voor wat betreft het onderscheiden van de diverse klinische stadia van perifeer vaatlijden. De best discriminerende parameters van de transcutane zuurstofmeting resulteerden in een predictieve waarde van 87 $\%$, m.a.w. $87 \%$ van de patienten met ernstige ischemie konden op grond van dit onderzoek juist worden geclassificeerd. Capillair-microscopie bleek onderscheid te kunnen maken tussen ernstig ischemische patiënten mèt en zónder een kritiek bedreigde nutritieve huiddoorbloeding (predictieve waarde $63 \%$ ). Laser Doppler fluxmetrie had een goed onderscheidend vermogen (predictieve waarde $81 \%$ ) voor patiënten in elke ischemie-groep, met name licht-ischemische en asymptomatische personen. Wanneer de best discriminerende parameters van alle drie technieken werden gecombineerd, konden $91 \%$ van alle onderzochte patiënten juist worden geclassificeerd. Wanneer alleen enkel- en teendrukken werden gemeten werd slechts een predictieve waarde van $78 \%$ bereikt.

Hoofdstuk 8 bevat de discussie omtrent de belangrijkste bevindingen van dit proefschrift. De conclusies luiden: 
1) toename van het aantal met erythrocyten geperfundeerde capillairen blijkt een essentieel fenomeen ter verbetering van de effectiviteit van de microcirculatoire perfusie van de huid. Derhalve is het ook een belangrijke factor bij de verlichting van ischemische pijn die sommige patiënten ervaren door het laten afhangen van hun been

2) de capillaire, nutritieve perfusie wordt gespaard, totdat een zekere grens is bereikt. Als de arteriële druk afneemt, heeft dit vaatbed prioriteit boven het thermoregulatoire vaatbed

3) houdingsafhankelijke microvasculaire reactiviteit blijkt voornamelijk locaal gereguleerd. Deze reactiviteit is een belangrijk mechanisme bij de regulering van de huiddoorbloeding en de preventie van post-operatieve oedeemontwikkeling

4) bij afnemende arteriële druk is laser Doppler fluxmetrie de eerste methode die stoornissen kan aantonen in de microcirculatie van de huid, gevolgd door transcutane zuurstofmeting. Capillair-microscopie is tenslotte nuttig om de toestand van de nutritieve huidcirculatie vast te stellen, vooral bij kritieke ischemie

5) wanneer slechts één techniek wordt toegepast, blijkt transcutane oxymetrie de beste techniek te zijn om een gestoorde microcirculatie van de huid aan te tonen. Combinatie van de drie microcirculatoire technieken levert een grotere accuratesse op bij het classificeren van de ernst van het perifere vaatlijden dan wanneer zij afzonderlijk worden toegepast of wanneer alleen de bestaande macrocirculatoire technieken worden gebruikt. 



\section{References}

1. AbuRahma AF, Woodruff BA, Lucente FC.

Edema after femoro-popliteal bypass surgery: lymphatic and venous theories of causation. J Vasc Surg 1990: 11: 461-467.

2. Allen PIM, Goldman M.

Skin blood flow: a comparison of transcutaneous oximetry and laser Doppler flowmetry. Eur J Vasc Surg 1987: 1: 315-318.

3. Bayliss WM.

On the local reactions of the arterial wall to changes in internal pressure.

J Physiol (London) 1902: 28: 220-231.

4. Beckers RCY, Jörning PJG, Slaaf DW, Reneman RS, Jacobs MJHM.

Effect of Ketanserin on macrocirculatory and microcirculatory blood flow in patients with intermittent claudication. A prospective randomized study. Eur J Clin Pharmacol 1989: 37: 295-296.

5. Belcaro G, Nicholaides AN.

Microvascular evaluation of the effects of Nifedipine in vascular patients by laser Doppler flowmetry. Angiology 1989:40:689-694.

6. Belcaro G, Vasdekis S, Rulo A, Nicholaides AN.

Evaluation of skin blood flow and veno-arteriolar" response in patients with diabetes and peripheral vascular disease by laser Doppler flowmetry. Angiology 1989: 40: 953-957.

7. Bernardi L, Rossi M, Fratino P, Finardi G, Mevio E, Orlandi C.

Relationship between phasic changes in human skin blood flow and autonomic tone. Microvasc Res 1989: 37: 16-27.

8. Bernstein EF, ed.

Noninvasive diagnostic techniques in vascular disease. Third edition, $\mathrm{CV}$ Mosby Co, St. Louis, 1985. 
9. Bollinger $\mathrm{A}$.

Function of the precapillary vessels in peripheral vascular disease. J Cardiovasc Pharmacol 1985: 7: S147-S151.

10. Bollinger $A$, Butti $P$, Barras JP, Trachsler $H$, Siegenthaler $W$.

Red blood cell velocity in nailfold capillaries of man measured by a television microscopy technique. Microvasc Res 1974: 7:61-72.

11. Bollinger $A$, Fagrell $B$.

Dynamic capillaroscopy without dyes. In: Hogrefe \& Huber (ed): Clinical Capillaroscopy. Toronto: 1990: p 9-15.

12. Bollinger $A$, Fagrell $B$.

Pathological conditions: Arterial occlusive disease (Ischemia). Ibidem, p 63-76.

13. Bongard O, Fagrell B.

Discrepancies between total and nutritional skin microcirculation in patients with peripheral arterial occlusive disease (PAOD). Vasa 1990: 19: 105-111.

14. Bos GMJ, Slatef DW, Majoor GD, Tangelder GI, Reneman RS.

A model for chronic study of vascular morphology and reactivity of physically intact rat skin microcirculation. Int I Microcirc: Clin \& Exp 1987: 1: 145-155.

15. Boss Ch, Schneuwly P, Mahler F.

Evaluation and clinical application of the flying spot in clinical nailfold capillary TV-microscopy. Int J Microcirc: Clin \& Exp 1988: 6: 15-23.

16. Brånemark P-I, Jonsson I.

Determination of the velocity of corpuscles in blood capillaries: a flying spot device. Biorheology 1963: 1:143-146.

17. Broek ThAA van den.

Chronic venous insufficiency and venous reconstructive surgery. Thesis, Free University Amsterdam, The Netherlands, 1989.

18. Burgess EM, Matsen FA III, Wyss CR, Simmons CW.

Segmental transcutaneous measurements of $\mathrm{PO}_{2}$ in patients requiring belowthe-knee amputation for peripheral vascular insufficiency. I Bone Joint Surg 1982: 64: 378-382.

19. Byme P, Provan JL, Ameli FM, Jones DP.

The use of transcutaneous oxygen tension measurements in the diagnosis of peripheral vascular insufficiency. Ann Surg 1984: 200: 159-165.

20. Carter SA.

The definition of critical ischaemia of the lower limb and distal systolic pressures. Br J Surg 1983: 70: 188-189. 
21. Carter SA, Lezack JD.

Digital systolic pressures in the lower limb in arterial disease. Cinculation 1971: 43: 905-913.

22. Caspary L, Creutzig A, Alexander K.

Biological zero in laser Doppler Auxmetry. Int J Microcinc: Clin \& Exp 1988: 7 : 367-71.

23. Christensen KS, Larsen IF, Klarke M.

Transcutaneous oxygen tension response to excercise in health and in occlusive arterial disease. Acta Chir Scand 1986: 152: 657-660.

24. Cina C, Katsamouris A, Megerman J, Brewster DC, Strayhorn EC, Robison $\mathbb{G}$, Abbott WM.

Utility of transcutaneous oxygen tension measurements in peripheral arterial occlusive disease. J Vasc Surg 1984: 1: 362-371.

25. Clark LC Jr.

Monitor and control of blood and tissue oxygen tensions. Trans Am Soc Artif Intern Organs 1956: 2: 41-48.

26. Cohen J.

A coefficient of agreement for nominal scales. Educ Psych M 1960: 20: 37-46.

27. Coleman LS, Dowd GSE, Bentley G.

Reproducibility of $t \mathrm{CO}_{2}$ measurements in normal volunteers. Clin Phys Physiol Meas 1986: 7: 259-263.

28. Conrad MC, Green HD.

Hemodynamics of large and small vessels in peripheral vascular disease. Circulation 1964: 29: 847-853.

29. Creutzing A, Caspary L, Alexander K.

Disturbances of skin microcirculation in patients with chronic arterial occlusive disease and venous incompetence. VASA 1988: 2: 77-83.

30. Creutzig A, Caspary L, Allexander K.

Skin surface oxygen pressure in healthy volunteers and patients with arterial occlusive disease. Int J Microcirc: Clin \& Exp 1991: 10: 231-240.

31. Creutzig A, Caspary L, Hertel RF, Alexander K.

Temperature-dependent laser Doppler fluxmetry in healthy and patients with arterial occlusive disease. Int J Microcirc: Clin \& Exp 1987: 6: 381-390. 
32. Creutzig A, Dau A, Caspary 1 , Alexander K.

Transcutaneous oxygen pressure measured at two different electrode core temperatures in healthy volunters and patients with arterial occlusive disease. Int J Microcirc: Clin Exp 1987: 5: 373-380.

33. Davis $\mathbb{E}_{\text {, Landaul. }}$.

Clinical capillary microscopy. Springfield: Charles C. Thomas Publisher, 1966.

34. De Boer EM, Bezemer PD, Bruynzeel DP, Nieboer C.

Does topical minoxidil increase skin blood flow? Acta Dermatol Venereol (Stockholm) 1988: 68: 271-274.

35. Doppler CI.

Uber das Larbige Licht der Doppelsterne und einiger anderer Gestirne des Himmels. Abh K Boh Ges Wiss (Prague) 1842: 2: 465.

36. Eickhoff JH.

Forefoot vasioconstrictor response to increased venous pressure in normal subjects and in atherosclerotic patients. Acta Chir Scand 1980: 502: 7-14.

37. Eickhoff $\mathrm{JH}$.

Normalization of local blood flow in the ischaemic forefoot after arterial reconstruction. Surgery 1985: $97: 72$.

38. Eickhoff JH, Engell $\mathrm{HC}$.

Local regulation of blood flow and the occurrence of edema after arterial reconstruction of the lower limbs. Ann Surg 1982: 195: 474-478.

39. Eickhoff $\mathrm{jH}$, Engell $\mathrm{HC}$.

Transcutaneous oxygen tension $\left(\mathrm{tcpO}_{2}\right)$ measurements on the foot in normal subjects and patients with peripheral arterial disease admitted to vascular surgery. Scand J Clin Lab Invest 1981: 41: 743-748.

40. Eickhoff JH, Henriksen $\mathrm{O}$.

Local regulation of subcutaneous forefoot blood flow during orthostatic changes in normal subjects, in sympathetically denervated patients and in patients with occlusive arterial disease. Cardiovasc Res 1985: 19: 219-27.

41. Eickhoff JH, Ishihara $\mathrm{S}$, Jacobsen $\mathrm{E}$.

The effect of arterial and venous pressure on transcutaneous oxygen pressure. Scand J Clin Lab Invest 1980: 40: 755-60.

42. Emanuele MA, Buchanan BJ, Abraira $C$.

Elevated leg systolic pressures and arterial calcification in diabetic occlusive vascular disease. Diab Care 1981: 4: 289-292. 
43. Esato $\mathrm{K}_{*}$ Ohara $\mathrm{M}$, Mohri $\mathrm{H}$.

Transcutaneous $\mathrm{PO}_{2}$ response to transient arterial occlusion in peripheral occlusive disease. Int Surg 1987: 72: 115-118.

44. Ewald U.

Evaluation of the transcutaneous oxygen method used at $37^{\circ} \mathrm{C}$ for measurement of reactive hyperaemia in the skin. Clin Physiol 1984: 4: 413-423.

45. Ewald U, Rooth $\mathrm{G}_{*}$ Tuvemo $\mathrm{T}$.

Postischaemic hyperaemia studied with a transcutaneous oxygen electrode used at $33-37^{\circ} \mathrm{C}$. Scand J Clin Lab Invest 1981: 41: 641-645.

46. Fagrell $B$.

How best to evaluate skin viability and the effect of therapy in patients with peripheral obliterative arterial disease. Vasc Med Rev 1990: 1: 59-68.

47. Fagrell B.

Laser Doppler flowmetry for evaluating skin microcirculation and its relation to nutritional capillary flow. Int I Clin Microcirc: Clin \& Exp 1984: 3: 434.

48. Fagrell B.

The physiology and pharmacology of the microcirculation. In. Microcirculation of the skin. Mortillaro AN, ed. Academic Press Orlando, Florida, USA, 1984: chapter IV.

49. Fagrell B.

The relationship between macro- and microcirculation. Clinical aspects. Acta Pharmacol Toxicol 1986: 58: Suppl 6: 67.

50. Fagrell B.

Vital capillary microscopy. A clinical method for studying changes of the nutritional skin capillaries in legs with arteriosclerosis obliterans. Thesis. Scand J Clin Lab Invest 1973: 31: suppl 133: 1-50.

51. Fagrell B.

Vital microscopy. A clinical method for evaluating the risk of skin necrosis in patients with occlusive arterial disease. Biblioth Anat 1973: 11: 328-333.

52. Fagrell B, Östergren J.

Reactive hyperemia response in human skin capillaries after varying occlusion duration. Biblioth Anat 1981: 20: 692-696.

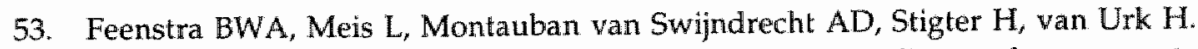

Assessment of peripheral vascular obliterative disease by transcutaneous oxygen tension tests. Eur J Vasc Surg 1988: 2: 19-26 
54. Flyrin $\mathrm{MD}$, Edmonds ME, Tooke JE, Watkins PJ.

Direct measurement of capillary blood flow in the diabetic neuropathic foot. Diabetologia 1988: 31: $652-656$

55. Flynn MD, Tooke JE.

Microcirculation and the diabetic foot. Vasc Med Rev 1990: 1: 121-138.

56. Folkow B.

Description of the myogenic hypothesis. Circ Res 1964: 14, 15 (suppl 1): I2791285 .

57. Fontaine $\mathbb{R}$, Riveaux $\mathrm{R}, \operatorname{Kim} \mathrm{M}$, Kieny $\mathrm{B}$.

Résultats des opérations hyperémiantes (sympathectomies lombaires et arteriectomies) dans les oblitérations artérielles chroniques spontanées des membres. Rev Chir 1953: 72: 204-230.

58. Formijne $\mathrm{P}$.

Investigation of the patency of peripheral arteries. Am Heart J 1934: 10: 1-16.

59. Franklin DL, Schlegel W, Rushmer RF.

Blood flow measured by Doppler frequency shift of back-scattered ultrasound. Science 1961: 134: 564-545.

60. Franzeck UK, Leu AJ, Geiger M, Huch A, Bollinger A.

Transcutaneous oxygen tension measurements in combination with capillaroscopy and laser Doppler fluxmetry in limb ischemia. Int J Microcirc: Clin \& Exp 1990: 9 (suppl 1): 143.

61. Franzeck UK, Talke P, Bernstein EF, Golbranson FL, Fronek A.

Transcutaneous $\mathrm{PO}_{2}$ measurements in health and peripheral arterial occlusive disease. Surgery 1982: 91: 156-163.

62. French-Sherry E.

Cuff artifact in digital pressures. Bruit 1981: $5: 33-35$.

63. Friedman SG, Kerner BA, Friedman MS, Moccio CG.

Limb salvage in ellderly patients. Is aggressive surgical therapy warranted?

I Cardiovasc Surg 1989: 30: 848-851.

64. Funk W, Endrich B, MeBner K, Intaglietta M.

Spontaneous arteriolar vasomotion as a determinant of peripheral vascular resistance. Int J Microcirc Clin Exp 1983: 2: 11-25.

65. Gaskell P. Becker WJ.

The erect posture as an aid to the circulation in the feet in the presence of arterial obstruction. Can Med Assoc J 1971: 105: 930-934. 
66. Gaskell P, Burton AC.

Local postural vasomotor reflexes arising from the limb velins. Cinc Res 1953: 1: $27-39$.

67. Goss DE, Trafford I, Roberts VC, Flynn MD, Edmonds ME, Watkins PJ.

Raised ankle/brachial pressure index in insulin-treated diabetic patients. Dials Med 1989: 6: $576-578$.

68. Gothgen I, Jacobsen E.

Transcutaneous oxygen tension measurement. I. Age variation and reproducibility. Acta Anaesth Scand 1987: suppl 67: 66-70.

69. Grant RT, Bland EF.

Observations on arteriovenous anastomoses in human skin and in the bird"s foot with special reference to reaction to cold. Heart 1931: $15: 385-411$.

70. Gregg RO.

Bypass or amputation. Concomitant review of bypass arterial grafting and major amputations. Am J Surg 1985: 149: 397-402.

71. Griffith TM, Edwards DH, Davies RLi, Harrison T], Evans KT.

EDRF coordinates the behaviour of vascular resistance vessels. Nature 1987: 329: $442-445$.

72. Grouden MC, Fitzpatrick P, Stanley ST, Colgan MP, Burke PE, Prendiville E, Moore DJ, Shanik GD.

Do transcutaneous oxygen tension pressure measurements accurately reflect tissue perfusion? J Vasc Technoll 1990: 14: 221-223.

73. Gunning WM.

Onderzoekingen over bloedsbeweging en stasis. Utrecht, 1857. Quoted in: Riegel F. Über den Einfluß des Nervensystems auf den Kreislauf und die Körpertemperatur. Pflügers Arch Ges Physiol 1871: 4: 350-434.

74. Guyton AC.

Circulation in the skin. In: Textbook of medical physiology, $8^{\text {th }}$ ed. 1991, p 379, W.B. Saunders Company, Philadelphia, London, Toronto.

75. Haaverstad R, Nilsen $G$, Myhre HO.

The use of MRI in the investigation of leg edema. Proceedings of the $\mathrm{V}^{\mathrm{th}}$ annual meeting of the European Society for Vascular Surgery, Warsaw, Poland 1991: 50 .

76. Hagen $W$.

Die Schwankungen im Kapillarkreislauf. Zeitschr Ges Exp Med 1921: 14: 364405. 
77. Hassan AAK, Rayman G, Tooke JE.

Effect of indirect heating on the postural control of skin blood flow in the human foot. Clin Sci 1986: 70:577-82.

78. Hassan A.AK, Tooke JE.

Mechanism of the postural vasoconstrictor response in the human foot. Clin Sci 1988: 75: 379-387.

79. Hauser CI, Appel P, Shoemaker WC.

Pathophysiological classification of peripheral vascular disease by positional changes in regional transcutaneous oxygen tension. Surgery 1984: 95: 689-93.

80. Hellebrandt FA, Franssen EB.

Physiological study of the vertical stance in man. Physiol Rev 1943: 23: 220255.

81. Henriksen $O$.

Local reflex in microcirculation in human subcutaneous tissue. Acta Phys Scand 1976: 98: 447-456.

82. Henriksen $O$.

Orthostatic changes of blood flow in subcutaneous tissue in patients with arterial insufficiency of the legs. Scand J Clin Lab Invest 1974: 34: 103-109.

83. Henriksen O, Paaske WP.

Local regulation of blood flow in peripheral tissue. Acta Chir Scand 1980: 502: $63-74$.

84. Henriksen $\mathrm{O}$, Sejrsen $P$.

Local reflex in microcirculation in human cutaneous tissue. Acta Phys Scand 1976: 98: 227-231.

85. Hesse B, Ring-Larsen H, Nielsen I, Christensen NJ.

Renin stimulation by passive tilting: the influence of an anti-gravity suit on postural changes in plasma renin activity, plasma nor-adrenalin concentration and kidney function in normal man. Scand J Clin Lab Invest 1978: 38: 163-169.

86. Hirai $M_{r}$ Kawai $S$.

Clinical significance of segmental blood pressure in arterial occlusive disease of the lower extremity. Vasa 1978: 7: 383-388.

87. Hoeks APG.

On the development of a multi-gate pulsed Doppler system with serial dataprocessing. Thesis, University of Limburg. The Netherlands, 1982. 
88. Hoffmann $\mathrm{U}$, Schneider $\mathrm{E}_{\mu}$ Bollinger $\mathrm{A}$.

Flow motion waves with high and low frequency in severe ischatmia before and after percutaneous transluminal angioplasty. Cardiovase Res 1990: 24: 711 718.

89. Holloway GA Jr, Watkins DW.

Laser Doppler measurement of cutaneous blood flow. I Invest Dermatol 1977: 69: 306-309.

90. Hovius SER, Sluimers MM, Vaandrager LNA, wan Adrichem JM. Wijthoff SM, van der Meulen $J C$.

The radial forearm flap. Netherlands J Surg 1988: 40:69-75.

91. Huch A, Franzeck UK, Huch R, Bollinger A.

A transparent transcutaneous oxygen electrode for simultaneous studies of skin capillary morphology, flow dynamics and oxygenation. Int I Microcirc: Clin \& Exp 1983: 2: 103-108.

92. Huch $\mathrm{R}$, Huch $\mathrm{A}_{\text {, }}$ Lübbers DW.

Transcutaneous $\mathrm{PO}_{2}$. Stuttgart, New York: Georg Thieme Verlag, Thieme Stratton Inc. 1981.

93. Huch $\mathrm{R}$, Lübbers DW, Huch A.

Reliability of transcutaneous monitoring of arterial $\mathrm{pO}_{2}$ in newborn infants. Arch Dis Child 1974: 49:213-218.

94. Jacobs MJHM.

Capillary microscopy and hemorrheology in vasospastic and occlusive vascular diseases. Thesis, Uniwersity of Limburg, Maastricht, The Netherlands, 1985.

95. Jacobs MJHM, Beckers RCY, Jörning PJG, Slaaf DW, Reneman RS.

Microcirculatory haemodymamics before and after vascular surgery in severe limb ischaemia - the relation to post-operative oedema formation. Eur I Vasc Surg 1990: 4: 525-529.

96. Jacobs MJHM, Breslau PJ, Slaaf DW, Reneman RS, Lemmens JAJ.

Nomenclature of Raynaud's phenomenon: a capillary microscopic and hemorheologic study. Surgery 1987: 2: 136-145.

97. Jacobs MJHM, Jörning PJG, Beckers RCY, Ubbink DTh, van Kleef M, Slataf DW, Reneman RS.

Foot sallvage and improvement of microvascular blood flow as a result of epidural spinal cord stimulation. J Vasc Surg 1990: 12: 354-360. 
98. Jacobs MHHM, Staa DW, Lemmens HA], Reneman RS.

The use of hemorheological and microcirculatory parameters in evaluating the effect of treatment in Raynaud's phenomenon. Vasc Surg 1987: 21: 9-16.

99. Jacobs MIHM, Slaaf DW, Reneman RS.

Dorsal column stimulation in critical limb ischaemia. Vasc Med Rev 1990: 1: 215-220

100. Jacobs MIHM, Ubbink DTh, Kitslaar PJEHM, Tordoir JHM, Slaaf DW, Reneman RS. Assessment of microcirculation provides additional information in critical limb ischaemia. Eur J Vase Surg: 1992: 6:135-141.

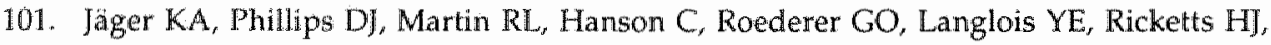
Strandness DE Jr.

Noninvasiwe mapping of lower limb arterial lesions. Ultrasound Med Biol 1985: 11: 515 .

102. Jäger" KA, Rilcketts HJ, Strandness DE Jr.

Duplex scanning for the evaluation of lower limb arterial disease. In: Bernstein

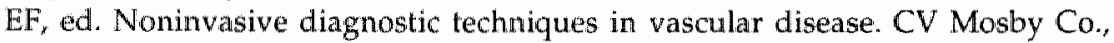
St. Louis 1985: 619 .

103. Jenkins S, Sepka R, Barwick WJ.

Routine use of laser Doppler flowmetry for monitoring autologous tissue transplants. Ann Plast Surg 1988: 21: 423-426.

104. Jones TW.

Discovery that the veins of the bat's wing (which are furnished with valves) are endowed with rhythmical contractility, and that the onward flow of blood is acceletated by each contraction. Phill Trans $\mathbb{R}$ Soc London 1852: 142: 131-136.

105. lünger $M$, Frey-Schnewlin $G$, Bollinger $A$.

Microvascular flow distribution and transcapillary diffusion at the forefoot in patients with peripheral ischemia. Int J Microcirc Clin Exp 1989: 8: 3-24.

106. Katsamouris A, Brewster DC, Megerman J, Cina C, Clement Darling $R$, Abbott WM. Transcutaneous oxygen tension in selection of amputation level. AM J Surg 1984: $147: 510-517$

107. Kitslaar PJEHM.

Doppler ultrasound thests in the diagnosis of chronic aortoiliac obstruction. Thesis, University of Limburg, Maastricht, The Netherlands, 1982.

108. Kohler TR, Nance DR, Crames MM, Vandenburghe $N$, Strandness DE Jr.

Duplex scanning for diagnosis of aortoiliac and femoropopliteal disease: a prospective study. Circulation 1987: 5: 1074-1080. 
109. Kram HB, White RA, Tabrisky J, Appel $\mathrm{PL}$, Fleming AW Shoemaker WC.

Transcutaneous oxygen recovery and toe pulse reappearance time in the assessment of peripheral vascular disease. Curculation 1985: 72: 1022-1027.

110. Kvernebo $\mathrm{K}$, Slagsvold $\mathrm{CE}$, Gjolberg $\mathrm{T}$.

Laser Doppler flux reappearance time (FRT) in patients with lower limb atherosclerosis and healthy controls. Eur J Vasc Surg 1988: 2: 171.

111. Kvernebo $\mathrm{K}$, Slagsvold CE, Stranden $\mathrm{E}$, Kroese A, Larsen $\mathrm{S}$.

Laser Doppler flowmetry in evaluation of lower limb resting skin circulation.

A study in healthy controls and atherosclerotic patients. Scand J clin Lab Invest 1988: 48: 621-626.

112. Lalka SG, Malone JM, Anderson GG, Hagaman RM, Mclntyre KE, Bernhare VM.

Transcutaneous oxygen and carbon dioxide pressure monitoring to determine severity of limb ischemia and to predict surgical outcome. J Vase Surg 1988: 7: 507-514.

113. Larsen JF, Jensen BV, Christensen KS, Egeblad K.

Forefoot transcutaneous oxygen tension at different leg positions in patients with peripheral vascular disease. Eur J Vasc Surg 1990: 4: 185-189.

114. Leonardo G, Arpaia MR, Del Guercio R.

A new method for the quantitative assessment of arterial insufficiency of the limbs: cutaneous postischaemic hyperaemia test by laser Doppler. Angiology 1987: 38: 378-385.

115. Lerche A, Paaske WP.

Laser Doppler examination of peripheral microvascular reactivity. Surg Gyn Obst 1986: 163: 410-414.

116. Levick JR, Michel CC.

The effects of position and skin temperature on the capillary pressures in the fingers and toes. J Physiol 1978: 274: 97-109.

117. Lezack JD, Carter SA.

The relationship of distal systolic pressures to the clinical and angiographic findings in limbs with arterial occlusive disease. Scand J clin Lab Invest 1973; 31: suppl 128: 97-101.

118. Lombard WP.

The blood pressure in the arterioles, capillaries and small veins of the human skin. Am J Physioll 1912: 29: 335-362. 
119. Lübbers, D.W.

Theory and development of transcutaneous oxygen pressure measurement. In:

Tremper, $K K$. Barker, S.J. Ads. Advances in oxygen monitoring. Boston: Little, Brown \& Company: 1987: 50-65.

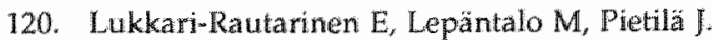

Reproducibility of skin blood fow, perfusion pressure and oxygen tension measurements in advanced lower limb ischaemia. Eur J Vasc Surg 1989: 3: 345350 .

121. Mahler $F$, Nagel $G_{j}$ Saner $H$, Kneubühl $F$.

In vivo comparison of the nailfold capillary diameter as determined by using the erythrocyte column and FITC-labelled albumin. Int J Microcirc: Clin \& Exp 1983: 2: 147-155.

122. Mannarino E, Maragoni $G$, Pasqualini $L$, Sanchini $R$, Rossi $P$, Orlandi $U$.

Transcutaneous oxygen tension behavior in the different stages of peripheral vascular disease and its correlation with ankle/arm pressure ratio and calf blood flow. Angiology 1987: 38: $463-468$.

123. Maricq HR, Spencer-Green G, LeRoy EC.

Skin capillary abnormalitie as indicators of organ involvement in scleroderma (systemic sclerosis), Raynaud's syndrome and dermatomyositis. Am I Med. 1976: $61: 862-870$.

124. Merode T van, Hick PIJ, Hoeks APG, Reneman RS.

The diagnosis of minor to moderate atherosclerotic lesions in the carotid artery bifurcation by means of spectral broadening combined with the direct detection of flow disturbances using a multi-gate pulsed Doppler system. Ultrasound in Med \& Biol 1988: 14: 459-464.

125. Merode T van, Lodder I, Smeets FAM, Hoeks APG, Reneman RS.

Accurate noninvasive method to diagnose minor atherosclerotic lesions in carotid a thery bulb. Stroke 1989: 20: 1336-1340.

126. Mescon H, Hurley I. Moretti G.

The anatomy and histochemistry of the arteriovenous anastomosis in human digital skin. J Invest Dermatol 1956: 27: 133-144.

127. Moosa HH, Peitzman AB, Makaroun MS, Webster MW, Steed DL.

Transcutaneous oxygen measurements in lower extremity ischemia: effects of position, oxygen inhalation, and arteriall reconstruction. Surgery 1988: 103: 193198.

128. Müller $\mathrm{O}$.

Die Kapillaren der menschlichen Körperoberfläche in gesunden und kranken "Tagen. Stuttgart: Ferdinand Enke Verlag, 1922. 
129. Myers KA.

Preoperative assessment of lower limb ischaemia. In. Diagnostic techniques and assessment procedures in vascular surgery. Greenhalgh RM ed., Crune \& Stratton, London, 1985: 224.

130. Myhre HO, Storen EJ, Ongre A.

The incidence of deep venous thrombosis in patients with leg oedema after arterial reconstruction. Scand J Thor Cardiovasc Surg 1974: 8:73-76.

131. Neufeld GR, Reilly CA, Galante $S R$, et al.

Response of cutaneous laser velocimetry to a temperature change: normal and dysvascular patients compared. Vasc Surg 1987: 21: 331-8.

132. Nicoll PA, Webb RL.

Vascular patterns and active vasomotion as determiners of flow through minute vessels. Angiology 1955: 6: 251-308.

133. Nilsson GE, Øberg $\mathbb{P A}$, Tenland $\mathrm{T}$.

A new instrument for continuous measurements of tissue blood flow by light: beating spectroscopy. IEEE Trans Biomed Eng 1980: BME 27: 12-19.

134. Nilsson GE, Tenland T, Øberg PA.

Evaluation of a laser Doppler flowmeter for measurement of tissue blood flow. IEEE Trans Biomed Eng 1980: BME 27: 597-604.

135. Ninet J, Fronek A.

Cutaneous postocclusive reactive hyperaemia monitored by laser Doppler flux metering and skin temperature. Microvasc Res 1985: 30: 125-132.

136. Norušis MJ.

Statistical Package for Social Sciences version 4.0 Manual 1990, SPSS Inc., Chicago.

137. Olszewski WL, Engeset $\mathrm{A}$.

Intrinsic contractility of prenodal $\mathbb{y}$ mph vessels and lymph flow in the humal leg. Am J Physiol 1980: 239: H775-H783.

138. Oparil S, Vassaux C, Saunders CA, Haber E.

Role of renin in acute postural homeostasis. Circulation 1970: 41: 89-95.

139. Östergren J. Schöps. P, Fagrell B.

Evaluation of a laser Doppler multiprobe for detecting skin microcirculatory disturbances in patients with obliterative arteriosclerosis. Inter Angio 1988: 7: $37-41$. 
140. Pater L de, Berg JW van den, Bueno AA.

A very sensitive photoplethysmograph using scattered light and a photosensitive resistance. Acta Physiol Pharmacol Neerl 1962: 10: 378.

141. Pearce WH, Yao JST, Bergan JI.

Noninvasive vascular diagnostic testing. Curr Probl Surg 1983: 20: 461.

142. Persson NH, Takolander R, Bergqvist D.

Lower limb oedema after arterial reconstructive surgery. Influence of preoperative ischaemia, type of reconstruction and postoperative outcome. Acta Chir Scand 1989: 155: 259-266.

143. Porter JM, Lindell TD, Lakin PC.

Leg edema following femoropopliteal autogenous vein bypass. Arch Surg 1972: 105: 883-888.

144. Quin RO, Evans DH, Fyfe T, et al.

Evaluation of indirect blood pressure measurement as a method of assessment of peripheral vascular disease. I Cardiovasc Surg 1977: 18: 109.

145. Ramsey DE, Manke DA, Sumner DS.

Toe blood pressure: A valuable adjunct to ankle pressure measurement for assessing peripheral arterial disease. J Cardiovasc Surg 1983: 24: 43.

146. Ranft J, Heidrich $\mathrm{H}_{*}$ Peters A, Trampisch $\mathrm{H}$.

Laser-Doppler examinations in persons with healthy vasculature and in patients with peripheral arterial occlusive disease. Angiology 1986: 818-827.

147. Ratcliff DA, Clyne CAC, Chant ADB, Webster JHH.

Prediction of amputation wound healing: the role of transcutaneous $\mathrm{pO}_{2}$ assessment. Br J Surg 1984: 71: 219-222.

148. Rayman G, Hassan AAK, Tooke JE.

Blood flow in the skin of the foot related to posture in diabetes mellitus. Brit Med J 1986: 292: 87-90.

149. Reneman RS, Merode T van, Hick P, Hoeks APG.

Flow velocity patterns in and distensibility of the carotid bulb in subjects of various ages. Circulation 1985: 71: 500-509.

150. Reneman RS, Merode T van, Hick PJ, Hoeks APG.

Cardiovascular applications of multi-gate pulsed Doppler systems. Ultrasound in Med \& Biol 1986: 12: 357-370.

151. Reneman RS, Slaaf DW, Lindbom L, Tangelder GJ, Arfors K-E.

Muscle blood flow disturbances produced by simultaneously elevated venous and total muscle tissue pressure. Microvasc Res 1980: 20: 307-318. 
152. Richardson D.

Effects of gravity on regional and capillary blood flows in the human toe. Microvasc Res 1988: 35: 334-340.

153. Riva C, Ross B, Benedek GB.

Laser Doppler measurements of blood flow in capillary tubes and retinal arteries. Invest Ophthalmol 1972: 11: 936-944.

154. Roddie IC, Shepherd JT.

The effects of carotid artery compression in man with special reference to changes in vascular resistance in the limbs. \Physiol (London) 1957: 139: 377384.

155. Rooke ThW, Hollier LH, Osmundson Ph].

The influence of sympathetic nerves on transcutaneous oxygen tension and ischaemic lower extremities. Angiology 1987: 38: 400-10.

156. Rosenberg $\mathrm{E}$.

Local character of the veno-vasomotor reflex. Am J Physiol 1956: 185: 471-473.

157. Rowell LB, Wyss CR, Brengelmann GL.

Sustained human skin and muscle vasoconstriction with reduced baroreceptor activity. J Appl Physiol 1973: 5: 639-643.

158. Schiff.

Ein accessorisches Arterienherz beï Kaninchen. Arch Physiol Heilk 1854: XIII: 523-527.

159. Schouten HJA.

Measuring pairwise agreement among many observers. Biomed J 1980: 22: 497-504

160. Second European consensus document on chronic crilical leg ischemia. Circulation 1991: suppl. to vol. 84 .

161. Seifert $H$, läger $K$, Bollinger $A$.

Analysis of flow motion by the laser Doppler technique in patients with peripheral arterial occlusive disease. Int J Microcirc Clin Exp 1988: 7: 223-236.

162. Seldinger $\mathrm{SI}$.

Catheter replacement of the needle in percutaneous arteriography. A new technique. Acta Radiol 1953: 39: 368-376.

163. Shepherd AP, Riedel GL, Kiel JW, Haumschild DJ, Maxwell LC.

Evaluation of an infrared laser-Doppler blood flowmeter. AM I Physioll 1987: 252: G832-G839. 
164. Simone FA; Husni EA.

The hyperemia of reconstructive arterial surgery. Ann Surg 1959: 150: 575-585.

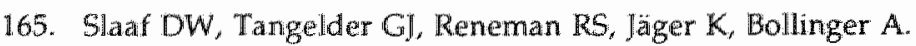

A versatile illuminator for intravital microscopy. Int J Microcirc: Clin \& Exp 1987: $6: 391-397$.

166. Slaaf DW, Tangelder GI, Teirlinck HC, Reneman RS.

Arteriolar vasomotion and arterial pressure reduction in rabbit tenuissimus muscle. Microvasc Res 1987: 33: 71-80.

167. Smits TM, Aarnoudse $\mathbb{T G}$.

Variability of foetal scalp blood flow during labour: continuous transcutaneous measurement by the laser Doppler technique. Br J Obstet \& Gynaec: 1984: 91: $524-531$.

168. Stern MD.

In vivo evaluation of microcirculation by coherent light scattering. Nature (Loindon) 1975: 524: 56-58.

169. Stern MD, Lappe D, Bowen PD, Chimosky JE, Holloway GA Jr, Keiser HR, Bowman RL

Continuous measurement of tissue blood flow by laser Doppler spectroscopy. Am J Physiol 1977: 232: H441-H448.

170. Stranden E, Myhre $\mathrm{HO}$.

Pressure-volume recordings of human subcutaneous tissue: A study in patients with edema following arterial reconstruction for lower limb atherosclerosis. Microvasc Res 1982: 24: 241-248.

171. Strandness DE Jr, McCutcheon EP, Rushmer RF.

Application of a transcutaneous Doppler flowmeter in the evaluation of occlusive arterial disease. Surg Gynecol Obstet 1966: 122: 1039-1045.

172. Strandness DE Jr, Schultz RD, Sumner DS, Rushmer RF.

Ultrasonic flow detection. A useful technique in the evaluation of peripheral vascular disease. Am J Surg 1967: 113: 311-320.

173. Sundberg $\mathrm{S}$.

Acute effects and long term variations in skin blood flow measured with laser Doppler flowmetry. Scand J clin Lab Invest 1984: 44: $341-345$.

174. Svensson H, Bornmyr S, Svedman $P$.

Skin perfusion pressure assessed by measuring the external pressure required to stop red blood cell flux. Angiology 1990: 41: 169-174. 
175. Tenland $T$, Salerud EG, Nilsson GE, Öberg $P A$.

Spatial and temporal variations in human skin blood flow. Int J Microcirc: Clin \& $\operatorname{Exp} 1983: 2: 81-90$.

176. Tooke J, Östergren J, Fägrell B.

Synchronous assessment of human skin microcirculation by laser Doppler flowmetry and dynamic capillaroscopy. Int J Microcirc: Clin \& Exp 1983: 2: 277-284.

177. Tremper KK, Shoemaker WC.

Transcutaneous oxygen monitoring of critically ill adults, with and without shock. Crit Care Med 1981: 9: 706-709.

178. Tyml K, Ellis CG.

Evaluation of the flying spot technique as a television method for measuring red cell velocity in microvessels. Int J Microcirc: Clin \& Exp 1982: 1: 145-155.

179. Ubbink DTh, Jacobs MJHM, Slaaf DW, Tangelder GJ, Reneman RS.

Capillary recruitment and pain relief on dependency in patients with severe lower limb ischemia. Circulation: 1992: 85: 223-229.

180. Ubbink DTh, Jacobs MJHM, Slaaf DW, Tangelder GJ, Reneman RS.

Posturally induced microvascular constriction in patients with lower limb ischaentia. Int J Microcirc: Clin \& Exp 1990: 9 (Suppl 1): 26.

181. Libbink DTh, Jacobs MJHM, Slaaf DW, Tangelder G, Reneman RS.

Microvascular reactivity differences in the two legs of patients with unilateral lower limb ischaemia. Eur J Vasc Surg 1992: 6: in press.

182. Ubbink DTh, Jacobs MJHM, Tangelder GJ, Slaaf DW, Reneman RS.

Posturally induced microvascular constriction in patients with different stages of leg ischaemia and the effect of local skin heating. Clin Sci 1991: 81: 43-49

183. Vincent DG, Salles-Cunha SX, Bernhard VM, Towne JB.

Noninvasive assessment of toe systolic pressures with special reference to diabetes mellitus. J Cardiovasc Surg 1983: 24: 22-28.

184. Warwick R, Williams PL.

Angiology. In: Gray's anatomy. Warwick R, Willams PL, eds. $36^{\text {th }}$ ed. Churchill Livingstone, Edinburgh, 1984, p 590-595.

185. Winsor T, Haumschild DI, Winsor DW, Mikail A.

Influence of local and environmental temperatures on cutaneous circulation with use of laser Doppler flowmetry. Angiology 1989: 40: 421-8. 
186. Wollersheim $\mathrm{H}$, Thien $\mathrm{T}$.

Dose-response study of Prazosin in Raynaud's phenomenon: clinical effectiveness versus side effects. J Clin Pharmacol 1988: 28: 1089-1093.

187. Yao JST.

Haemodynamic studies in peripheral arterial disease. Br J Surg 1970: 57: 761766.

188. Yao JST, Peterson LK, Payne K.

Lower limb systolic pressure measurements: technique and clinical application. Inter Angio 1985: 4: 31-39.

189. Zierler RE, Strandness DE Jr.

Ultrasonic techniques of lower extremity arterial diagnosis. In: Introduction to vascular ultrasonography. Zwiebel WJ, ed. Grune \& Stratton Inc., New York 1982: 251-272. 


\section{In appreciation}

The work put down in this booklet could not have been accomplished without the contribution of many persons, whom I owe my sincere gratitude. A list of contributors is always defective. Nevertheless, I wish to express a word of gratitude to some of these people.

\section{Rob Reneman}

To me, Rob has been a most amiable promotor, whose profound knowledge has guided me to a broader insight in this subject. Through the years, the red blaze of revised manuscripts has become stimulating rather than embarrassing. His thoroughness and speed in revising each and every paper is memorable, as well as the similarity between the way he writes the quite dissimilar words niet ( med ) and wel (wed )!

\section{Peter Kitslaar}

Although your contribution to this thesis has only been in the final stage of its preparation, you have meant more than the proverbial finishing touch. You kindly provided not only the facilities for microcirculatory studies, but also the opportunity to participate in other services of the vascular laboratory.

Michael Jacobs

You deserve many thanks for bringing up AlO's such as $\mathrm{I}$, and for the full support you gave me so far and still do in the continuation of microcirculatory investigations.

Geert Jan Tangelder

I feel fortunate that you have continually sentenced me to short sentences in the preparing of manuscripts and this thesis, so that this booklet has gained more lucidity, but I should also express gratitude for the many enlightening ideas from the physiological point of view, which means an enrichment for clinicians who venture on scientific investigation. 
The Paranymphs Therèse van Gorcum and Ton Langeveld.

'Joop' is quite a character, which has been very stimulating both as paranymph and as collegue in the vascular laboratory.

Therèse, I want to thank you in particular for the efforts you made as a contribution to this thesis and not in the least for painstakingly reading the manuscript. I admire the stamina you showed to endure this tough period of time.

Dick Slaaf

You have managed to bring at least some order in the chaos of my 'first youthful transgression'. Your straight-forward approach and methodological contribution to this booklet has been that of a co-promotor.

Rinus Alewijnse

Although you frequently seemed to be bowed down by our ostensibly insurmountable instrumental problems, technical ignorance and urging demands from the clinic, I have very much appreciated and still appreciate your prompt response and substantial technical support.

Yvonne Reynders

I am very much obliged for organizing the purple colour in the agenda so well for several years. I will not forget our time-consuming, but fruitful computing hours behind your museum piece.

Renée Dresens, Edith Ermers, Monique Kuijpers and Ineke Zwiers

These four deserve gratitude for cherishing research guys like me in the pleasant family of vascular technologists.

\section{Hubert Labega}

Many thanks for designing a spendid cover drawing and being a faithful friend.

Committee of reviewers

Professors A. Bollinger, F. ten Hoor " P.W. de Leeuw, H.A.J. Struijker Boudier and H.J.J. Wellens are acknowledged for their acceptance and constructive criticisms of the manuscript. 


\section{Curriculum vitae}

Dirk Theodoor Ubbink was born on January $28^{\text {th }} 1961$ in Enkhuizen, The Netherlands. He attended secondary school (Gymnasium B) at the 'Werenfridus Scholengemeenschap' in Hoorn from 1972 to 1978. He studied medicine at the Free University of Amsterdam and obtained his M.D. degree in February 1985.

From June 1985 to September 1986 he worked as a urological and surgical resident in the Military Hospital 'Dr. A. Mathyssen' in Utrecht. From August 1986 he was a resident in surgery and orthopaedics in the "Prof. Lorentz Ziekenhuis' in Zeist, until February 1988. Subsequently, he became a research fellow in the Academic Hospital in Maastricht, where the investigations as described in this thesis were performed.

His work was honoured with a European Microcirculation Society Travel Award in August 1990 (Zürich, Switzerland) and a World Congress for Microcirculation Travel Award in September 1991 (Louisville, Ky, USA). Since November 1991 he is involved in a multicentre microcirculation study in the Netherlands. 